\title{
DISCLAIMER
}

This report was prepared as an account of work sponsored by an agency of the United States Government. Neither the United States Government nor any agency thereof, nor any of their employees, makes any warranty, express or implied, or assumes any legal liability or responsibility for the accuracy, completeness, or usefulness of any information, apparatus, product, or process disclosed, or represents that its use would not infringe privately owned rights. Reference herein to any specific commercial product, process, or service by trade name, trademark, manufacturer, or otherwise does not necessarily constitute or imply its endorsement, recammendation, or favoring by the United States Government or any agency thereof. The views and opinions of authors expressed herein do not necessarily state or reflect those of the United States Government or any agency thereof.

\section{Calvert Cliffs RELAP5/MOD3/SCDAP Plant Deck}

\author{
C. E. Hendrix \\ J. C. Determan
}

Published December 1992

\section{Idaho National Engineering Laboratory EG\&G Idaho, Inc. Idaho Falls, Idaho 83415}

\author{
Prepared for the \\ Division of Reactor Systems Safety \\ Office of Nuclear Regulatory Research \\ U. S. Nuclear Regulatory Commission \\ Washington, D.C. 20555 \\ Under DOE Idaho Field Office \\ Contract DE-AC07-76ID01570
}

FIN A6328 



\begin{abstract}
This report documents the development of a RELAP5/MOD3/SCDAP input deck for the Calvert Cliffs nuclear power plant. Through the addition of SCDAP inputs, NPA interactive capabilities, and significant nodalization enhancements the range of applicability of this input deck has been greatly increased.
\end{abstract}




\section{SUMMARY}

A RELAP5/MOD3/SCDAP input deck of the Calvert Cliffs nuclear reactor has been developed and is described in this report. The primary purpose of this task is to enhance the plant analysis capability of the NRC by modifying and upgrading existing RELAP5 plant decks of LWR systems.

This report provides a detailed description of the input deck, with sections covering the RELAP5/MOD3 nodalization, the SCDAP core description, and the nuclear plant analyzer (NPA) input and graphic display features. The results of three transient anaiyses performed with the deck are also discussed. To facilitate the use of this input deck the process of analysis with RELAP5 and the NPA is outlined. 


\section{CONTENTS}

ABSTRACT $\ldots \ldots \ldots \ldots \ldots \ldots \ldots \ldots \ldots \ldots \ldots \ldots \ldots \ldots \ldots \ldots \ldots \ldots \ldots \ldots \ldots \ldots$

SUMMARY $\ldots \ldots \ldots \ldots \ldots \ldots \ldots \ldots \ldots \ldots \ldots \ldots \ldots \ldots \ldots \ldots \ldots \ldots \ldots \ldots$

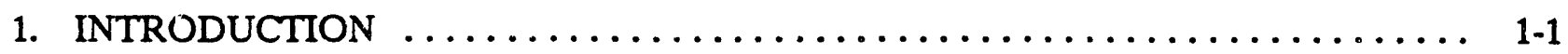

2. PLANT DECK DESCRIPTION $\ldots \ldots \ldots \ldots \ldots \ldots \ldots \ldots \ldots \ldots \ldots \ldots \ldots \ldots \ldots \ldots$

2.1 RELAP5/MOD3 Input Description $\ldots \ldots \ldots \ldots \ldots \ldots \ldots \ldots \ldots \ldots \ldots \ldots \ldots$

2.1.1 Plant Deck Nodalization $\ldots \ldots \ldots \ldots \ldots \ldots \ldots \ldots \ldots \ldots \ldots \ldots \ldots$ 2-2

2.1.2 Main Feedwater Train, Main Steam Line, Reactor Trip Logic, and Control Systems $\ldots \ldots \ldots \ldots \ldots \ldots \ldots \ldots \ldots \ldots \ldots \ldots \ldots \ldots \ldots . \ldots \ldots$

2.2 SCDAP Input Deck for Severe Accident Analysis $\ldots \ldots \ldots \ldots \ldots \ldots \ldots \ldots$

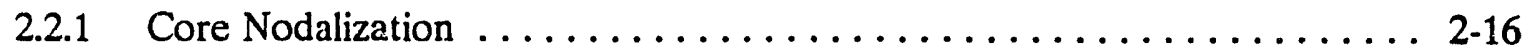

2.2.2 Fuel Pin Component Inputs ...................... 2-16

2.2.3 Control Rod Components ........................ 2-19

2.2.4 SCDAP Component Connection to RELAP5/MOD3 . . . . . . . . . 2-19

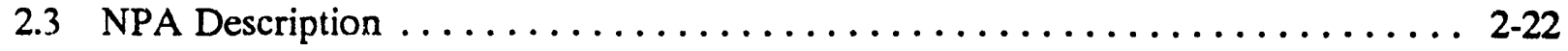

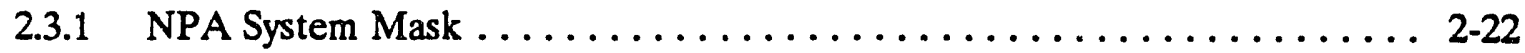

2.3.2 NPA Core Region Mask ..................... 2-25

2.3.3 Interactive Options for the Calvert Cliffs NPA ............. 2-25

3. PLANT DECK APPLICATIONS $\ldots \ldots \ldots \ldots \ldots \ldots \ldots \ldots \ldots \ldots \ldots \ldots \ldots \ldots$

3.1 Loss of Feedwater Transients $\ldots \ldots \ldots \ldots \ldots \ldots \ldots \ldots \ldots \ldots \ldots \ldots \ldots \ldots \ldots$

3.2 Large Break LOCA Accident $\ldots \ldots \ldots \ldots \ldots \ldots \ldots \ldots \ldots \ldots \ldots \ldots \ldots$

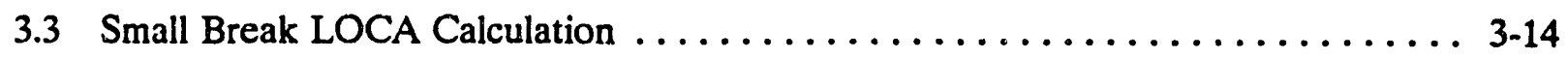

3.4 User Instructions and Recommendations $\ldots \ldots \ldots \ldots \ldots \ldots \ldots \ldots \ldots \ldots$

3.4.1 Plant Transient Applications . . . . . . . . . . . . . . . . . 3-32

3.4.2 Loss of Coolant Accident Applications . . . . . . . . . . . . . . 3-33

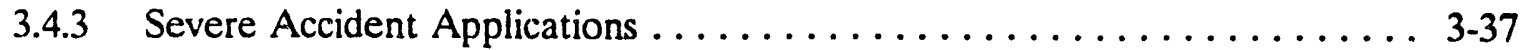

3.5 Problem Resolution $\ldots \ldots \ldots \ldots \ldots \ldots \ldots \ldots \ldots \ldots \ldots \ldots \ldots \ldots \ldots$ 


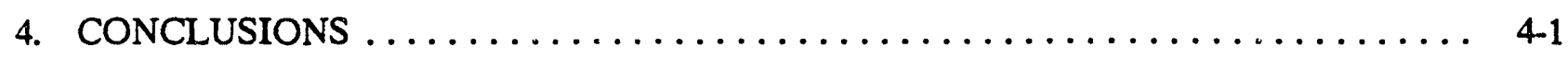

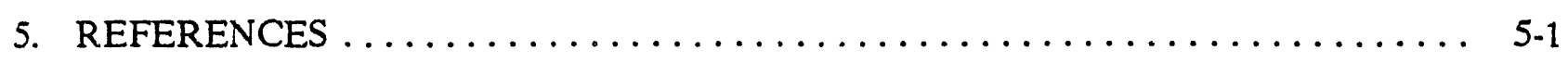

\section{FIGURES}

2-1. SCDAP/RELAP5 reactor coolant system interactions $\ldots \ldots \ldots \ldots \ldots \ldots \ldots, 2 \cdot 1$

2-2. Calvert Cliffs RELAP5/MOD3/SCDAP core nodalization $\ldots \ldots \ldots \ldots \ldots \ldots$ 2-3

2-3. Calvert Cliffs core nodalization for SCDAP heat structure modeling $\ldots \ldots \ldots, 2-4$

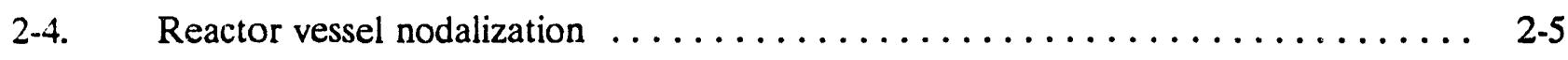

2-5. Calvert Cliffs downcomer nodalization $\ldots \ldots \ldots \ldots \ldots \ldots \ldots \ldots \ldots \ldots \ldots \ldots \ldots$

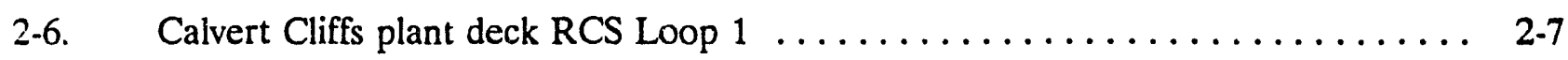

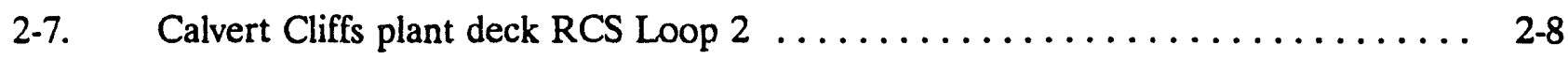

2-8. Calvert Cliffs plant deck Loop 1 steam generator $\ldots \ldots \ldots \ldots \ldots \ldots \ldots$ 2-9

2-9. Calvert Cliffs plant deck Loop 2 steam generator $\ldots \ldots \ldots \ldots \ldots \ldots \ldots \ldots$

2-10. Calvert Cliffs plant deck main feedwater system $\ldots \ldots \ldots \ldots \ldots \ldots \ldots \ldots$ 2-11

2-11. Calvert Cliffs plant deck main steamline nodalization $\ldots \ldots \ldots \ldots \ldots \ldots \ldots .2-12$

2-12. Axial power distribution (taken from the Calvert Cliffs FSAR) $\ldots \ldots \ldots \ldots \ldots 2-17$

2-13. Calvert Cliffs fuel pin and control rod geometry $\ldots \ldots \ldots \ldots \ldots \ldots \ldots \ldots .2-18$

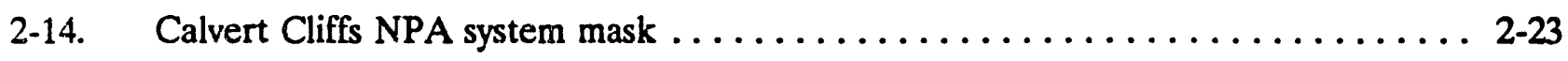

2-15. Calvert Cliffs NPA thermal-color parameters $\ldots \ldots \ldots \ldots \ldots \ldots \ldots \ldots \ldots \ldots \ldots \ldots$

2-16. Calvert Cliffs rod/chan and magnitude parameters $\ldots \ldots \ldots \ldots \ldots \ldots \ldots .2-29$

2-17. Calvert Cliffs NPA levels and on/off parameters $\ldots \ldots \ldots \ldots \ldots \ldots \ldots \ldots .2-31$

2-18. Calvert Cliffs NPA digital display parameters $\ldots \ldots \ldots \ldots \ldots \ldots \ldots \ldots \ldots .2-33$

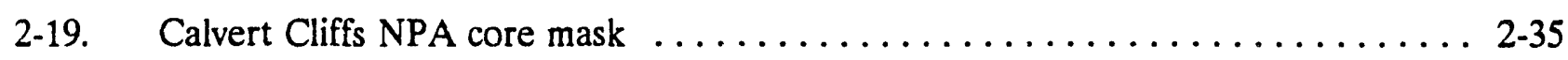

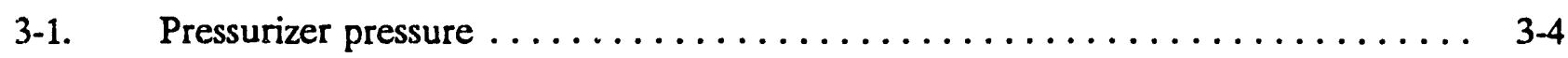




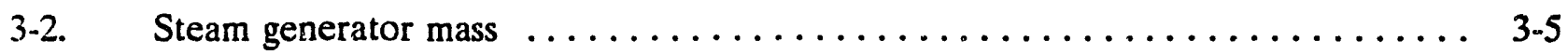

33. Steam generator pressures $\ldots \ldots \ldots \ldots \ldots \ldots \ldots \ldots \ldots \ldots \ldots \ldots \ldots \ldots \ldots \ldots \ldots, 3-6$

3-4. Hot and cold leg liquid temperatures $\ldots \ldots \ldots \ldots \ldots \ldots \ldots \ldots \ldots \ldots \ldots \ldots \ldots \ldots \ldots$

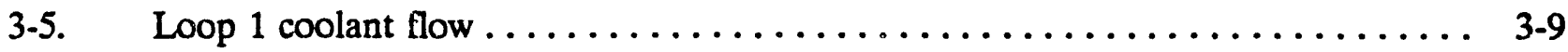

3-6. Pressurizer level $\ldots \ldots \ldots \ldots \ldots \ldots \ldots \ldots \ldots \ldots \ldots \ldots \ldots \ldots \ldots \ldots, 3-10$

3-7. Break nodalization for a large break LOCA $\ldots \ldots \ldots \ldots \ldots \ldots \ldots \ldots \ldots .11$

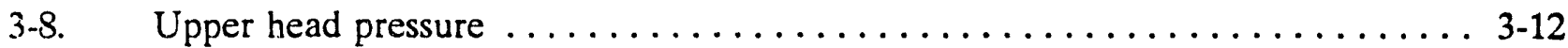

3-9. Break flow $\ldots \ldots \ldots \ldots \ldots \ldots \ldots \ldots \ldots \ldots \ldots \ldots \ldots \ldots \ldots \ldots \ldots \ldots \ldots \ldots \ldots, 13$

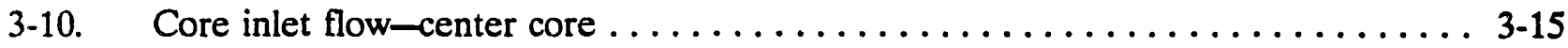

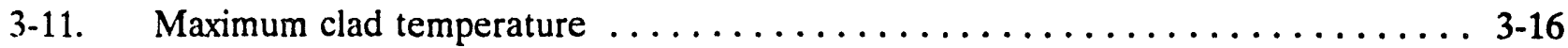

3-12. Break nodalization for a small break LOCA $\ldots \ldots \ldots \ldots \ldots \ldots \ldots \ldots \ldots .17$

3-13. Primary and secondary pressures $\ldots \ldots \ldots \ldots \ldots \ldots \ldots \ldots \ldots \ldots \ldots \ldots, 3-18$

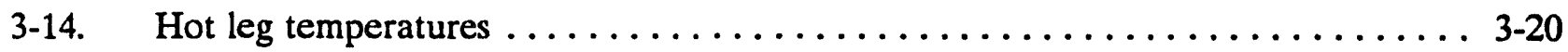

3-15. Pressurizer level $\ldots \ldots \ldots \ldots \ldots \ldots \ldots \ldots \ldots \ldots \ldots \ldots \ldots \ldots \ldots \ldots \ldots, 3-21$

3-16. Break flow $\ldots \ldots \ldots \ldots \ldots \ldots \ldots \ldots \ldots \ldots \ldots \ldots \ldots \ldots \ldots \ldots \ldots, 3-22$

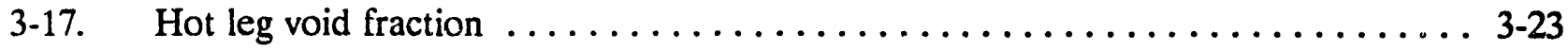

3-18. Void fraction upstream of the break $\ldots \ldots \ldots \ldots \ldots \ldots \ldots \ldots \ldots \ldots \ldots \ldots \ldots \ldots .24$

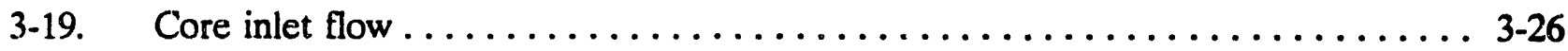

3-20. Total HPE flow $\ldots \ldots \ldots \ldots \ldots \ldots \ldots \ldots \ldots \ldots \ldots \ldots \ldots \ldots \ldots \ldots \ldots, 3-27$

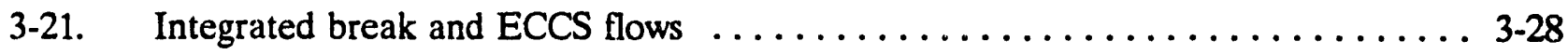

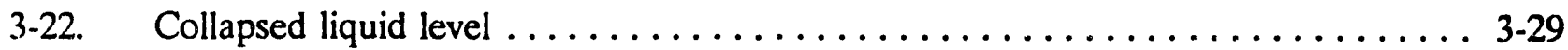

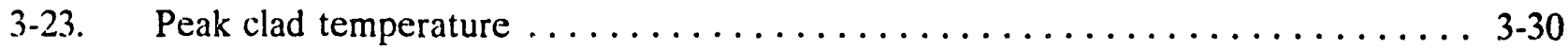

3-24. Problem execution using the Calvert Cliffs plant deck $\ldots \ldots \ldots \ldots \ldots \ldots .31$ 


\section{TABLES}

2-1. Reactor protection system $\ldots \ldots \ldots \ldots \ldots \ldots \ldots \ldots \ldots \ldots \ldots \ldots \ldots \ldots \ldots \ldots \ldots \ldots, 15$

2-2. System parameters available as RELAP5 control variables $\ldots \ldots \ldots \ldots \ldots \ldots$ 2-15

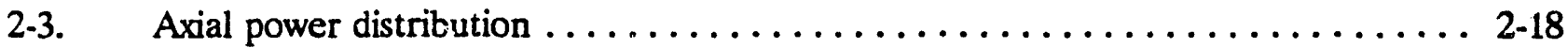

2-4. SCDAP quantities available in RELAP5/MOD3/SCDAP minor edits $\ldots \ldots \ldots \ldots$ 2-20

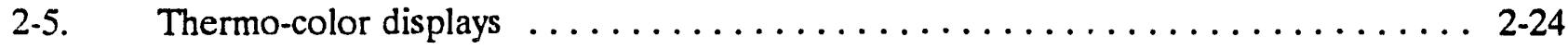

2-6. Calvert Cliffs NPA display-THERMO-COLOR paraneters $\ldots \ldots \ldots \ldots \ldots$ 2-27

2-7. Calvert Cliffs NPA display-ROD/CHAN and MAGNITUDE parameters $\ldots \ldots$ 2-30

2-8. Calvert Cliffs NPA display-LEVEL and ON/OFF parameters $\ldots \ldots \ldots \ldots \ldots$ 2-32

2-9. Calvert Cliffs NPA display-DIGITAL parameters $\ldots \ldots \ldots \ldots \ldots \ldots \ldots .2-34$

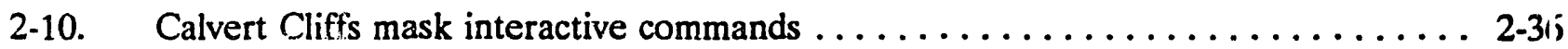

3-1. Steady state parameter comparison $\ldots \ldots \ldots \ldots \ldots \ldots \ldots \ldots \ldots \ldots \ldots, 3-2$

3-2. Calvert Cliffs plant deck interactive variable input summary $\ldots \ldots \ldots \ldots \ldots \ldots$ 3-34

3-3. Restart deck input listing $\ldots \ldots \ldots \ldots \ldots \ldots \ldots \ldots \ldots \ldots \ldots \ldots \ldots \ldots \ldots \ldots \ldots, 37$

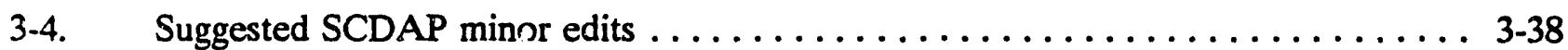

3-5. Inputs to remove the main feedwater line $\ldots \ldots \ldots \ldots \ldots \ldots \ldots \ldots \ldots, 3-41$ 


\section{Calvert Cliffs RELAP5/MOD3/SCDAP Plant Deck}

\section{INTRODUCTION}

A Plant Deck of the Calvert Cliffs $2700 \mathrm{MWt}$ CE nuclear reactor system has been developed and is described in this report. The primary purpose of this task is to enhance the plant analysis capability of the NRC by modifying and upgrading existing RELAP5 plant decks of LWR systems. The deck described here is for applications with the RELAP5/MOD3/SCDAP code (1) and has nuclear plant analyzer (NFA) $(2,3)$ interactive capabilities. The starting point for this study was the Calvert Cliffs RELAP5/MOD2 input deck used in the operational safety study described in Reference 4. A QA review of this deck was completed and then the improvements to the deck were identified and added. These improvements include:

1. Multiple channel modeling of the core fluid region with cross flow between radial regions

2. Split downcomer nodalization

3. Modeling of the ECC inlet locations with the RELAP5/MOD3 ECCMIX component

4. Conversion of the RELAP5 input from RELAP5/MOD2 format to RELAP5/MOD3 format

5. Use of SCDAP heat structures to describe the fuel rods and control rods in the core region

6. Addition of NPA option in the deck to allow the user interactive analysis capability.

The Calvert Cliffs plant deck was balanced so the initial pressures, fluid t/mperatures, system mass flow, and other thermodynamic conditions simulated $100 \%$ power/flow conditions. Approximations were used for the fuel rod temperatures and conductivity at $100 \%$ power. The completed and balanced input deck was then exercised and tested by applying it for the analysis of several postulated accident and transien; scenarios. These test scenarios included a loss of feedwater (LOFW) transient, a small break loss of coolant accident (SBLOCA), and a large break loss of coolant accident (LBLOCA). Also, the NPA capabilities of the deck were tested ty executing interactive commands while rur ning problems with the NPA display selected.

The Calvert Cliffs plant deck described here was developed to be applicable to a wide range of accidents and transients. The results of the test problems were satisfactory and show that the development goals were achieved. The RELAP5 input deck modifications summarized above are discussed in Section 2.1, the SCDAP input in Section 2.2, and the NPA capabilities in Section 2.3. The analyses are discussed in Section 3.1 through Section 3.3. User instructions are provided in Section 3.4 to aid engineers who apply the deck for accident and transient analysis. Section 3.5 explains methods for resolving problems that may be encountered during applications of the deck. 


\section{PLANT DECK DESCRIPTION}

This section contains the Calvert Cliffs RELAP5/MOD3/SCDAP plant deck description. There are three primary parts of the deck. Section 2.1 explains the inputs related to the RELAP5/MOD3 code. System fluid volume nodalization, vessel and piping heat conductors, ECC systems, trips, and control system" are modeled with RELAP5 inputs. The core heat structures are modeled with SCDAP and are explained in Section 2.2. The SCDAP inputs are separated from the RELAP5 inputs in the deck but the two codes are connected as shown in Figure 2-1 (1). Models and numerical solutions in the RELAP5 code predict system thermal-hydraulics, control system interaction, ECC injection rates, etc. The SCDAP code is primarily directed to the prediction of damage progression phenomena in the core region during severe accident conditions. However, the methods presented in this report allowed development of a general deck applicable for many studies including transients that progress into severe accident situations.

The plant deck has interactive applications capability in conjunction with the NPA. Section 2.3 describes the NPA capabilities. To use the NPA, a mask, which is the name given to the computer terminal schematic of the reactor system modeled with RELAP5/MOD3/SCDAP, is created. The Calvert Cliffs system mask has reactor vessel, core, reactor coolant loop, steam generator, pressurizer, ECCS, and other components. The lat $3 i$ versions of the NPA have special core region displays that show fuel and control rod behavior provide detailed displays of core data a second mask was developed. The core mask is also explained in Section 2.3.

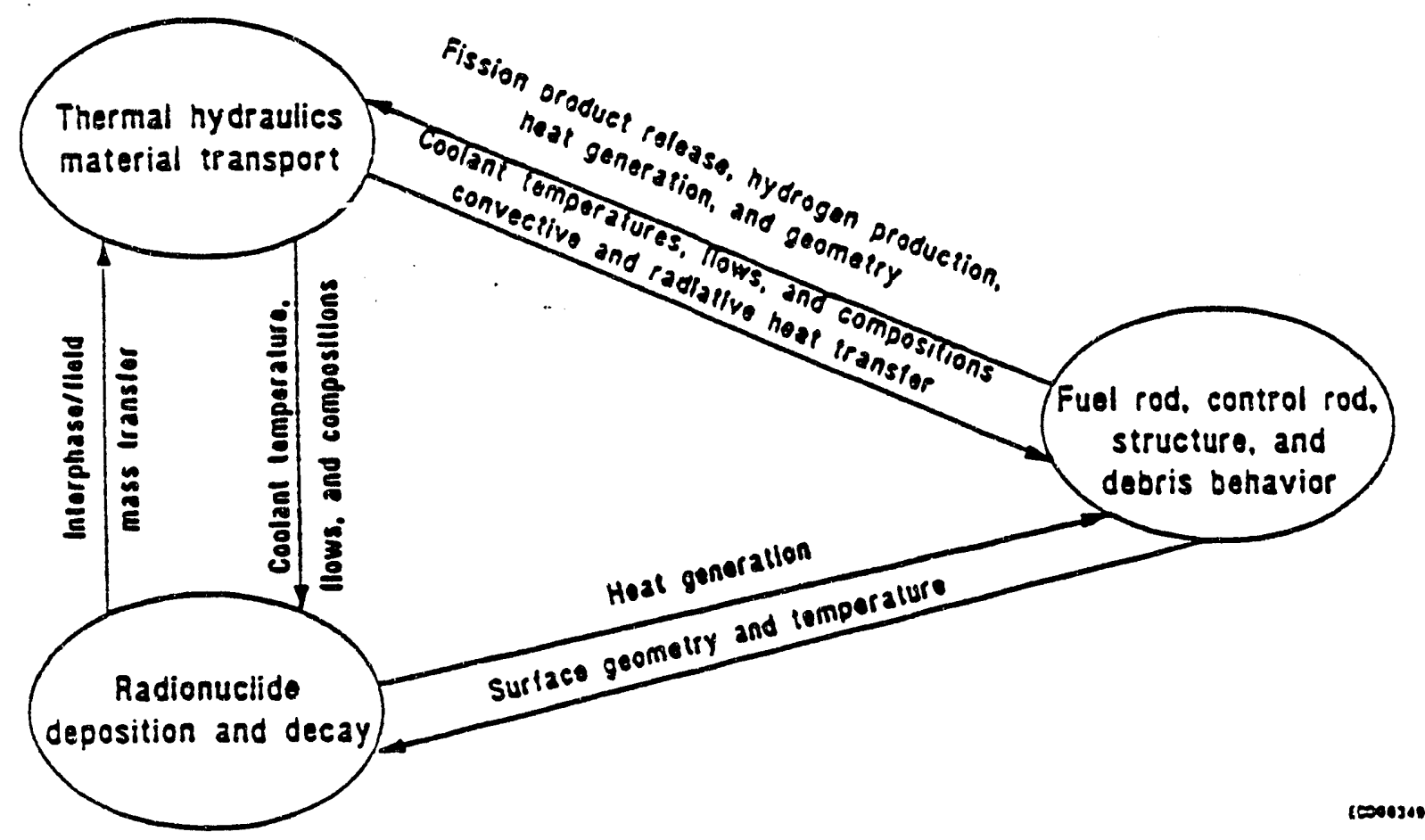

Figure 2-1. SCDAP/RELAP5 reactor coolant system interactions. 


\subsection{RELAP5/MOD3 Input Description}

The principal enhancements to the Calvert Cliffs deck that relate to RELAP5 input include: (a) core region modifications; (b) downcomer region modifications; (c) addition of ECCMIX components; (d) conversion from RELAP5/MOD2 format to RELAP5/MOD3 format. The significant features in the RELAP5 portion of the input are discussed in this section.

Reference 1 contains the RELAP5/MOD3 input description. The Calvert Cliffs plant deck user should review the User Manual (7) and become familiar with the basic input requirements before applying the deck. This will make it easier to interpret the results. For purposes of this discussion the RELAP5 component designation should be uriderstood to avoid any confusion. RELAP5 hydrodynamic components and their alphanumeric designation include: (a) single volumes (snglvol); (b) branches (branch); (c) pipes (pipe); (d) annulus (annulus); (e) time dependent volumes (tmdpvol); (f) single junciions (sngljun); (g) time dependent junctions (tmdpjun); (h) separators (separatr); (i) turbines (turbine); (j) valves (valve); (k) pumps (pump); (l) multiple junctions (mtpljun); (m) accumulators (accum). There is only one type of heat structure component and there is no alphanumeric designator for heat conductors. In the text and the figures showing components, the components will normally be referred to by a three digit identifier. Hcwever, in the code output or in the NPA a nine digit identifier is used. For example the hot leg in Loop 1 is component 105. This will be identified as 105010000 in the output. A pipe or annulus component contains several volumes and junctions. The third volume node of pipe component 125 , the primary side of the steam generator U-tubes, would be referred to as 12503.

\subsubsection{Plant Deck Nodalization}

The nodalization used to describe fluid volumes in the reactor vessel and steam generators is given in Figures 2-2 through 2-11. 137 RELAP5 fluid nodes are used to model the Calvert Cliffs primary and secondary systems. The nodalization selection contains enough detail to make the deck applicable to most analyses. In some calculations the nodalization detail may be reduced to improve computer running time. This is not difficult for the experienced user.

2.1.1.1 Core Region. The core is modeled with three radial channels and ten axial volumes per sadial channel. Figure 2-2 shows the core region. RELAP5 component 513 is the outer core containing $6014 \times 14$ fuel rod bundles. Component 515 is the middle core containing 92 bundles and component 517 describes the center core containing 65 bundles. Figure 2-3 shows the radial division in detail. The ten axial nodes in each channel are of equal length and are connected by cross flow junctions. The RELAPS/MOD3 code allows the user to specify a junction as a cross flow junction rather than a normal junction, thereby eliminating momentum flux terms in the momentum equation. The values of the loss coefficients for the cross flow junctions were determined using Reference 5. Reasonable values for the mass flow rates through the cross flow junctions were predicted by the code when these loss coefificients were used.

This modeling method for the core region was selected to allow the prediction of core damage progression during severe accident situations. In some scenarios, debris formation, debris melting, and slumping of core material may occur in the central region of the core while the outer region 
To 520

Axial
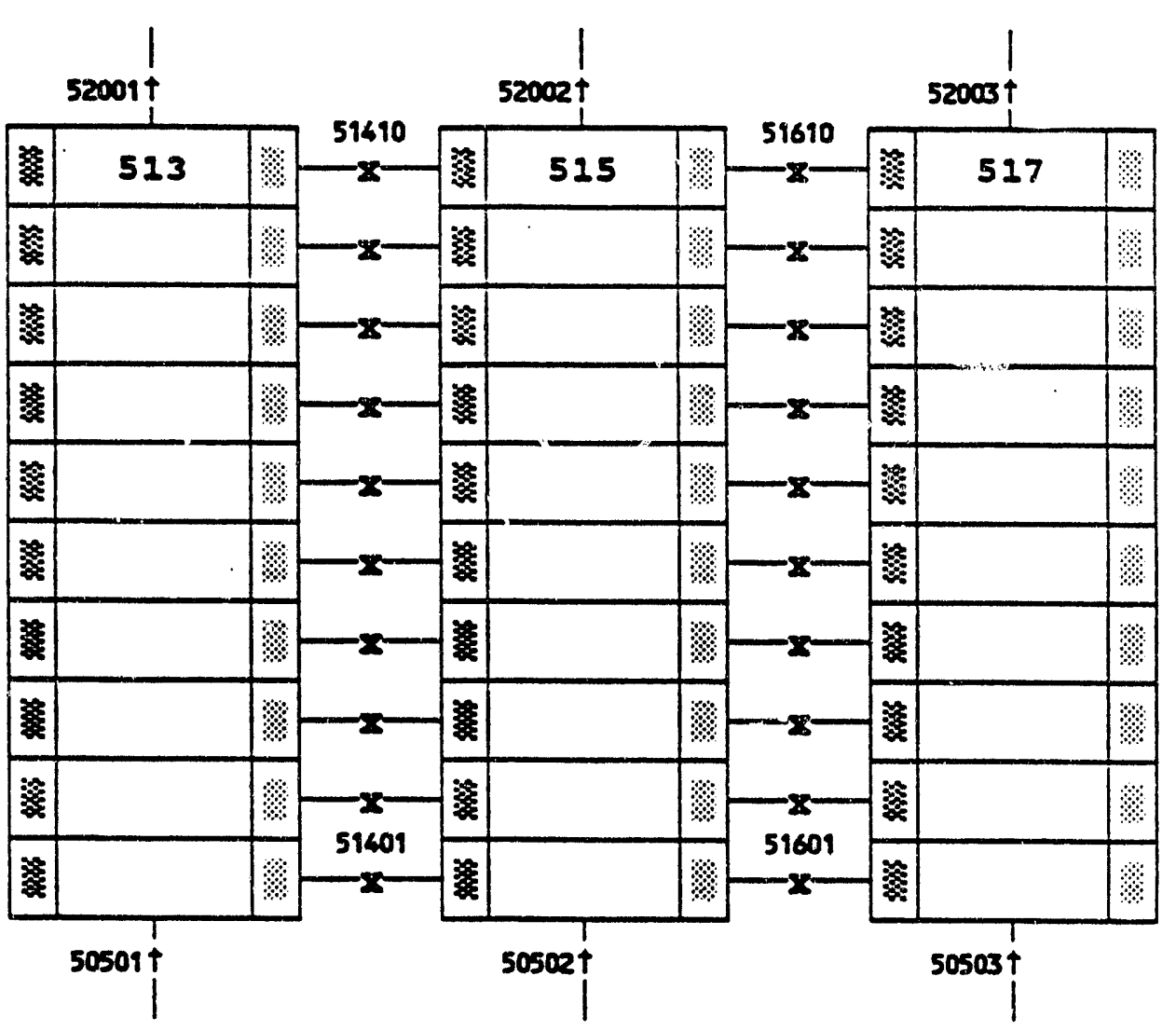

Level

SCDAP

From 505

component

number: \&

2

3

4

5

10

9

8

7

6

5

4

3

2

1

\begin{tabular}{|c|c|c|c|}
\hline Junction & & $\begin{array}{l}\text { SCDAR } \\
\text { Component }\end{array}$ & \\
\hline crosselow & $\rightarrow x-$ & Fuel Rod & : \\
\hline normal & $t$ & Control Rod & \& \\
\hline
\end{tabular}

Figure 2-2. Calvert Cliffs RELAP5/MOD3/SCDAP core nodalization. 


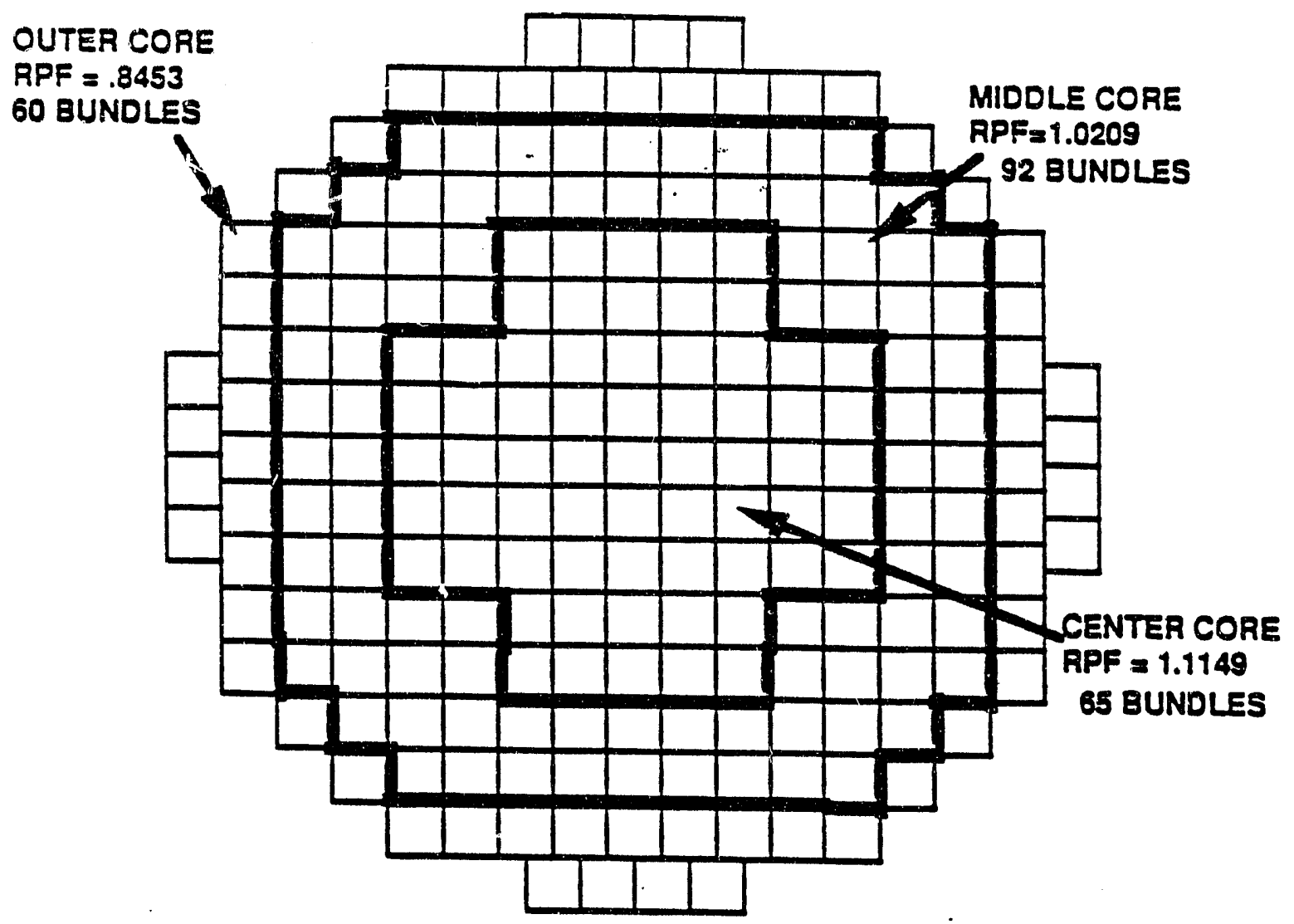

Figure 2-3. Calvert Cliffs core nodalization for SCDAP heat structure modeling. 


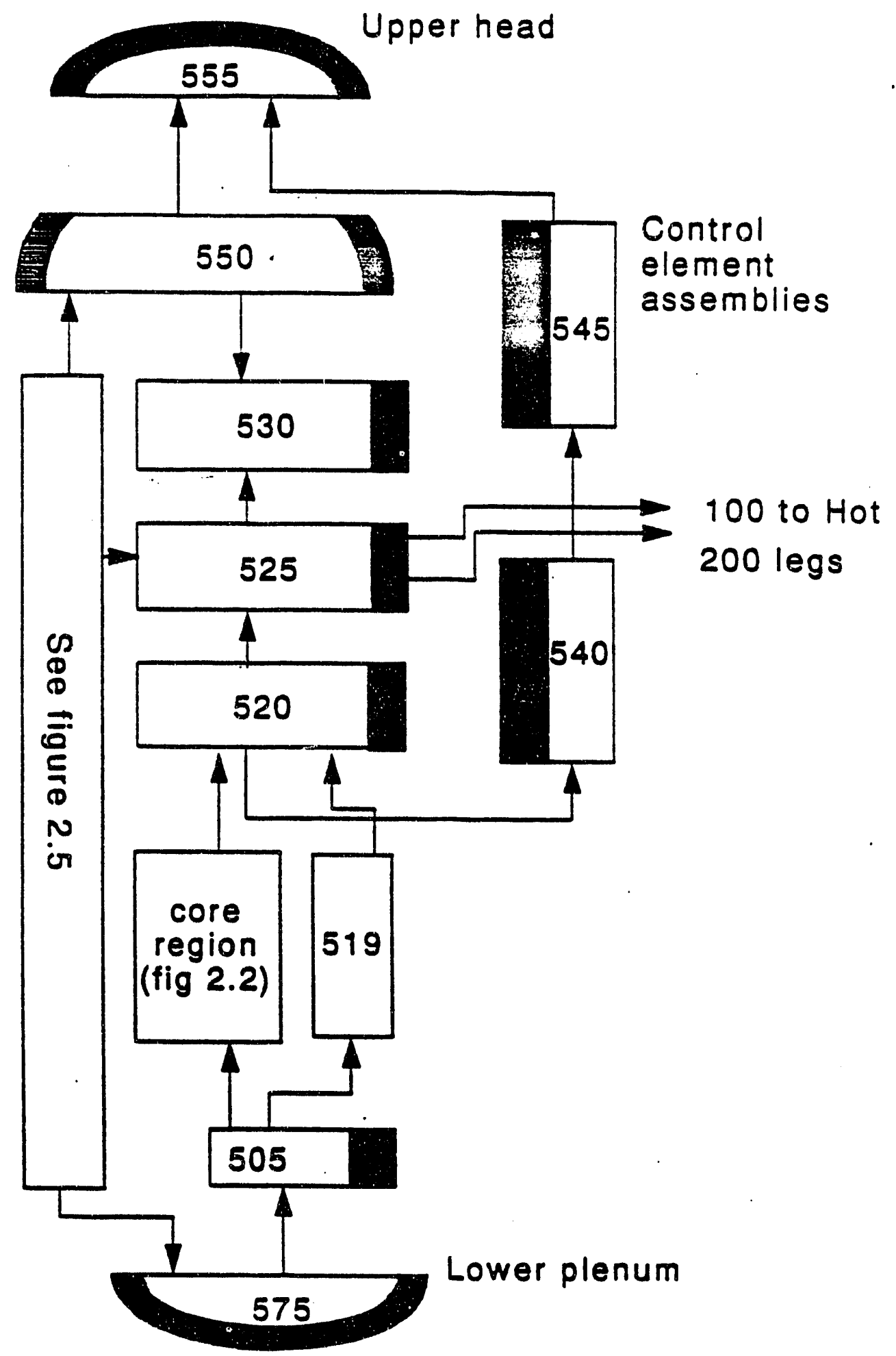

Figure 2-4. Reactor vessel nodalization. 

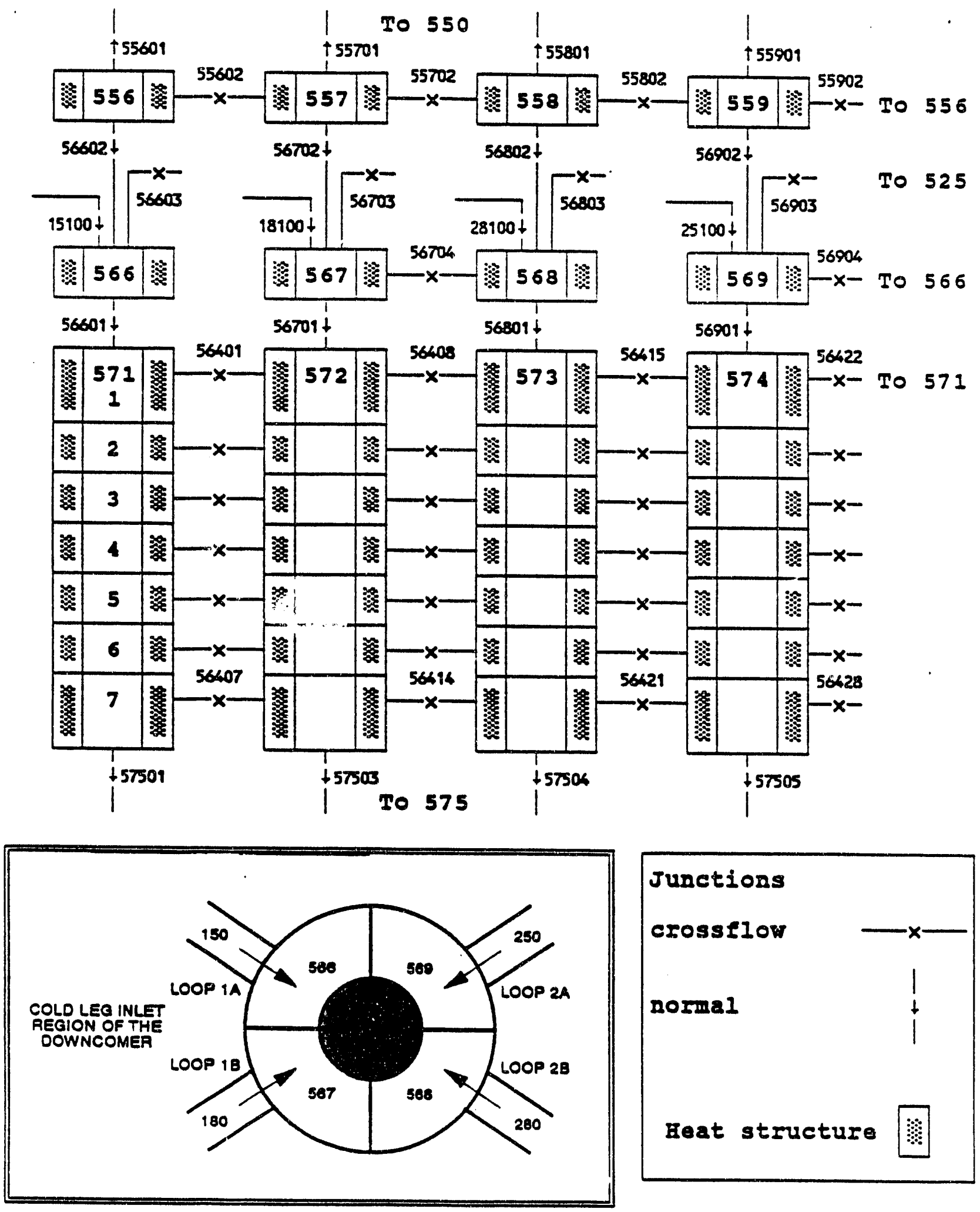

Figure 2-5. Calvert Cliffs downcomer nodalization. 


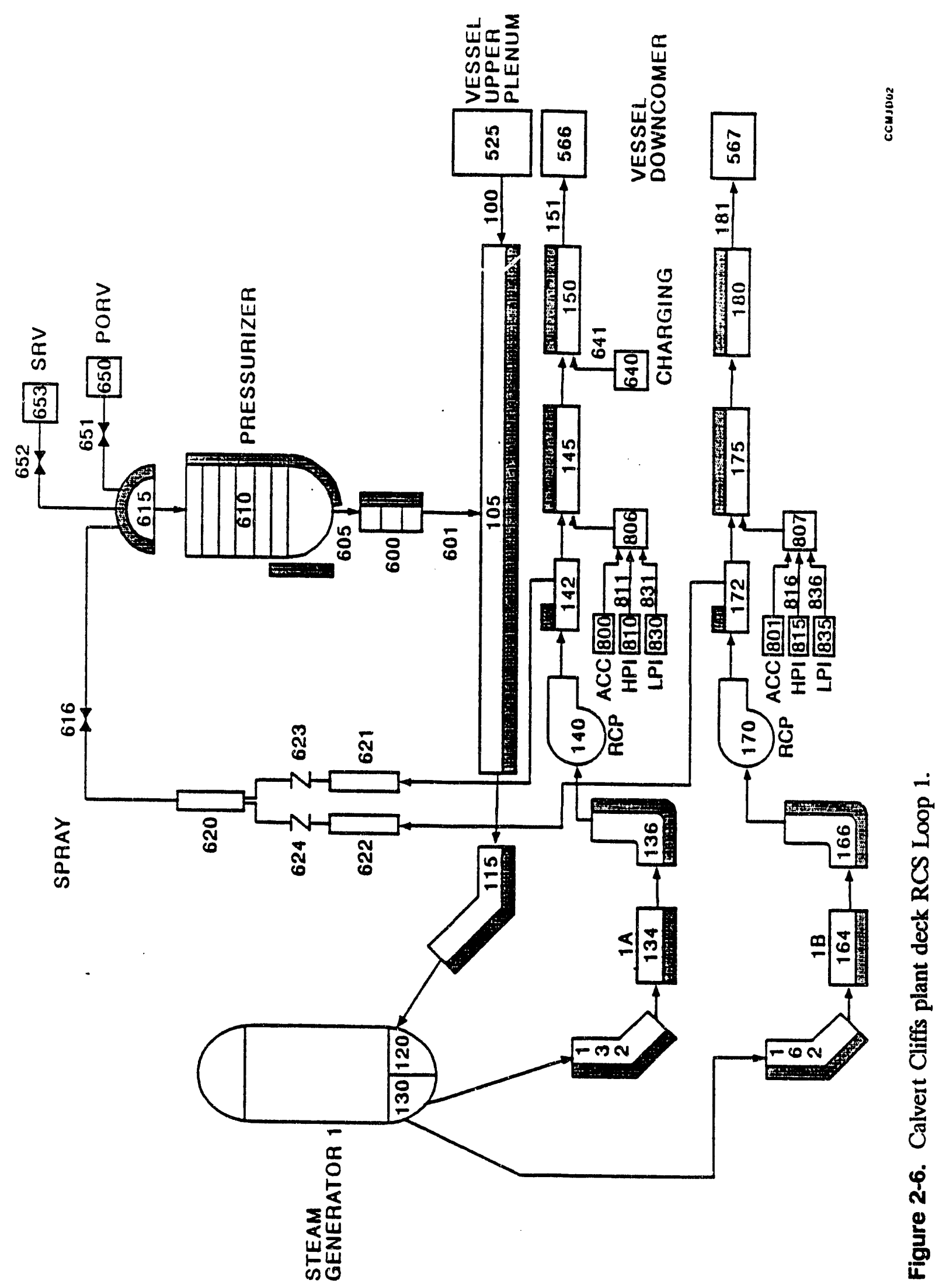




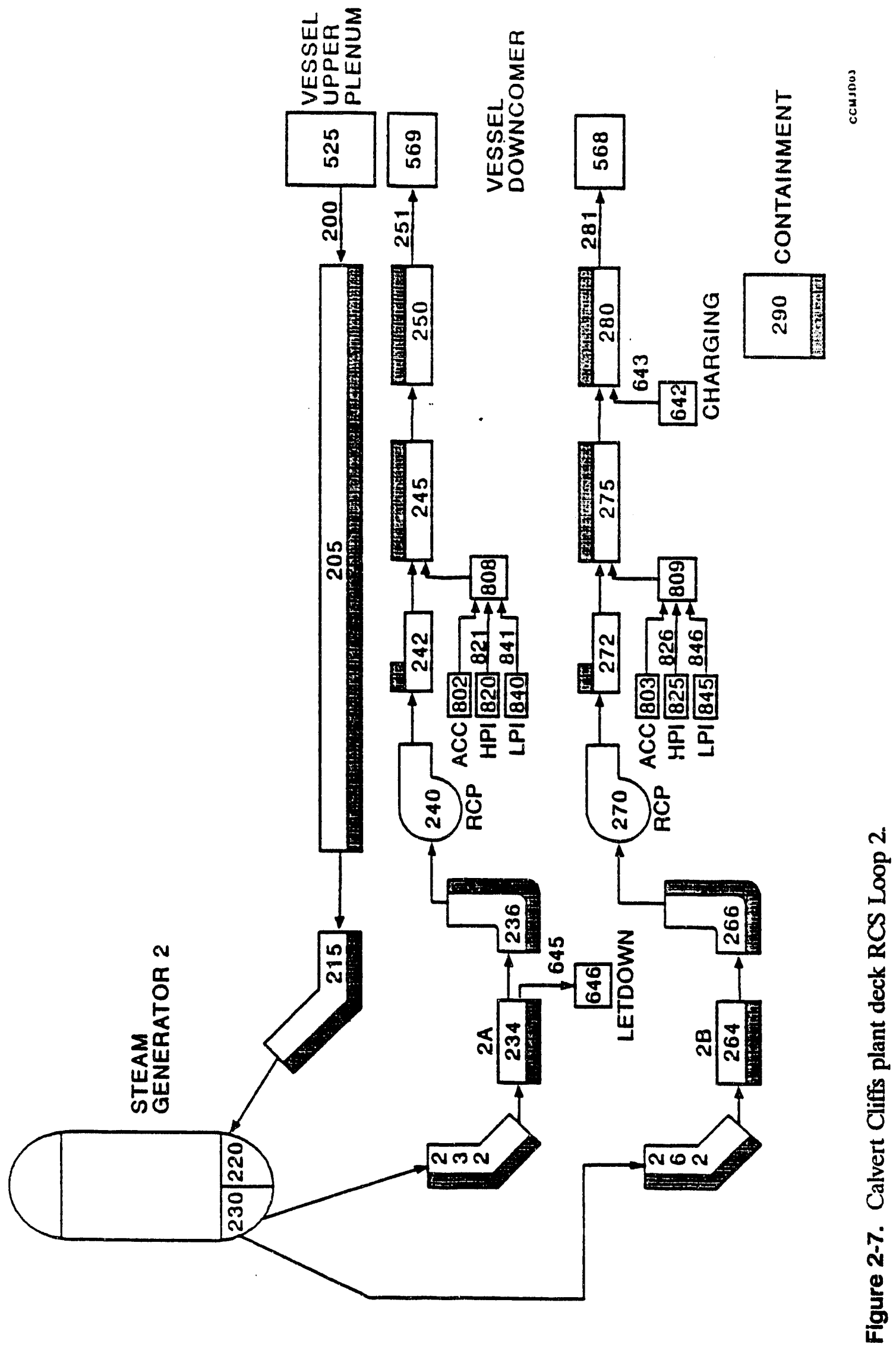




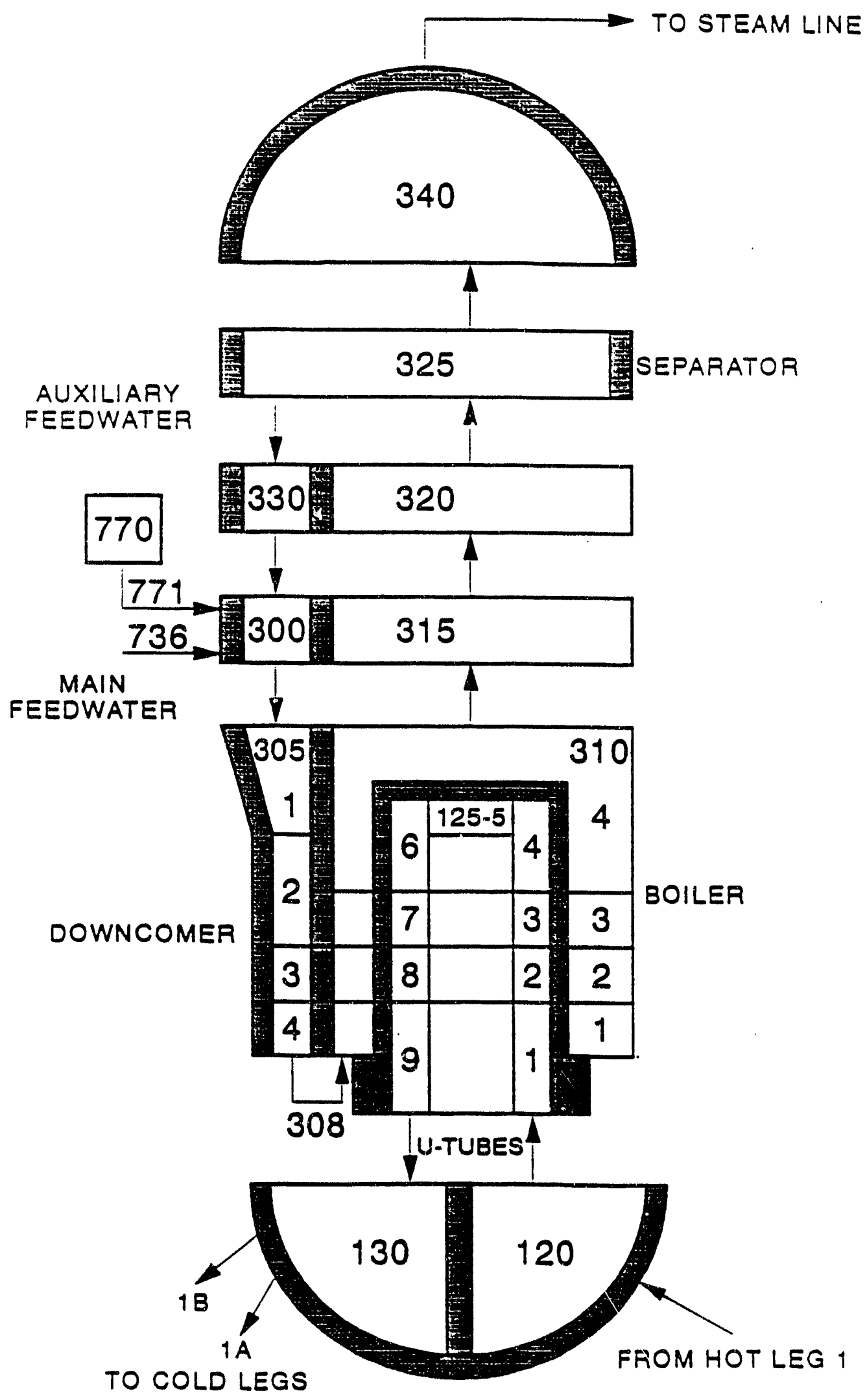

cemsoos

Figure 2-8. Calvert Cliffs plant deck Loop 1 steam generator. 


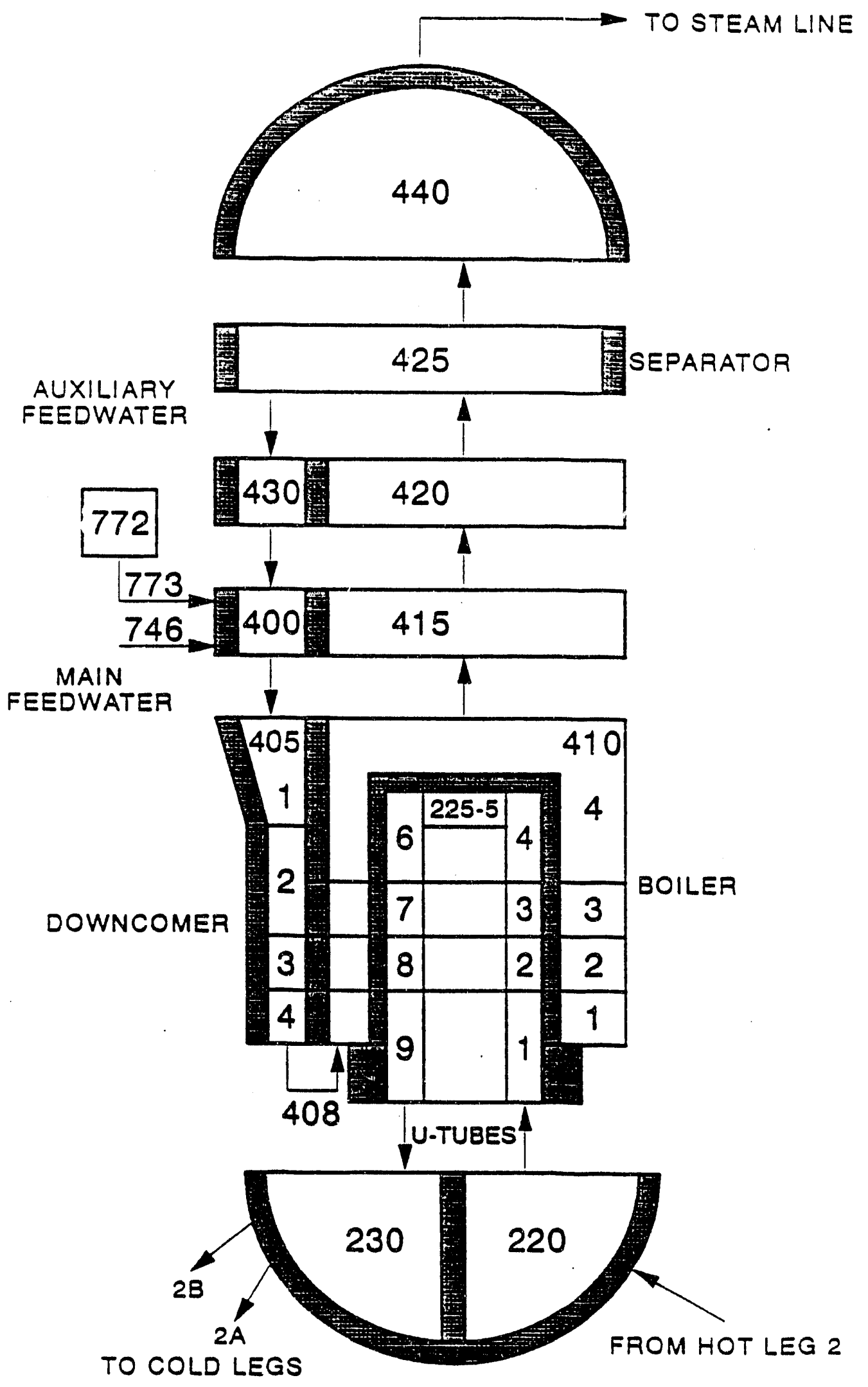

Figure 2-9. Calvert Cliffs plant deck Loop 2 steam generator.. 


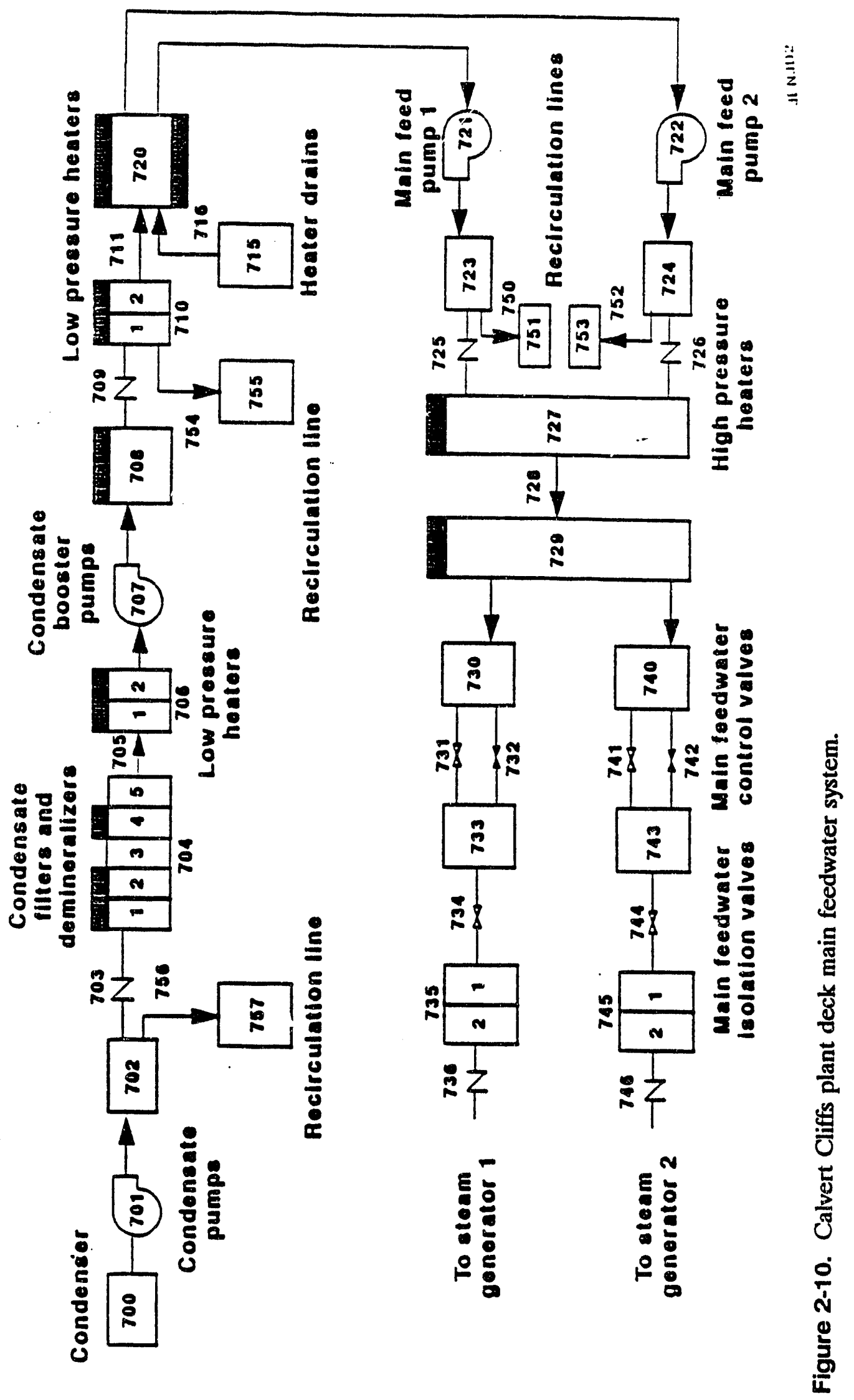




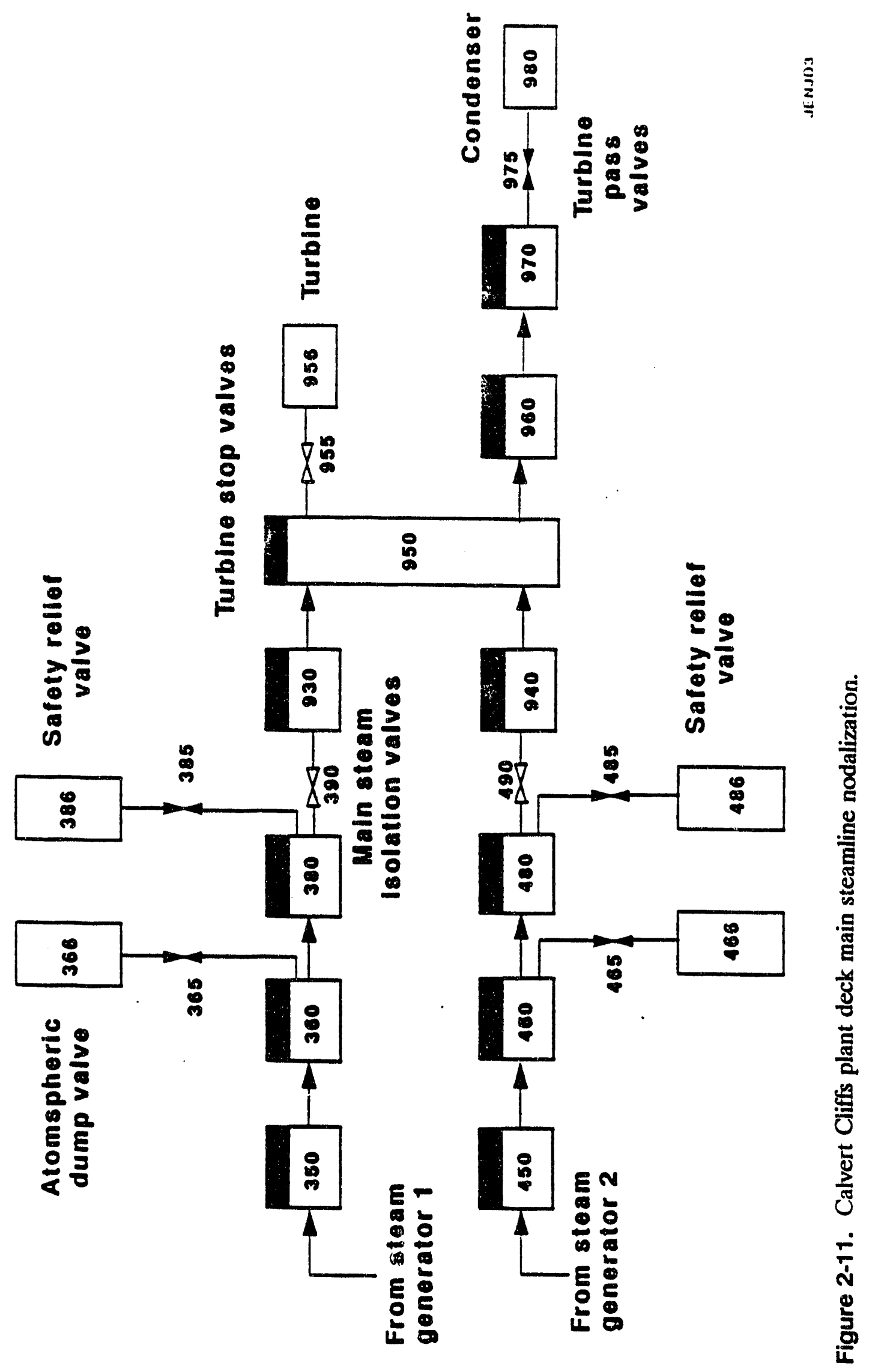


remains essentially intact. Therefore, the core nodalization must allow the radial power distribution to be modeled as is done here. The Plant .Deck testing described in Section 3.0 confirned that the core input performs well in calculations where severe accident behavior does not occur. Thus, a general core model, suitable for a wide range of applications is provided in the deck.

2.1.1.2 Reactor Vessel and Downcorner. Figure 2-4 shows the reactor vessel nodalization outside the core. Components 575 and 505 are the lower plenum and core inlet region respectively. The upper plenum region is described by components 520,525 , and 530 . The upper head is modeled with components 550 and 555 . Components 540 and 545 describe a leakage path between the core and the upper head through the control elements.

Asymmetric thermal-hydraulic conditions can occur in the downcomer region during ECC injection. This asymmetric behavior car be predicted by RELAP5 if a split downcomer is modeled. Since Calvert Cliffs is a $2 \times 4$ design the downcomer is modeled with four azimuthal channels connected by cross flow junctions. The loss coefficients of the cross flow junctions were determined by considering the curvature of the downcomer and fanning friction losses. Fanning friction is not included in the equations for cross flow junctions; so a loss coefficient that will approximate the fanning losses was included. Figure 2-5 shows the details of the split downcomer model.

2.1.1.3 Reactor Coolant Loops and Steam Generators. Figures 2-6 and 2-7 show the Loop 1 and Loop 2 reactor coolant piping systems respectively. The pressurizer is cnnnected to Loop 1 and includes the spray line, proportional heaters, backup heaters, PORV, and SRV. Eight nodes are used in the pressurizer and three in the surge line. The PORV opens on high pressurizer pressure of 2400 psia (16.55 $\mathrm{MPa}$ ) and closes at 2280 psia (15.72 $\mathrm{MPa})$. The SRV opens at $2532.2 \mathrm{psia}(17.46 \mathrm{MPa})$ and closes at $2430.9 \mathrm{psia}(16.76 \mathrm{MPa})$. The spray line valve positions and heater powers are controlled by the reactor coolant pressure regulating system and the pressurizer level control system.

Homologous curves are used in the RCP input to determine pump head and hydraulic torque. The pumps are controlled interactively by the analyst, as described later in the discussion of the NPA mask, or may be told to follow a predefined course of action using the RELAPs trip logic.

The safety injection (HPI, LPI, and makeup) systems are connected to the cold legs between the pump and the vessel. The ECC pumps are not explicitly described, but are modeled with flow versus pressure tables, and the safety injection actuation signal occurs on low pressurizer pressure at $1754.7 \mathrm{psia}$ (12.1 MPa). The temperature of the injected fluid is defined by time dependent volumes (components $640,642,810,815,820,825,830,835,840$, and 845). The accumulators are modeled using the RELAP5 accumulator component option, which gives a lumped parameter treatment of accumulator behavior. Heat transfer to the nitrogen gas in the accumulators is considered and the surge line fanning friction losses are modeled.

The HPI, LPI, and accumulators inject into ECCMIX components (7). The ECC mixer models the ECC injection location where a jet of cold water is injected into a two-phase mixture. The primary phenomenon modeled by this component is the resulting condensation of the steam in the volume. When no steam is present this component behaves as an ordinary BRANCH component. Reference 1 gives a detailed discussion of this new feature of RELAP5/MOD3. 
Figures 2-8 and 2-9 show the Loop 1 and 2 steam generator respectively. The steam generator U-tube fluid volumes are described with nine nodes on the primary side. The secondary side tube bundle region has four fluid volumes. There are six nodes in the downcomer and four nodes in the separator and steam dome region.

\subsubsection{Main Feedwater Train, Main Steam Line, Reactor Trip Logic, and Control Systems}

Other systems and parameters described using RELAP5/MOD3 input include the main feedwater train, the main steam line, the reactor trip logic, and other control variables. These portions of the plant deck are discussed in this section. The main feedwater train and the main steam line are described with the valves and pumps in these lines appropriately modeled. The principal control systems and reactor protection system trips are described in the input deck using the RELAP5/MOD3 controller, trip, and table function inputs.

2.1.2.1 Main Feedwater Train. Figure 2-10 shows the main feedwater system and the components modeled in the main feedwater train. Homologous curves are used to calculate the head, torque and pump speed relationships for the condensate pump, the condensate booster pump, and the main feed pumps. The main feed pumps will trip automatically on high discharge pressure (1464.7 psia, 10.1 MPa) or low suction pressure (225.7 psia, $1.56 \mathrm{MPa}$ ) and also trip if the steam generator isolation signal (SGIS) occurs on low steam generator pressure (667.7 psia, 4.6 $\mathrm{MPa}$ ) or asymmetric steam generator pressure (115 psid, $0.79 \mathrm{MPa})$.

2.1.2.2 Main Steam Line. The RELAP5/MOD3 nodalization and component modeling of the main steam line is shown in Figure 2-11. The main steam isolation valves (MSIV) and the turbine stop valve (TSV) close on the SGIS. The atmospheric dump valve and the turbine bypass valve positions are regulated by the steam dump and turbine bypass controller. The safety relief valve component describes four safety valves in each line. The valves progressively open with increasing steam line pressure. The set points are $950,960,980$, and 1000 psia. The closing set points are 1000 , 1010,1030 , and 1050 psia. The condenser is modeled as a time dependent volume component.

2.1.2.3 Reactor Trip Logic. The Calvert Cliffs reactor protection system is described in the plant deck using trips that cause scram on: (a) low RCS flow; (b) low steam generator level; (c) low steam generator pressure; (d) high RCS pressure; (e) low RCS pressure; (f) asymmetric steam generator pressure. Table $2-1$ lists the trips and set points modeled.

2.1.2.4 Other Control Variat:'es. Some thermal-hydraulic parameters that are important to the analyst are not directly calculated by the code. For example, the density in each volume component in the steam generators will be given in the output, but the total mass in the steam generator, which is often of greater interest than node densities, will not appear in the major edit data. Therefore, control systems are used to calculate and display these quantities. Table 2-2 gives the system parameters that are calculated at each time step by RELAP5 control system variables. 
Table 2-1. Reactor protection system.

Set point

Low RCS flow

Low steam generator level

Low steam generator pressure

High RCS pressure

Low RCS pressure

Asymmetric steam generator pressure
$39952.4 \mathrm{lbm} / \mathrm{s}$

-50.0 in.

667.7 psia

2400.0 psia

2100.0 psia

115.0 psid

Table 2-2. System parameters available as RELAPS control variables.

Control

Parameter

variable number

Units

310

320

336

344

410

420

436

444

604

1875 $\mathrm{lb}_{\mathrm{m}}$

MW

in.

in.

$\mathrm{lb}_{\mathbf{m}}$

MW

in.

in.

in.

W

\subsection{SCDAP Input Deck for Severe Accident Analysis}

The SCDAP code predicts core behavior during a severe accident. Phenomena analyzed with SCDAP include fuel rod heat up, ballooning and rupture, fission product release, rapid oxidation, zircaloy melting, UO2 dissolution, $\mathrm{ZrO} 2$ breach, flow and freezing of molten fuel and cladding, and debris formation. The RELAP5/MOD3/SCDAP code fully couples the SCDAP and RELAP5/MOD3 codes at each time step. Figure 2-1 shows the functional interaction of the SCDAP and RELAP5/MOD3 codes. Therefore, a general plant deck for LOCA, plant transient, and severe accident analysis can be created by modeling the core fuel and other heat structures with SCDAP components, and modeling the remainder of the system with RELAP5/MOD3 components. This section describes the SCDAP core model. 


\subsubsection{Core Nodalization}

The Calvert Cliffs reactor core is described with three radial regions and ten axial nodes per region to enhance the severe accident prediction capability of the input deck as explained in Section 21.1.1. Figure 2-3 shows this radial division. There are 217 total $14 \times 14$ fuel bundles in the core. In this plant deck the center core region contains 65 bundles with a radial peaking factor (RPF) of 1.1149, the middle core has 92 bundles with an RPF of 1.0209 , and the outer core region contains 60 bundles with an RPF of 0.8453 . The RPFs were determined by using typical beginning of life (BOL) power distribution data from the Calvert Cliffs FSAR (6).

The axial power distribution is given in Figure 2-12. SCDAP requires that an axial power fraction (APF) be input for each axial node in a radial region. So:

$\Sigma A P F=$ Number of axial nodes $=10$, for each radial region.

The APFs were determined by integrating the curve in Figure 2-12 and calculating the power fraction in each of the ten equal length axial nodes. Table 2-3 gives the resulting axial distribution.

The axial nodalization of the core was shown previously in Figure 2-2. Each of the 30 nodes contains a SCI)AP fuel rod heat structure and a SCDAP control rod heat structure. Sections 2.2 .2 and 2.2.3 explain the modeling of these components.

\subsubsection{Fuel Pin Component Inputs}

The fuel pin inputs include parameters describing the basic bundle and fuel geometry plus other key parameters. The sides of each bundle are 7.980 inches giving an area of $63.680 \mathrm{in}^{2}$ per bundle. The fuel rods are 136.7 inches in length with a pin diameter of 0.440 inches. There are eight zircaloy spacer grids in each bundle. Figure 2-13 shows the cross-sectional geometry of the fuel pins and the control rods.

Generally the SCDAP inputs were either calculated from fuel rod data or entered using recommended values where appropriate. The recommended values are given in the SCDAP input manual (7). The inputs that may be of special interest to the analyst are discussed here.

The SCDAP code requires power history data for the fuel rods. It was decided that selection of the generic power history data option would be best for a general model. The generic power history data extends to exposures of $33800 \mathrm{MWD} / \mathrm{MT}$.

The SCDAP fuel behavior calculation uses a fixed gap conductance input by the user. The initial gap conductance value will vary if rod ballooning occurs during an analysis. In the plant deck a fixed gap conductance of $1000 \mathrm{Btu} / \mathrm{hr}-\mathrm{ft}^{2}-{ }^{\circ} \mathrm{F}\left(6.6111 \mathrm{E}+04 \mathrm{~W} / \mathrm{m}^{2}-\mathrm{K}\right)$ was used at all axial locations for all rods. This approximate value gave a reasonable prediction of fuel rod stored energy at $100 \%$ power. If an analysis is performed requiring highly accurate calculations of initial stored energy, some gap coefficient adjustments would be required. The code also requires input of a radial temperature distribution at each axial node. However, these temperatures will adjust when a steady-state calculation is performed with the deck. The rod gap pressure is modeled at 2620 psia $(1.806 \mathrm{E}+07$ $\mathrm{N} / \mathrm{m}^{2}$ ) to equal the maximum design pressure. 


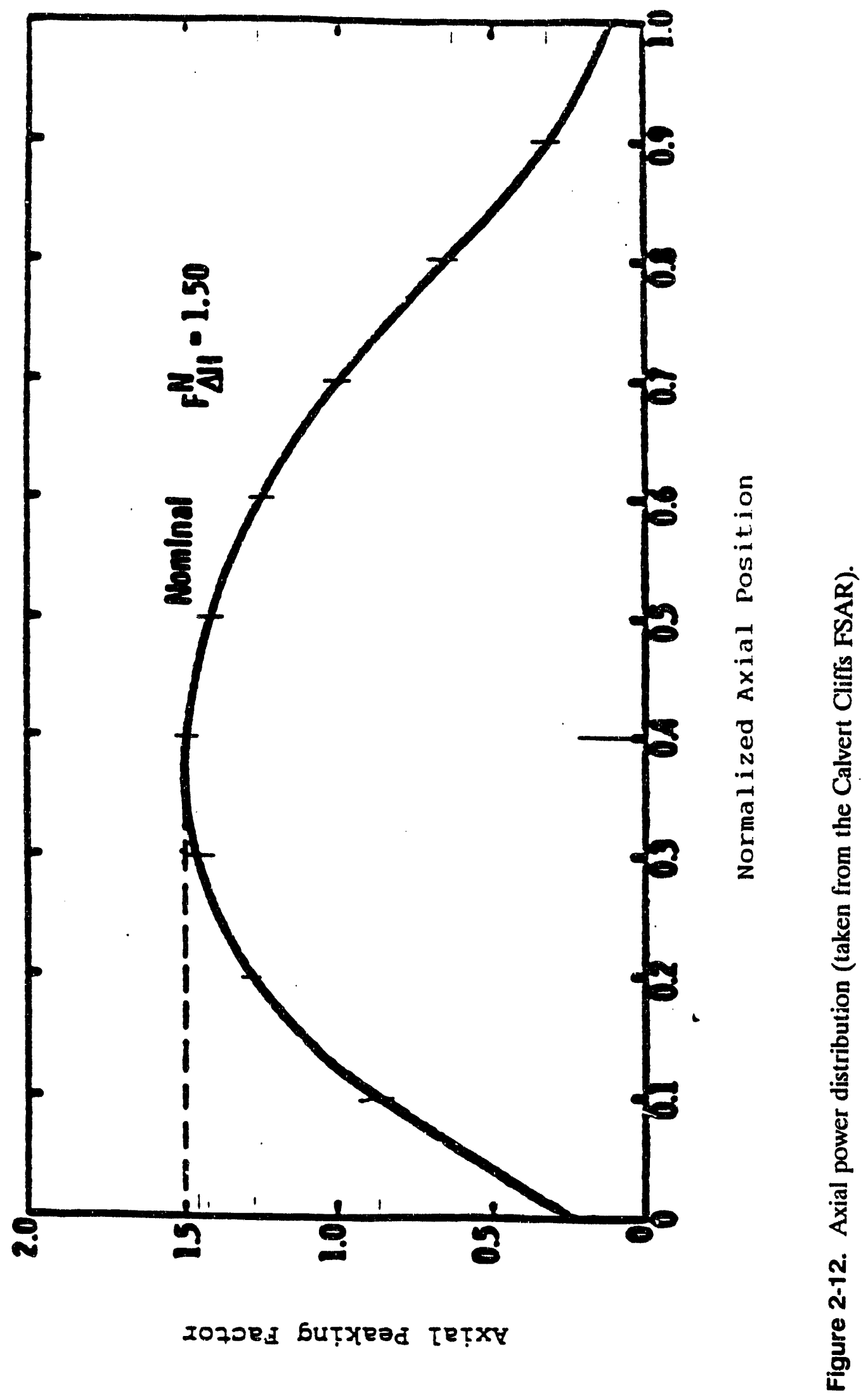


Table 2-3. Axial power distribution.

\begin{tabular}{cc}
$\begin{array}{c}\text { Axial } \\
\text { node }\end{array}$ & $\begin{array}{c}\text { Axial } \\
\text { power fraction }\end{array}$ \\
\hline 1 & 0.5647 \\
2 & 1.0790 \\
3 & 1.3733 \\
4 & 1.4925 \\
5 & 1.4742 \\
6 & 1.3593 \\
7 & 1.1453 \\
8 & 0.8240 \\
9 & 0.4764 \\
10 & 0.2102 \\
$\Sigma$ & 10.0 \\
\hline
\end{tabular}

SCDAP Heat Structure Geometries

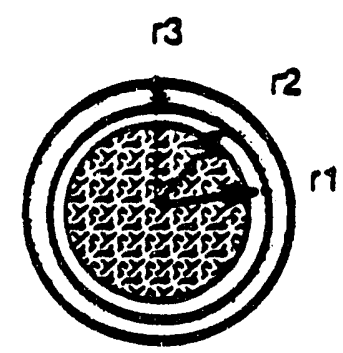

Fuel Pin

$r l$ - fuel pellet radius

$=0.0156875 \mathrm{ft}$

r2 - clad inner radius

$=0.016000 \mathrm{ft}$

r3 = pin outer radius

$=0.018333 \mathrm{ft}$

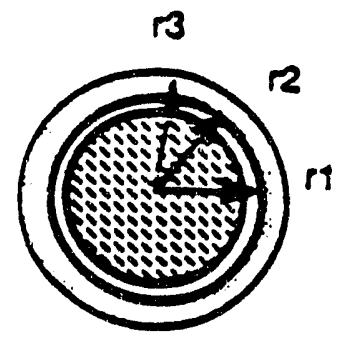

Control Rod $r l=B_{4} C$ radius

$=0.03583 \mathrm{ft}$

r2 - clad inner radius

$=0.03617 \mathrm{ft}$

r3 = rod outer radius

$=0.03950 \mathrm{ft}$

\section{Radial Modalization}

Fuel pellet -4 nodes $\quad$ Control rod -2 nodes
gap
clad

Figure 2-13. Calvert Cliffs fuel pin and control rod geome..y. 


\subsubsection{Control Rod Components}

Difficulties were encountered in modeling the control rods. SCDAP input was developed for Westinghouse type fuel bundles, where the control rods and fuel rods are about the same size, but the fuel bundles described in Reference 6 contain control rods that occupy the space of four fuel rods. Inputs were developed which satisfied SCDAP requirements and conserved the mass of the control rod cladding at any given axial level. The number of control rods modeled was increased four-fold, and the inner and outer radii were adjusted to conserve cladding mass. This allows accurate calculation of the time to cladding failure, the significant event in a severe accident scenario for this fuel configuration.

\subsubsection{SCDAP Component Connection to RELAP5/MOD3}

Figure 2-2 shows the Calvert Cliffs core with the SCDAP heat structures and the RELAP5/MOD3 fluid volumes. The SCDAP input requires that the user specify which RELAP5/MOD3 component volumes connect to each heat structure. The SCDAP heat structures are identified by the code iikkjj.

where

ii $=$ heat structure radial node number

$\mathrm{kk}=$ heat structure axial node number

$\mathrm{jj}=$ heat structure component number.

In the deck the SCDAP heat structure components are defined as follows:

$\begin{array}{lc}\text { Region/component } & \text { SCDAP number } \\ \text { Outer core/fuel rods } & 01 \\ \text { Outer core/control rods } & 02 \\ \text { Middle core/fuel rods } & 03 \\ \text { Middle core/ control rods } & 04 \\ \text { Center core/fuel rods } & 05 \\ \text { Center core/control rods } & 06\end{array}$

The fuel rod radial mesh definition includes four equally spaced nodes for the fuel pellet, one node for the fuel to clad gap, and one node for the clad, for a total of six nodes. The control rods are modeled with only two nodes because of a SCDAP limitation. Therefore, the surface temperature of the seventh axial node of the middle fuel rod sets would be cadct 050703 , where cadct refers to the component temperatures. Table 2-4 lists the SCDAP quantities that can be edited using the RELAP5 minor edit or strip inputs. Note the SCDAP variables are always in SI units even if British units are selected on the RELAP5 102 card. 
Table 2-4. SCDAP quantities available in RELAP5/MOD3/SCDAP minor edits.

Code Index ${ }^{\mathrm{a}} \quad$ Quantity

\begin{tabular}{|c|c|c|}
\hline CADCT & iikkjj & Component temperatures $(\mathrm{K})$ \\
\hline BGTH & 0 & Core total hydrogen generation rate $(\mathrm{kg} / \mathrm{s})$ \\
\hline BGNHG & 0 & Core nuclear heat generation $(\mathrm{W})$ \\
\hline BGMCT & 0 & Core maximum surface temperature $(\mathrm{K})$. \\
\hline BGTFPRS & 0 & Core cumulative soluble fission product release ( $\mathrm{gg}$ ) \\
\hline BGTFPRN & 0 & Core cumulative noncondensable fission product release $(\mathrm{kg})$ \\
\hline SHQIN & 0 & $\begin{array}{l}\text { Total heat flowing through the inside surface of the flow shroud (W). } \\
\text { (Available only if the shroud component is input.) }\end{array}$ \\
\hline SHQOUT & 0 & $\begin{array}{l}\text { Shroud total heat out (W). (Available only if the shroud component is } \\
\text { input.) }\end{array}$ \\
\hline BGTHQ & 0 & Core total oxidation heat generation (W) \\
\hline CAOXDEO & kkjj & Component axial oxide thickness $(\mathrm{m})$ \\
\hline WDTQLP & $\mathrm{jj}$ & $\begin{array}{l}\text { Thermal energy in the material from component } j \mathrm{j} \text { that slumped below } \\
\text { the bottom of component } \mathrm{jj}(\mathrm{J})\end{array}$ \\
\hline THKHPN & $\mathrm{jj}$ & Thickness of cohesive debris layer in component $\mathrm{jj}(\mathrm{m})$ \\
\hline PGAS & $\mathrm{jj}$ & Gas pressure inside component $\mathrm{jj}(\mathrm{MPa})$ \\
\hline HOOP & $\mathrm{kkjj}$ & Cladding hoop strain of component $\mathrm{jj}$ at axial node $\mathrm{kk}$ \\
\hline ROCRST & $\mathrm{kkjj}$ & $\begin{array}{l}\text { Outside radius of cladding (including the crust of the solidified } \\
\text { material) of component } \mathrm{jj} \text { at axial node } \mathrm{kk}(\mathrm{m})\end{array}$ \\
\hline RPEL & kkjj & Radius of fuel pellet of component $\mathrm{jj}$ at axial node $\mathrm{kk}(\mathrm{m})$ \\
\hline WREMZR & kkjj & Mass of removed cladding of component $\mathrm{jj}$ at axial node $\mathbf{k k}(\mathrm{kg})$ \\
\hline WREMUO & kkjj & Mass of removed fuel of component $\mathrm{jj}$ at axial node $\mathrm{kk}(\mathrm{kg})$ \\
\hline DZFRCQ & kkjj & Height of cohesive debris at axial node $k \mathrm{k}$ of component $\mathrm{jj}(\mathrm{m})$ \\
\hline ACHDPN & $\mathrm{jj}$ & $\begin{array}{l}\text { Temperature of the bottom surface of the cohesive debris layer for } \\
\text { component } \mathrm{jj}(\mathrm{K})\end{array}$ \\
\hline
\end{tabular}


Table 2-4. (continued).

Code Index ${ }^{\mathrm{a}}$

Quantity

REPOOL - $\quad$ Equivalent radius of the molten pool of core material (m)

ZBTRUB ji Elevation of the bottom of the rubble debris bed for component $\mathrm{jj}(\mathrm{m})$

ZTPRUB ji Elevation of the top of the rubble debris bed for component $\mathrm{jj}(\mathrm{m})$

$\mathrm{ZBTCOH} \quad \mathrm{jj} \quad$ Elevation of the bottom surface of the cohesive debris bed for component $\mathrm{jj}(\mathrm{m})$

ZTPCOH $\quad$ jj Elevation of the top surface of the cohesive debris bed for component jj (m)

DAMLEV k k jij Level of damage at axial node $\mathrm{kk}$ of component $\mathrm{jj}$ (unitless)

$0.0=$ intact geometry

$0.1=$ ruptured due to ballooning

$0.2=$ rubble (fragmented)

$0.4=$ cohesive debris

$1.0=$ molten pool

OXDEO $\mathrm{kkjj} \quad$ Oxide thickness of the cladding at axial node $\mathrm{kk}$ of component $\mathrm{jj}(\mathrm{m})$

$\mathrm{RCI} \quad \mathrm{kkjj} \quad$ Inside radius of the cladding at axial node $\mathrm{kk}$ of component $\mathrm{jj}(\mathrm{m})$

RULIQ $\quad \mathrm{kkjj} \quad$ Outside radius of the solid part of the fuel pellet at axial node kk of component $\mathrm{jj}(\mathrm{m})$

$\mathrm{RCO} \quad \mathrm{kkjj} \quad$ Outside radius of the cladding (not including the crust of solidified material) at axial node $\mathrm{kk}$ of component $\mathrm{jj}(\mathrm{m})$

H20XD2 kkjj Hydrogen production rate at axial node $\mathbf{k k}$ of component $\mathrm{jj}(\mathrm{kg} / \mathrm{s})$

a. $i i$ is the radial number, $k k$ is the axial number, and $j j$ is the component number. For example, if the temperature is to be plotted at the sixth radial node of the fourth axial node of the third component, then the code CADCT with index 060403 would be specified. 


\subsection{NPA Description}

The NPA allows the user to observe a RELAP5/MOD3/SCDAP analysis with the thermalhydraulic, heat transfer, control system, and trip data animated on a computer terminal screen. Also, interactive inputs can be selected by the user to trip pumps, begin ECCS flow, etc. while observing the calculation. Reference 2 and 3 explain the NPA display system. This section will explain the necessary information to use the Calvert Cliffs plant deck with the NPA.

There are two files required to use the NPA. These are the pax file (<file name>.pax) and the dls file (<file name>.dls). These files drive the NPA mask, which is an animated display of the reactor system for NPA use. The techniques for creating these files are given in References 2 and 3. For the Calvert Cliffs deck two masks were created. The system mask displays all the significant system parameters plus some SCDAP core parameters. The core mask shows the reactor core and the core inlet plenum, but is driven by detailed SCDAP data that will show severe accident phenomena. Pax and dls files have been developed for both masks.

\subsubsection{NPA System Mask}

Figure 2-14 shows the NPA system mask with the display at steady state conditions. There are several NPA display components used in this mask. These are: (a) thermo-colors; (b) rod/chan; (c) levels; (d) digital displays; (e) on/off; and (f) magnitude indicators. The thermo-color option is used to display fluid conditions in the primary coolant loops, reactor vessel, and the steam generator secondary. A RELAP5/MOD3 component is associated with a defined region on the mask via the pax file and the RELAP5 code then inputs the void fraction (voidg), fluid temperature (tempf), gas temperature (tempg), saturation temperature (sattemp), and noncondensable state data to the NPA. The color shown on the mask is a function of these parameters. Table 2-5 shows the color selection. The NPA user has the option of changing the color selection scheme when developing the pax file. Default values were generally used in the Calvert Cliffs masks and it is recommended these not be changed.

The Rod/Chan display option is used in the core. With this option selected the thermalhydraulic parameters in the core are shown with the thermo-color scheme on the outside of the mask component. The fuel rod behavior is displayed on the inside of the component. Rod surface temperature is indicated by color changes, and a temperature $\left({ }^{\circ} \mathrm{F}\right)$ versus color chart is included on the mask. Other core behavior phenomena are also shown when the Rod/Chan option is used. Core damage is indicated when the rod and the fluid region colors change to gray. Rod ballooning and oxidation are shown as changes in the rod radius on the mask. Control rod parameters are not shown on the system mask to keep the display from becoming too crowded.

The level display is used in the pressurizer, the accumulators, and in the downcomers of both steam generator secondaries. This NPA component displays a calculated level from RELAP5 as a colored box whose height represents the level.

Digital indicators of the following parameters, in British units, are included:

1. Reactor power 


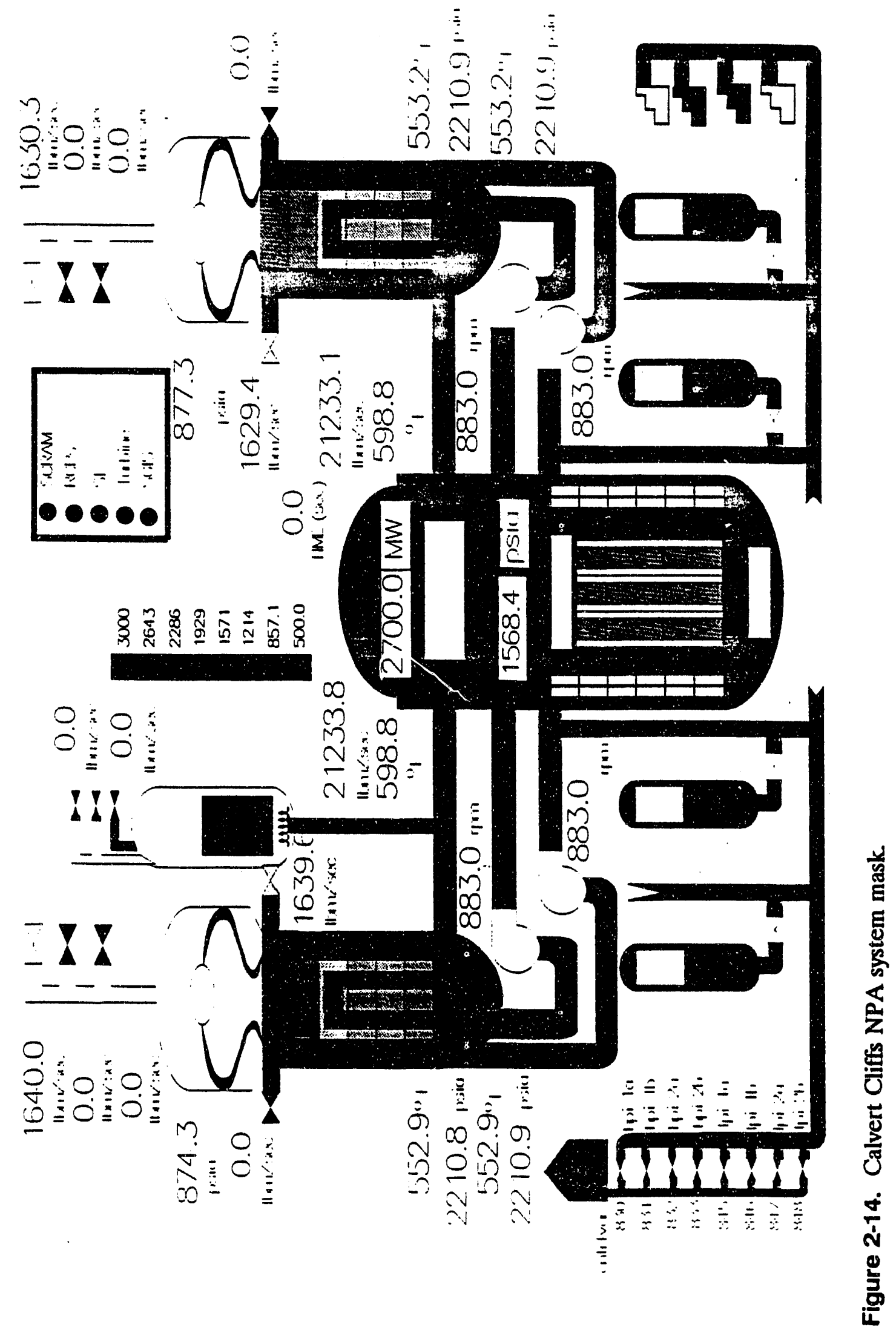


Table 2-5. Thermo-color displays. ${ }^{a}$

\begin{tabular}{lcll} 
Liquid/vapor & Subcooled & Saturated & Superheated \\
\hline Subcooled & Green & Cyan & Orange \\
Saturated & - & Blue & Magenta \\
Superheated & - & - & Red \\
\cline { 1 - 2 } & & & \\
a. A vapor void fraction exceeding & 0.01 will cause the displayed color to lighten. \\
\hline
\end{tabular}

2. Mass flow in each hot leg

3. Upper plenum pressure, Steam generator pressures.

It should be noted that the NPA defaults to SI values for all parameters. For example, conversion factors were input to convert the digital indicator outputs to British units. If a user adds a new digital indicator it would also be necessary to include a conversion factor to maintain consistency.

On/off indicators are used to show if valves are open, pumps are running, etc. White is used to indicate an open valve or an operating pump, black indicates a trippes pump or a closed valve. The On/off option is applied to the following parameters:

1. Reactor coolant pumps, make up and letdown pumps

2. HPI and LPI pumps, accumulator isolation valves

3. Pressurizer PORV, SRV, and heater.

The magnitude display option is used to animate the remaining valves. This option represents a specified data range with a predefined color scale. In this case, fully closed valves are black, fully open valves are white, and partially open valves are a shade of gray.

Finally, any parameter calculated by the RELAP5/MOD3 or the SCDAP portions of the code may be displayed graphically by selecting the plot option and then identifying the desired variable or variables. These plots will be displayed on the terminal screen in SI units.

The following figures and tables summarize the parameters that are displayed on the Calvert Cliffs system mask. 
Display

Thermo-colors

Rod/chan and magnitude

Level and on/off

Digital
Figure

2-15

2-16

2-17

2-18
Table

$2-6$

$2-7$

$2-8$

$2-9$

\subsubsection{NPA Core Region Mask}

A separate mask was developed for the core region because the system mask display would become too crowded if detailed core behavior phenomena and system thermal-hydraulics were displayed on one animation. The core mask uses the Rod/Clad/Chan option, which is similar to the Rod/Chan option explained above but gives more detail.

Figure 2-19 shows the NPA core mask. Parameters displayed included: (a) The thirty core region volume components; (b) The thirty SCDAP core fuel rod heat structures; (c) The SCDAP control rod heat structures; (d) The core inlet plenum volume; (e) Fixed graphic displays of core oxidation, core hydrogen generation, and maximum clad temperature. To save computer space only the five even numbered control rod components were modeled for each radial region. That is the second control rod tructure from the bottom. the fourth, etc. are described.

The core behavior is displayed with the Rod/Clad/Chan option. This option displays rod temperature across the rod radius at each axial node. The fuel pellet radius, clad radius, clad deformation and oxidation, and core damage are all displayed. The thermal-hydraulic conditions in the core channels are shown using the thermo-color scheme, and the rod temperatures vary according to the temperature versus color chart on the mask. Thus, the core mask will give a larger and more detailed display of core phenomena than the system mask.

The core inlet plenum conditions are given using the thermo-color display. The fixed graphs differ from the graphs produced by using the plot option in that they are in British rather than SI units. It is not possible to change the scales on these graphs.

\subsubsection{Interactive Options for the Calvert Cliffs NPA}

The NPA provides a visual and graphic display of the predictions of the RELAP5/MOD3/SCDAP model. It also allows the analyst to interactively simulate operator actions during problem execution. Table 2-10 lists the interactive options that are available to the user. The interactive parameters are selected by clicking the mouse control with the cursor on the appropriate mask component to get the interactive options list displayed. For example, clicking on the reactor coolant pump component will display the pump trip option. Output and restart files are created during interactive runs so the time that the interactive operations are performed will be recorded. 


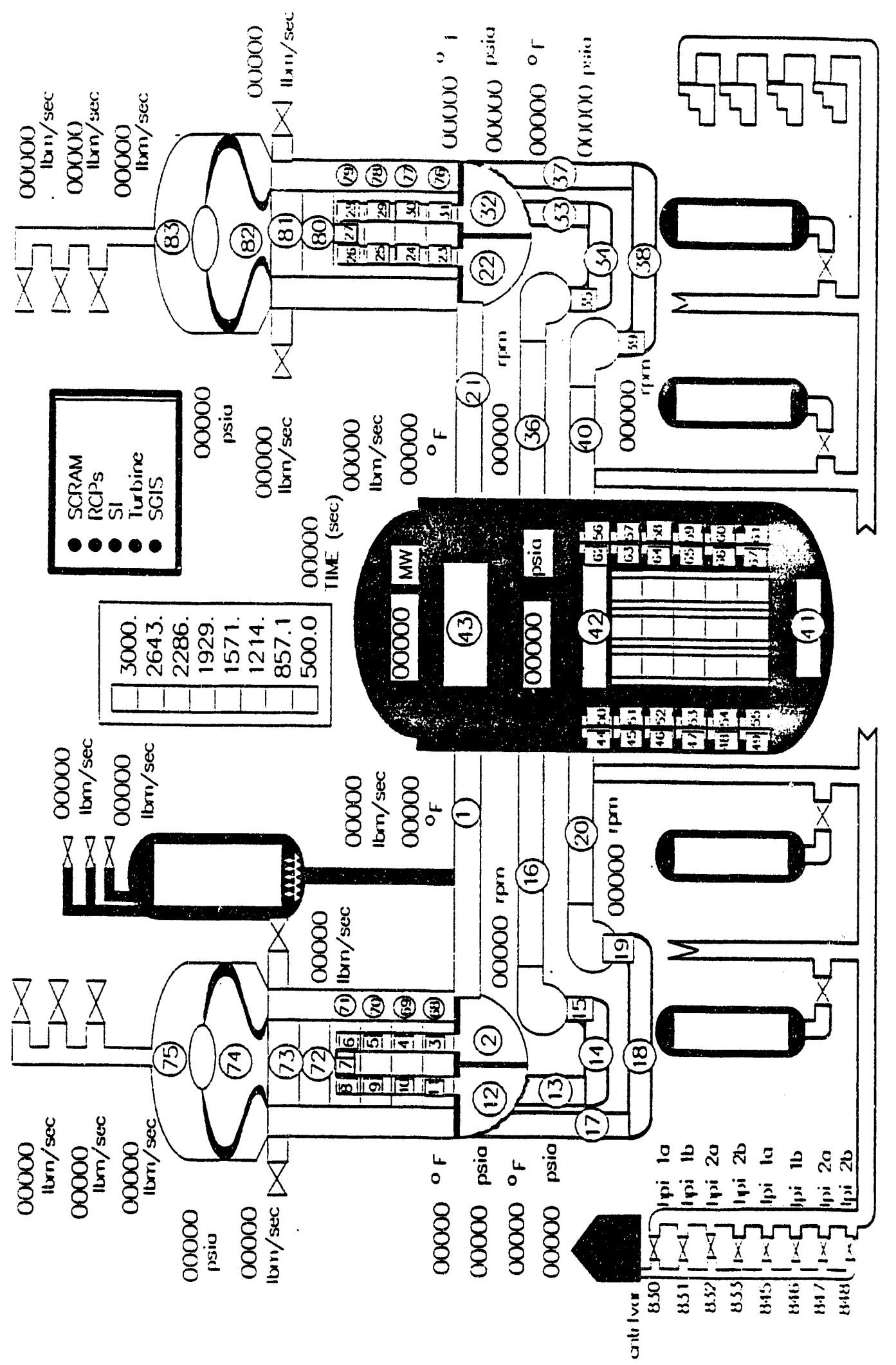

它 
Table 2-6. Calvert Cliffs NPA display-THERMO-COLOR parameters.

Region Number ${ }^{\mathrm{a}} \quad$ Component number

Loop 1

Hot leg

Steam generator inlet plenum

U-tubes (primary side)

Steam generator outlet plenum

Loop la cold leg (suction)

Loop 1a cold leg (discharge)

Loop $1 b$ cold leg (suction)

Loop $1 \mathrm{~b}$ cold leg (discharge)

Loop 2

Hot leg

Steam generator inlet plenum

U-tubes (primary side)

Steam generator outlet plenum

Loop 2a cold leg (suction)

Loop 2 a cold leg (discharge)

Loop $2 \mathrm{~b}$ cold leg (suction)

Loop $2 \mathrm{~b}$ cold leg (discharge)

Reactor Vessel

Lower lenum

Upper plenum

Upper head

Downcomer (Loop 1a side)

Downcomer (Loop 1b side)

Downcomer (Loop 2a side)

Downcomer (Loop 2b side)
1

2

3-11

12

13-15

16

17-19

20

21

22

21-31

32

33-35

36

$37-39$

40

41

42

43

44-49

50-55

$56-61$

$62-67$
10501

12001

12501-12509

13001

$13201,13401,13601$

14501

$16201,16401,16601$

17501
20501

22001

22501-22509

23001

$23201,23401,23601$

24501

$26201,26401,26601$

27501

\section{Steam Generator Loop 1}

Tube bundle region

Separator inlet region

Separator

Steam dome
68-71

72,73

74

75
31001-31004

31501,32001

32501

34001
57501

52001

55001

56601,57102-57106

56701,57202-57206

$56801,57302-57306$

56901,57402-57406 
Table 2-6. (continued).

Steam Generator Loop 2

Tube bundle region

Separator inlet region

Separator

Steam dome
$76-79$

80,81

82

83
41001-41004

41501,42001

42501

44001

a. This number refers to the labeled components in Figure 2-15. 


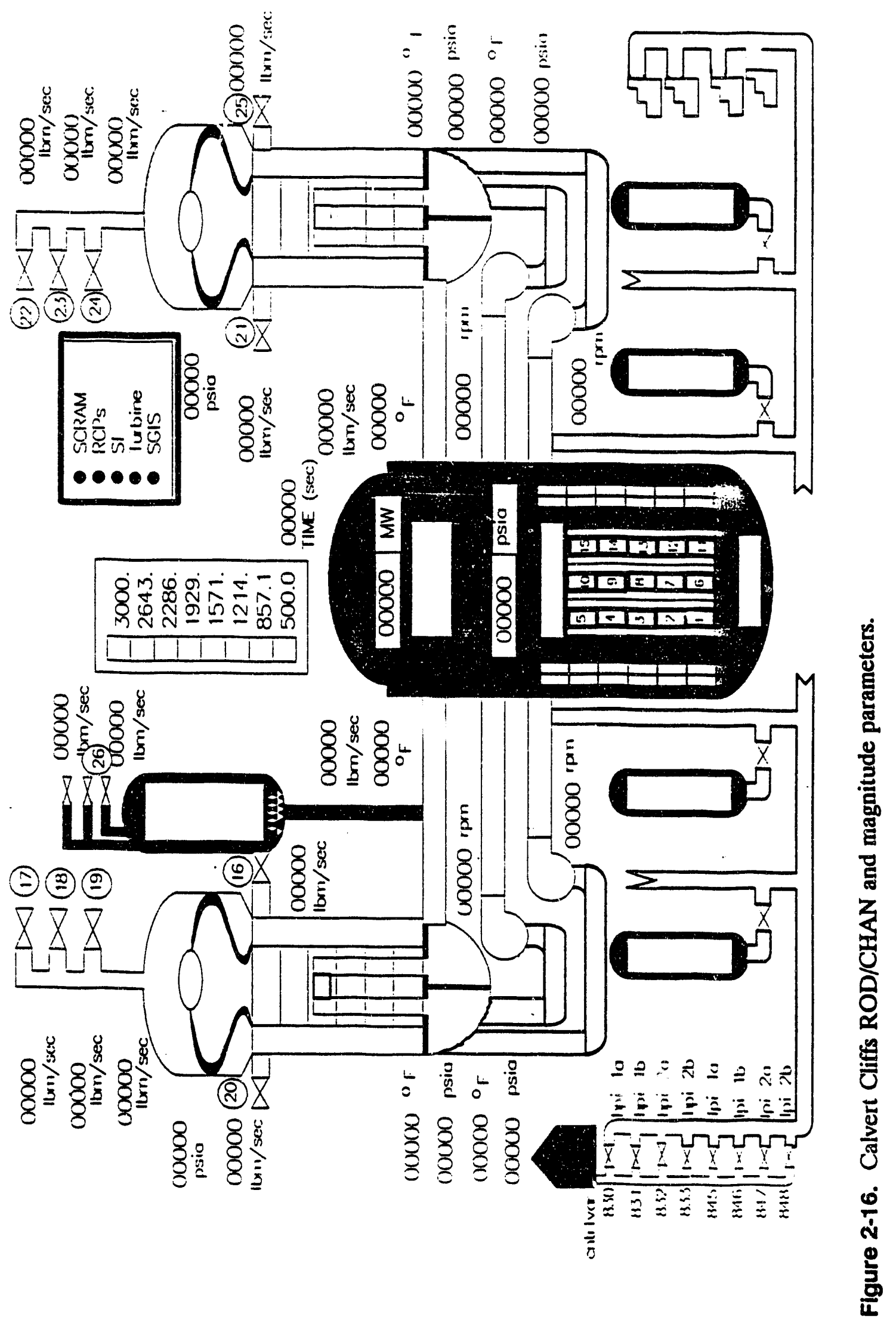


Table 2-7. Calvert Cliffs NPA display-ROD/CHAN and MAGNITUDE parameters.

\begin{tabular}{|c|c|c|c|}
\hline Region & Number $^{\mathbf{a}}$ & $\begin{array}{l}\text { Heat conductor } \\
\text { number }\end{array}$ & $\begin{array}{c}\text { Thermal-hydraulic } \\
\text { component } \\
\text { number }\end{array}$ \\
\hline
\end{tabular}

ROD/CFAN Parameters

Outer core

Middle rore

Center core

$11-15$
1-5 0201, 0401, 0601, 0801,1001

$6-10$
$0203,0403,0603$, 0803,1003

0205, 0405, 0605, 0805,1005
$51302,51304,51306$, 51308, 51310

51502, 51504, 51506, 51508,51510

51702, 51704, 51706, $5170 €, 51710$

\section{MAGNITUDE}

Parameters

$\begin{array}{ll}\text { Loop } 1 \text { MFIV } & 16 \\ \text { Loop } 1 \text { MSIV } & 17 \\ \text { Loop 1 SRV } & 18 \\ \text { Loop 1 ADV } & 19 \\ \text { Loop 1 AFW } & 20 \\ \text { Loop 2 MFIV } & 21 \\ \text { Loop } 2 \text { MSIV } & 22 \\ \text { Loop 2 SRV } & 23 \\ \text { Loop 2 ADV } & 24 \\ \text { Loop 2 AFW } & 25 \\ \text { Pressurizer spray } & 26\end{array}$

$\begin{array}{lr}\text { ylvarea } & 734 \\ \text { vivarea } & 390 \\ \text { cntrlvar } & 385 \\ \text { Cintrlvar } & 956 \\ \text { cntrlvar } & 785 \\ \text { vlvarea } & 744 \\ \text { vivarea } & 490 \\ \text { enirlvar } & 485 \\ \text { cntrlvar } & 957 \\ \text { cntrlvar } 786 \\ \text { cintilvar } 1867\end{array}$

a. This number refers to the labeled components in Figure 2-16.

b. The ROD/CHAN display option shows both fuel rod behavior data and thermal-hydraulic data. The fuel rod parameter is the SCDAP heat structure associated with the NPA location. The format used to number this heat structure is $\mathbf{k k j j}$,

where

$\mathbf{k k}=$ axial location

ij $=$ component number. 


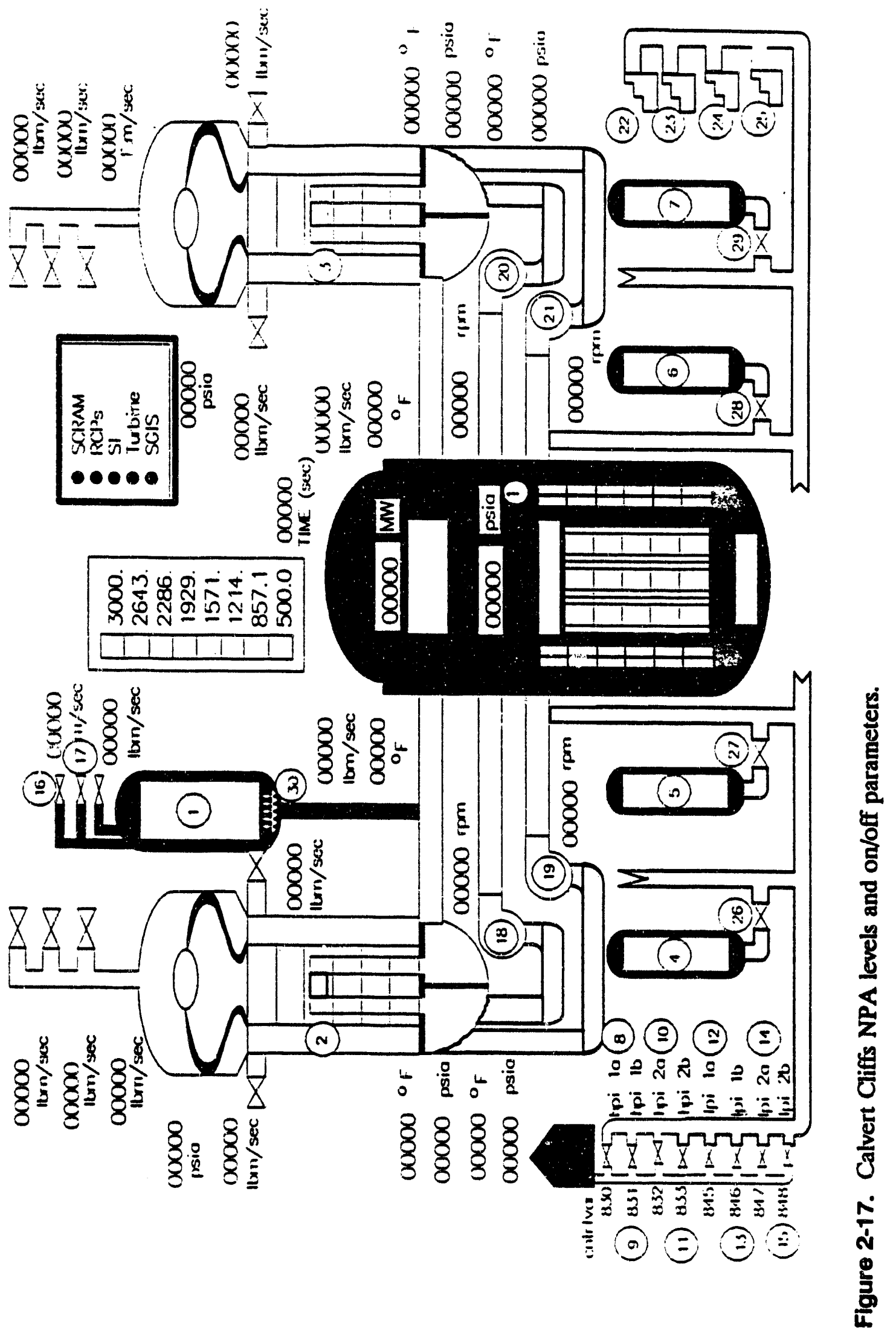


Table 2-8. Calvert Cliffs NPA display-LEVEL and ON/OFF parameters.

Region Number ${ }^{3} \quad$ Variable number

Level Displays

Pressurizer

1

Loop 1 steam generator downcomer

Loop 2 steam generator downcomer

Accumulator 1a

Accumulator $1 \mathrm{~b}$

Accumulator $2 b$

Accumulator $2 \mathrm{a}$

\section{2}

3

4

5

6

7 cntrlvar 1845

cntrlvar 325

cntrlvar 425

cntrlvar 1842

cntrlvar 1841

cntrlvar 1843

cntrlvar 1844

On/Off Displays

Loop 1a HPI

Loop 1b HPI

Loop 2a HPI

Loop $2 b$ HPI

Loop la LPI

Loop 1b LPI

Loop 2a LPI

Loop 2b LPI

SRV

PORV

Loop la pump

Loop 1b pump

Loop 2a pump

Loop 2b pump

Makeup pump 1

Makeup pump 2

Makeup pump 3

Let down pump

Accumulator isolation valve $1 \mathrm{a}$

Accumulator isolation valve $1 \mathrm{~b}$

Accumulator isolation valve $2 b$

Accumulator isolation valve $2 a$

Pressurizer heater
8 cntrlvar 830

9 cntrlvar 831

10 cntrlvar 832

11 cntrlvar 833

12

13

14

15

16

17

18

19

20

21

22

23

24

25

26

27

28

29

30 cntrlvar 845

cntrlvar 846

cntrlvar 847

cntrlvar 848

vlvarea 652

vlvarea 651

cntrlvar 1834

cntrlvar 1835

cntrlvar 1836

cntrlvar 1837

cntrlvar 1850

cntrlvar 1850

cntrlvar 1850

cntrlvar 648

cntrlvar 1861

cntrlvar 1862

cntrlvar 1863

cntrlvar 1864

cntrlvar 615

a. This number refers to the labeled components in Figure 2-17. 


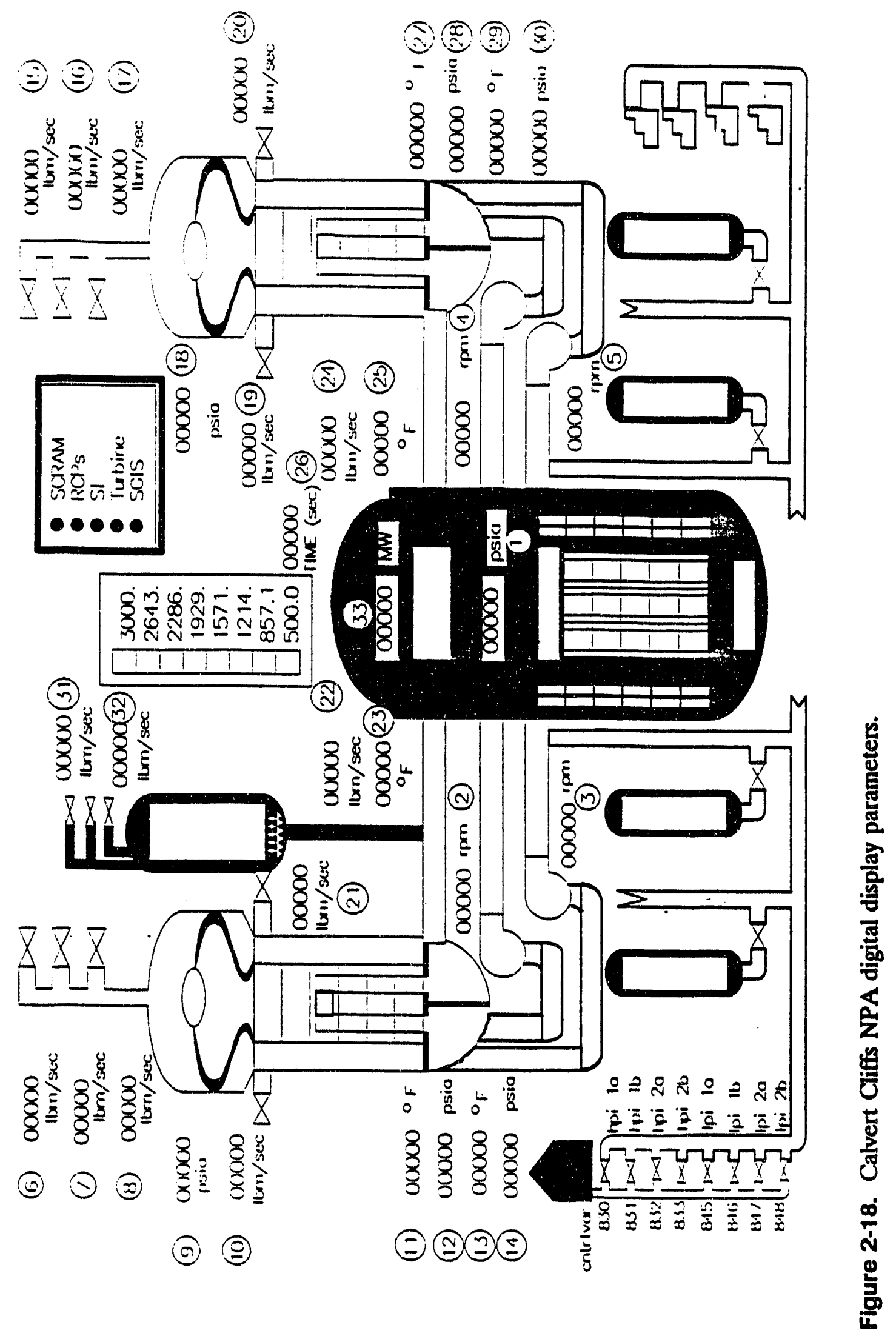


Table 2-9. Calvert Cliffs NPA display-DIGITAL parameters.

\begin{tabular}{|c|c|c|c|}
\hline Quantity & Number ${ }^{a}$ & \multicolumn{2}{|c|}{ Variable number } \\
\hline Upper plenum pressure & 1 & $\mathrm{p}$ & 52001 \\
\hline Loop la pump rpm & 2 & pmpvel & 140 \\
\hline Loop 16 pump rpm & 3 & pmpvel & 170 \\
\hline Loop 2a pump rpm & 4 & pmvel & 240 \\
\hline Loop $2 b$ pump rpm & 5 & pmpvel & 270 \\
\hline Loop 1 steam generator MSIV tlow & 6 & mflowj & 39000 \\
\hline Loop 1 SRV flow & 7 & mflowj & 38500 \\
\hline Loop 1 ADV flow & 8 & mflowj & 36500 \\
\hline Loop 1 steam generator dome pressure & 9 & $\mathrm{p}$ & 32501 \\
\hline Loop $1 \mathrm{AFW}$ flow & 10 & mflowj & 7710 \\
\hline Loop 1a cold leg temperature & 11 & temp & 13201 \\
\hline Loop la cold leg pressure & 12 & $\mathrm{p}$ & 13201 \\
\hline Loop $1 b$ cold leg temperature & 13 & tempf & 16201 \\
\hline Loop 1b cold leg pressure & 14 & p & 16201 \\
\hline Loop 2 steam generator MSIV flow & 15 & mflowj & 49000 \\
\hline Loop 2 SRV flow & 16 & mflowj & 48500 \\
\hline Loop 2 ADV flow & 17 & mflowj & 46500 \\
\hline Loop 2 steam generator dome pressure & 18 & $\mathrm{p}$ & 42501 \\
\hline Loop 2 MFW flow & 19 & mflowj & 74600 \\
\hline Loop 2 AFW flow & 20 & mflowj & 77300 \\
\hline Loop 1 MFW flow & 21 & mflowj & 73600 \\
\hline Loop 1 hot leg flow & 22 & mflowj & 10000 \\
\hline Loop 1 hot leg temperature & 23 & tempf & 10501 \\
\hline Loop 2 hot leg flow & 24 & mflowj & 20000 \\
\hline Loop 2 hot leg temperature & 25 & tempf & 20501 \\
\hline Time & 26 & time & 0 \\
\hline Loop 2a cold leg temperature & 27 & tempf & 23201 \\
\hline Loop 2a cold leg pressure & 28 & $\mathrm{p}$ & 23201 \\
\hline Loop $2 b$ cold leg temperature & 29 & tempf & 26201 \\
\hline Loop $2 b$ cold leg pressure & 30 & p & 26201 \\
\hline SRV flow & 31 & mflowj & 65200 \\
\hline PORV flow & 32 & mflowj & 65100 \\
\hline Core power & 33 & cntrlvar & 1868 \\
\hline
\end{tabular}

a. This number refers to the labeled components in Figure 2-18. 

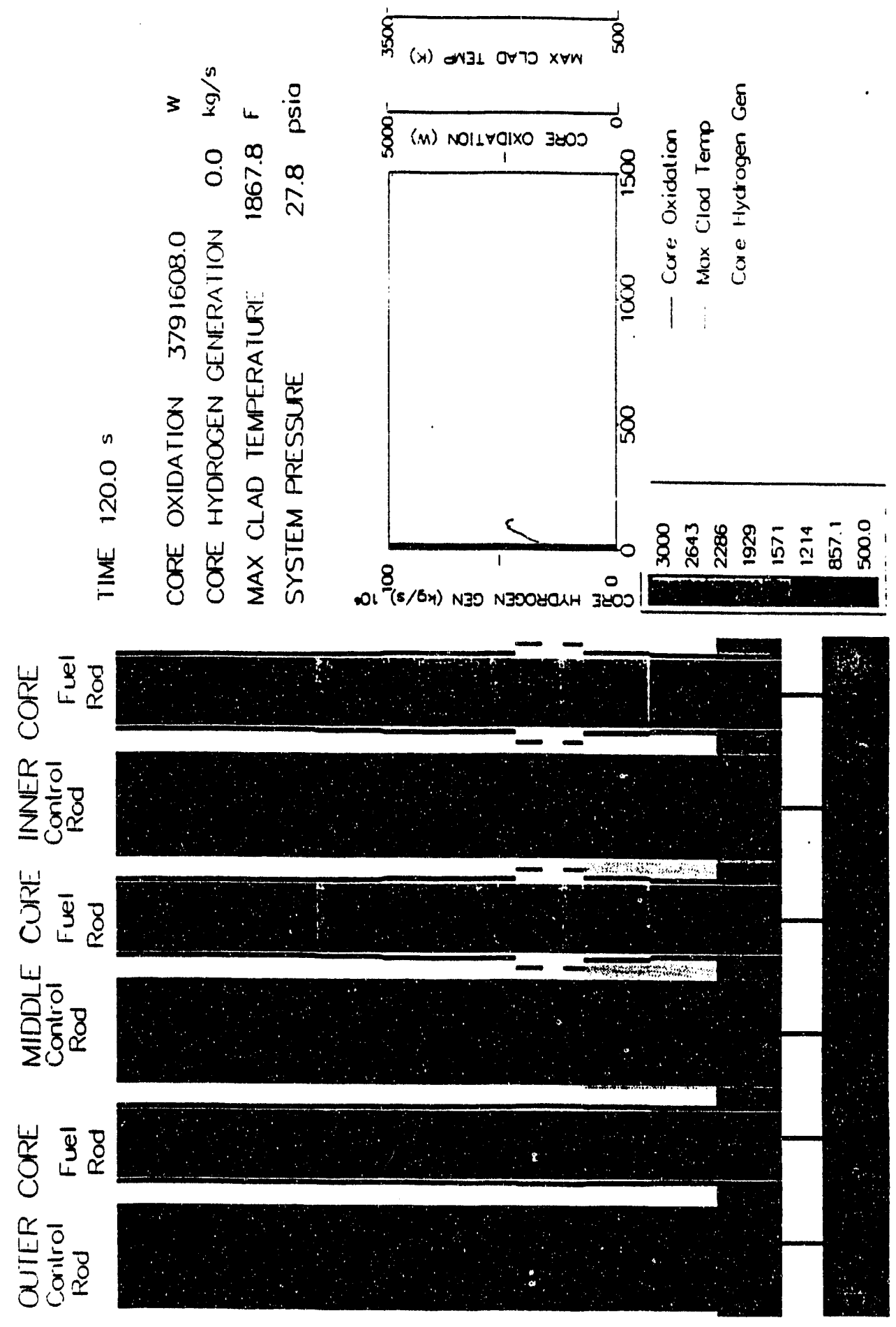
Table 2-10. Calvert Cliffs mask interactive commands.

\begin{tabular}{|c|c|c|}
\hline Component & Command & Function \\
\hline Reactor coolant pumps & $\begin{array}{l}\text { Start } \\
\text { Stop } \\
\text { Auto }\end{array}$ & $\begin{array}{l}\text { Manually on at rated speed } \\
\text { Manually trip pump } \\
\text { Automatic control }\end{array}$ \\
\hline Control panel & $\begin{array}{l}\text { Start RCPs } \\
\text { Stop RCPs } \\
\text { Auto RCPs }\end{array}$ & $\begin{array}{l}\text { Start all } \mathrm{RCPs} \\
\text { Manually trip all } \mathrm{RCPs} \\
\text { Automatic control all } \mathrm{RCP}\end{array}$ \\
\hline & $\begin{array}{l}\text { Initiate SI } \\
\text { Inhibit SI } \\
\text { Auto SI }\end{array}$ & $\begin{array}{l}\text { Manual SI signal } \\
\text { SI signal manually inhibited } \\
\text { Automatic operation }\end{array}$ \\
\hline & $\begin{array}{l}\text { Scram } \\
\text { No scram } \\
\text { Auto scram }\end{array}$ & $\begin{array}{l}\text { Manual reactor trip } \\
\text { Reactor trip inhibited } \\
\text { Automatic operation }\end{array}$ \\
\hline & $\begin{array}{l}\text { Turbine trip } \\
\text { No turbine trip } \\
\text { Auto turbine } \\
\text { trip }\end{array}$ & $\begin{array}{l}\text { Manual turbine trip signal } \\
\text { Turbine trip signal inhibited } \\
\text { Automatic operation }\end{array}$ \\
\hline & $\begin{array}{l}\text { SGIS } \\
\text { No SGIS } \\
\text { Auto SGIS }\end{array}$ & $\begin{array}{l}\text { Manual SG isolation signal } \\
\text { SG isolation signal inhibited } \\
\text { Automatic operation }\end{array}$ \\
\hline ECC header & $\begin{array}{l}\text { HPI1 } \\
\text { HPI2 } \\
\text { LPI }\end{array}$ & $\begin{array}{l}\text { One pump delivery multiplier }(0-1) \\
\text { Two pump delivery multiplier }(0-1) \\
\text { LPI pump delivery multiplier }(0-1)\end{array}$ \\
\hline Spray valve & $\begin{array}{l}\text { Open } \\
\text { Close } \\
\text { Auto } \\
\text { Offset }\end{array}$ & $\begin{array}{l}\text { Valve manually wide open } \\
\text { Valve manually closed } \\
\text { Automatic operation } \\
\text { User enters }-1<x<1 \text { to vary normal area }\end{array}$ \\
\hline Accumulators & $\begin{array}{l}\text { Isolate } \\
\text { Auto }\end{array}$ & $\begin{array}{l}\text { Isolate accumulator } \\
\text { Automatic operation }\end{array}$ \\
\hline
\end{tabular}


Table 2-10. (continued).

\begin{tabular}{|c|c|c|}
\hline Component & Command & Function \\
\hline Pressurizer heater & $\begin{array}{l}\text { On } \\
\text { Off } \\
\text { Auto } \\
\text { Offset }\end{array}$ & $\begin{array}{l}\text { Manually full on } \\
\text { Manually off } \\
\text { Automatic operation } \\
\text { User enters }-1<\mathrm{x}<1 \text { to vary power } \\
\text { by }-2 \mathrm{MW}<\mathrm{p}(\mathrm{x})<2 \mathrm{MW}\end{array}$ \\
\hline PORV & $\begin{array}{l}\text { Open } \\
\text { Close } \\
\text { Auto }\end{array}$ & $\begin{array}{l}\text { Manually open PORV } \\
\text { Manually close PORV } \\
\text { Automatic operation }\end{array}$ \\
\hline Makeup pump & $\begin{array}{l}\text { No pumps } \\
\text { Two pumps } \\
\text { Three pumps } \\
\text { Auto }\end{array}$ & $\begin{array}{l}\text { No MU pumps operating } \\
\text { Two MU pumps operating } \\
\text { Three MU pumps operating } \\
\text { Automatic operation }\end{array}$ \\
\hline Letdown pump & $\begin{array}{l}\text { Max } \\
\text { Isolate } \\
\text { Auto } \\
\text { Offset }\end{array}$ & $\begin{array}{l}\text { Maximum letdown flow } \\
\text { Letdown isolated } \\
\text { Automatic operation } \\
\text { User enters }-0.03<\mathrm{x}<0.03 \text { to vary velocity } \\
\text { by }-0.3<\mathrm{v}(\mathrm{x})<0.3\end{array}$ \\
\hline Main feed valves & $\begin{array}{l}\text { Open IV } \\
\text { Close IV } \\
\text { Auto IV }\end{array}$ & $\begin{array}{l}\text { Manually open isolation valve } \\
\text { Manually close isolation valve } \\
\text { Automatic operation }\end{array}$ \\
\hline & $\begin{array}{l}\text { Open RV } \\
\text { Close RV } \\
\text { Auto RV } \\
\text { Offset RV }\end{array}$ & $\begin{array}{l}\text { Manually open regulating valve } \\
\text { Manually close regulating valve } \\
\text { Automatic operation } \\
\text { User enters }-1<x<1 \text { to vary normal area }\end{array}$ \\
\hline & $\begin{array}{l}\text { Open BV } \\
\text { Close BV } \\
\text { Auto BV } \\
\text { Offset BV }\end{array}$ & $\begin{array}{l}\text { Manually open bypass valves } \\
\text { Manually close bypass valves } \\
\text { Automatic operation } \\
\text { User enters }-1<\mathrm{x}<1 \text { to vary normal area }\end{array}$ \\
\hline Main steam isolation valves & $\begin{array}{l}\text { Open } \\
\text { Close } \\
\text { Auto }\end{array}$ & $\begin{array}{l}\text { Manually open MSIV } \\
\text { Manually close MSIV } \\
\text { Automatic operation }\end{array}$ \\
\hline
\end{tabular}


Table 2-10. (continued).

\begin{tabular}{|c|c|c|}
\hline Component & Command & Function \\
\hline Main feed pumps & $\begin{array}{l}\text { On } \\
\text { Off } \\
\text { Auto }\end{array}$ & $\begin{array}{l}\text { Pump manually on } \\
\text { Pump manually tripped } \\
\text { Automatic operation }\end{array}$ \\
\hline Atmospheric dump valves & $\begin{array}{l}\text { Open } \\
\text { Close } \\
\text { Auto } \\
\text { Otisct }\end{array}$ & $\begin{array}{l}\text { Manually open ADV } \\
\text { Manually close ADV } \\
\text { Automatic operation } \\
\text { User enters }-1<x<1 \text { to vary normal area }\end{array}$ \\
\hline Turbine bypass valves & $\begin{array}{l}\text { Open } \\
\text { Close } \\
\text { Auto } \\
\text { Offset }\end{array}$ & $\begin{array}{l}\text { Manually open TBV } \\
\text { Manually close TBV } \\
\text { Automatic operation } \\
\text { User enters }-1<x<1 \text { to vary normal area }\end{array}$ \\
\hline Auxiliary feedwater valves & $\begin{array}{l}\text { Feed } \\
\text { No feed } \\
\text { Flow }\end{array}$ & $\begin{array}{l}\text { Manual full feed } \\
\text { Manually block feedwater } \\
\text { User enters } 0<=x<=2 \text { to set flow from } \\
\text { none to } 200 \%\end{array}$ \\
\hline
\end{tabular}




\section{PLANT DECK APPLICATIONS}

Three calculations were performed to test the Calvert Cliffs plant deck to assure that it produces reasonable results when applied for the prediction of plant transients and accidents, and also to check the proper function of the basic features of the model. The calculations were also displayed on the NPA to check out the mask. The calculations selected were a loss of feedwater transient (LOFW), a small break loss of coolant accident (SBLOCA), and a large break loss of coolant accident (LBLOCA). This selection was judged to provide a representative set of problems for evaluating the model. These problems are intended as a test of the plant deck rather than as an independent validation of the RELAP5/MOD3/SCDAP code.

A calculation was run without the activation of any trips to obtain a steady state at $100 \%$ power, $100 \%$ flow conditions. The results of the steady state calculation are summarized in Table 3-1. If the analyst desires to obtain a steady state at nonrated conditions, then the analyst will need to perform another analysis of this type adjusting the power (RELAP5 Table 900 word 4) and changing the initial reactor coolant pump speed as required. No major problems would be anticipated in doing this. The time is reset to zero by restarting the steady state run with stdy-st input on word 2 of RELAP5/MOD3 card 100. This will also write a very short restart-plot file that can be used to begin transient calculations. Therefore, it is not necessary to perform input processing for every calculation.

\subsection{Loss of Feedwater Transients}

The results of the LOFW analyses are presented in this section. A LOFW transient will cause a loss of steam generator heat transfer and RCS over-pressurization. If feedwater flow for the steam generators cannot be reestablished it would require several hours to recover from this type of transient. The plant operators would use feed and bleed techniques to maintain the mass inventory of the primary system and to control the primary pressure. Safety injection could be required to assure recovery. Since this calculation was performed only to test the input deck the analysis was stopped at $2500 \mathrm{~s}$ after the transient initiation. Feed and bleed recovery procedure would be used after this time if the MFW pumps have not been restarted.

The boundary conditions for the LOFW analyses are:

1. Rated power and flow at the time of transient initiation

2. Trip MFW pumps to begin transient

3. Assume failure of the auxiliary feedwater system

4. Operator trip of the RCPs at $420 \mathrm{~s}$ after the start of the transient to simulate operating procedures

5. SCRAM was set to occur at $30 \mathrm{~s}$, bypassing the automatic trip logic. 
Table 3-1. Steady state parameter comparison.

\section{Parameter}

RELAP5/MOD3

Desired value

Source

Primary:

$\begin{array}{lrrl}\text { Mass flow }\left(\mathrm{lb}_{\mathrm{m}} / \mathrm{s}\right) & 42361.0 & 42282.0 & \text { BG\&E 4 }^{\mathrm{a}} \\ \text { Hot leg temp. }\left({ }^{\circ} \mathrm{F}\right) & 598.8 & 594.6 & \text { BG\&E 2 }^{\mathrm{a}} \\ \text { Cold leg temp. }\left({ }^{\circ} \mathrm{F}\right) & 552.8 & 547.1 & \text { BG\&E 2 }^{\mathrm{a}} \\ \text { Pressure (psia) } & 2250.1 & 2250.0 & \text { Ref. 6 }^{\mathrm{a}} \\ \text { PZR level (in.) } & 215.9 & 215.0 & \text { LANL }^{\mathrm{b}} \\ \text { Core power (MW) } & 2700.0 & 2700.0 & \text { BG\&E 2 }^{\mathrm{a}} \\ \Delta \mathrm{P}_{\text {SG }} \text { (psi) } & 35.0 & 28.15 & \text { BG\&E 5 }^{\mathrm{a}} \\ \Delta \mathrm{P}_{\text {PUMP }}(\mathrm{psi}) & 77.0 & 78.73 & \text { BG\&E 5 }^{\mathrm{a}}\end{array}$

Bypass flows (\%)

Guide tube

HL nozzle (leak)

$\mathrm{UH}$ to DC

1.94

1.89

0.62

$\mathrm{CE} 2^{\mathrm{c}}$

0.60

0.097

$\mathrm{CE} 2^{\mathrm{c}}$

0.092

$\mathrm{CE} 2^{c}$

Secondary

Pressure (psia)

Mass $\left(\mathrm{lb}_{\mathrm{m}}\right)$

NR level (in.)

WR level (in.)

Recirculation ratio

Steam flow $\left(\mathrm{lb}_{\mathrm{m}} / \mathrm{s}\right)$

MFRV area (\%)

$872-883$
150000.0
0.15
-62.1
3.6
3268.5
90.0

$870-880$

138000.0

0.0

$-70.0$

4.0

3268.0

90.0
BG\&E $2^{\mathrm{a}}$

$\mathrm{CE} 1^{\mathrm{c}}$

BG\&E $6^{\mathrm{a}}$

BG\&E $10^{a}$

$\mathrm{CE} 1^{\mathrm{c}}$

BG\&E $2^{a}$

Ref. 8

a. Information received from Baltimore Gas and Electric (BG\&E) as part of the pressurized thermal shock study.

b. Information received from Los Alamos National Laboratory (LANL) as part of the pressurized thermal shock study.

c. Information received from Combustion Engineering (CE) as part of the pressurized thermal shock study. 
Boundary condition five was imposed because the system behavior in a LOFW transient is very sensitive to the time of SCRAM. In a previously performed LOFW analysis of the Calvert Cliffs system (4) the reactor tripped at approximately $30 \mathrm{~s}$. Therefore, assumption five was used to aid in evaluating the input deck by making the boundary conditions similar to those in the previous analysis.

Figure 3-1 shows the calculated pressurizer pressure during the 2500 second transient. The pressure initially rises because the turbine stop valve (TSV) closes on the feedwater pump trip. A combination of the opening of the PORV at 2400 psia (16.55 MPa), reactor scram, and orening of the turbine bypass valves causes the pressure to drop rapidly after $20 \mathrm{~s}$. The PORV closes at 2280 psia (15.72 MPa). After $80 \mathrm{~s}$ the pressure generally begins to increase because of reduced steam generator heat transfer. The pressure drop between 530 and $610 \mathrm{~s}$ is a result of the opening and closing of the turbine bypass valve (TBV). The TBV area varies as a function of average primary temperature and $\Delta \mathrm{T}$ (hot leg-cold leg temperature), and these two variables change when the pumps trip at $420 \mathrm{~s}$. At $1840 \mathrm{~s}$ the PORV begins to cycle resulting in pressure oscillations between the PORV set points.

Figure 3-2 shows the calculated steam generator mass for both the Loop 1 and Loop 2 steam generators. The mass immediately begins to fall below the initial mass of $150000 \mathrm{lbm}(68 \mathrm{MT})$ after feedwater pump trip. The mass loss stops when the TBV closes between 580 and $800 \mathrm{~s}$. The U-tubes begin to uncover after $400 \mathrm{~s}$ and become essentially uncovered by $1750 \mathrm{~s}$.

Figure 3-3 shows the steam generator pressures. The pressure initially rises after feedwater is lost, but then drops back to its initial value of 875 psia after scram. The steam dump and turbine bypass control system acts to maintain constant pressure during this part of the transient. The pressure drops when the TBV opens after the RCPs trip as was explained above. When the TBV closes, the pressure increases until the TBV again opens at $800 \approx$ The pressure then remains constant until the U-tubes effectively uncover and the heat transter into the steam generators becomes very low. The pressure then decreases. The figure indicates that there is some asymmetric behavior between the two loops with the Loop 2 steam generator U-tubes uncovering before the Utubes in Loop 1. This asymmetry can be attributed to the pressurizer influence on heat transfer during the period before reactor scram. Less mass was lost in the pressurizer loop (Loop 1) during the initial part of the transient because some heat is transferred from Loop 1 to the pressurizer and therefore, U-tube uncovery occurs later in Loop 1 than in Loop 2.

Figure 3-4 shows the hot and cold leg temperatures. The temperature behavior is identical for both loops during the period before $1800 \mathrm{~s}$. The temperature increases until reactor trip, then decreases to $535^{\circ} \mathrm{F}(553 \mathrm{~K})$ in the hot legs and $533^{\circ} \mathrm{F}(552 \mathrm{~K})$ in the cold legs. It remains constant until RCP trip at $420 \mathrm{~s}$. After the RCPs trip the primary system $\Delta \mathrm{T}$ increases because of the drop in core flow. When the TBVs close at $580 \mathrm{~s}$ the cold leg temperature increases because of lower heat transfer. The hot leg thermo-hydraulic parameters lag the cold leg parameters because the system fluid transit time is long during natural circulation. The temperatures are constant between 800 and $1750 \mathrm{~s}$. When the U-tubes effectively uncover the cold and hot leg temperatures begin increasing again with the Loop 2 cold leg temperature rising before the Loop 1 temperature because the tubes uncover sooner in Loop 2 as explained above. 


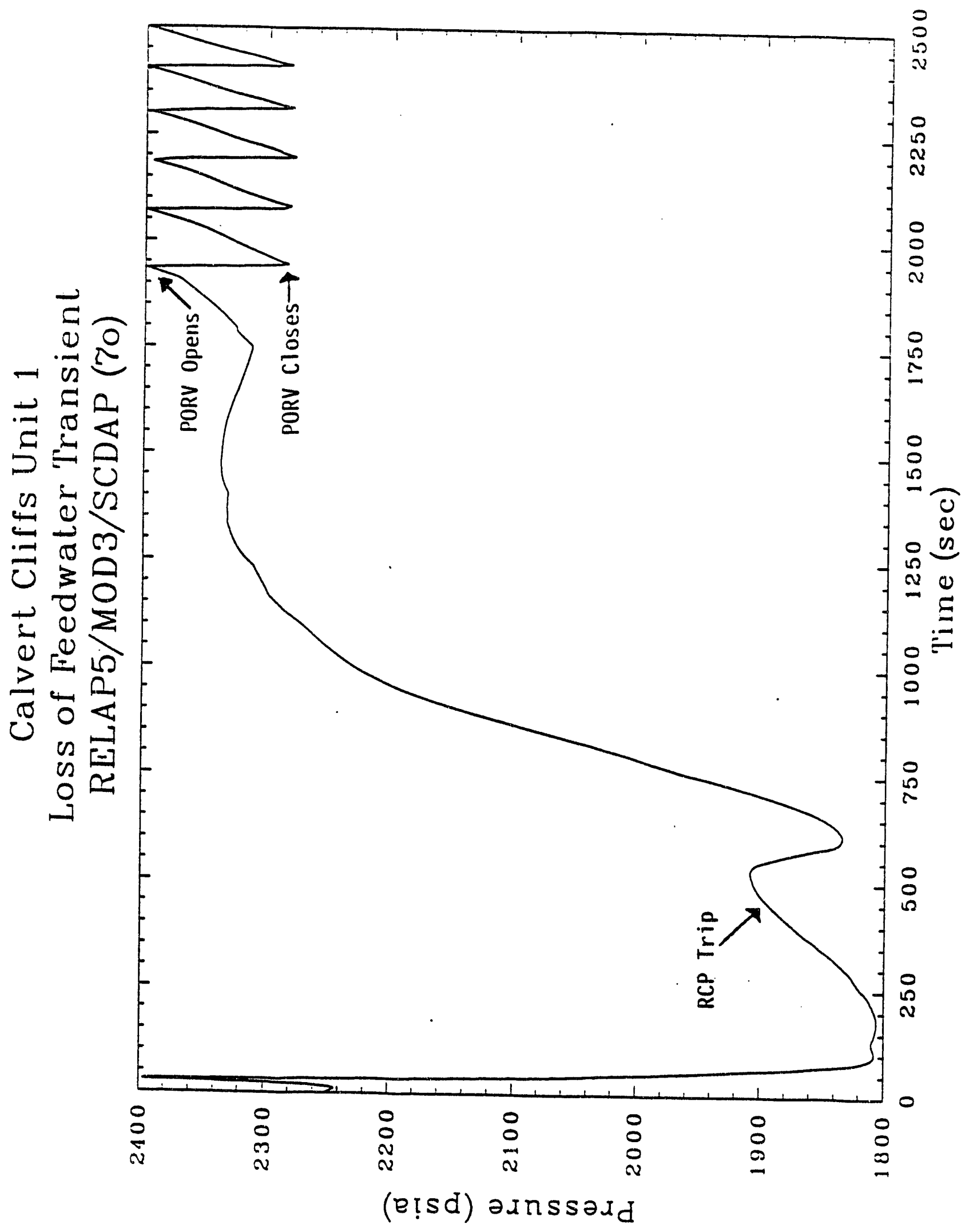

通 


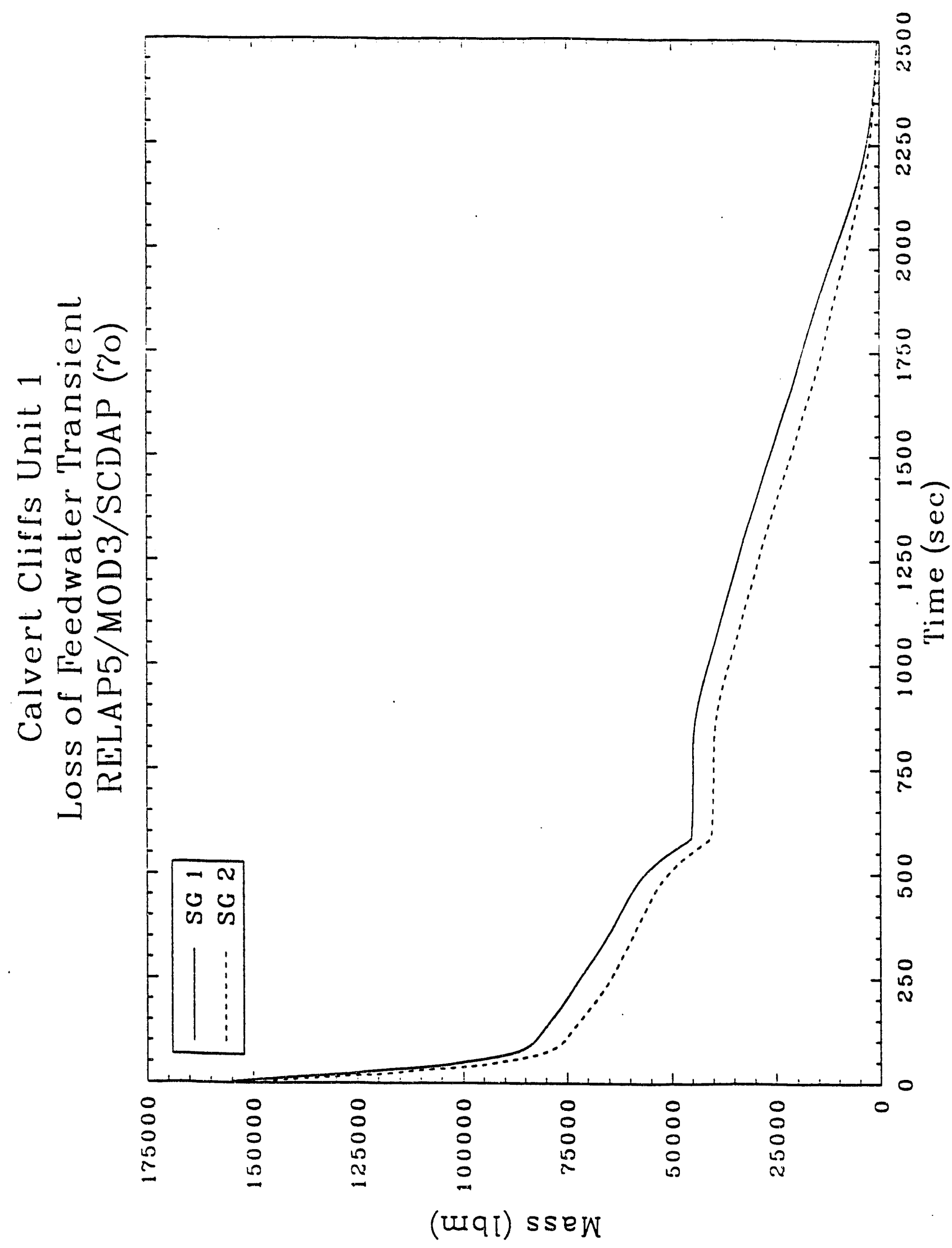

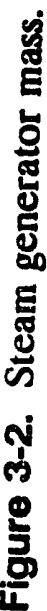




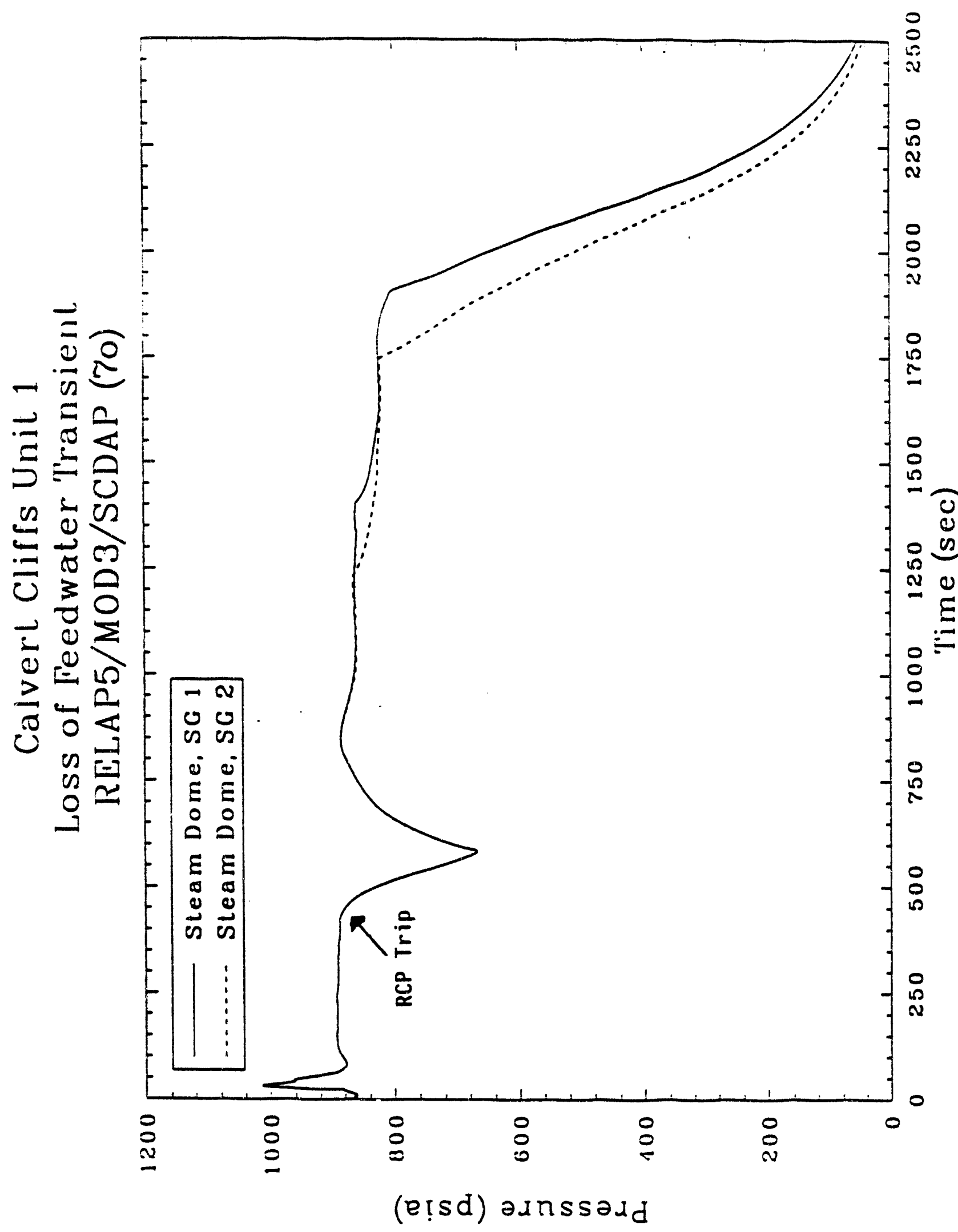

包 


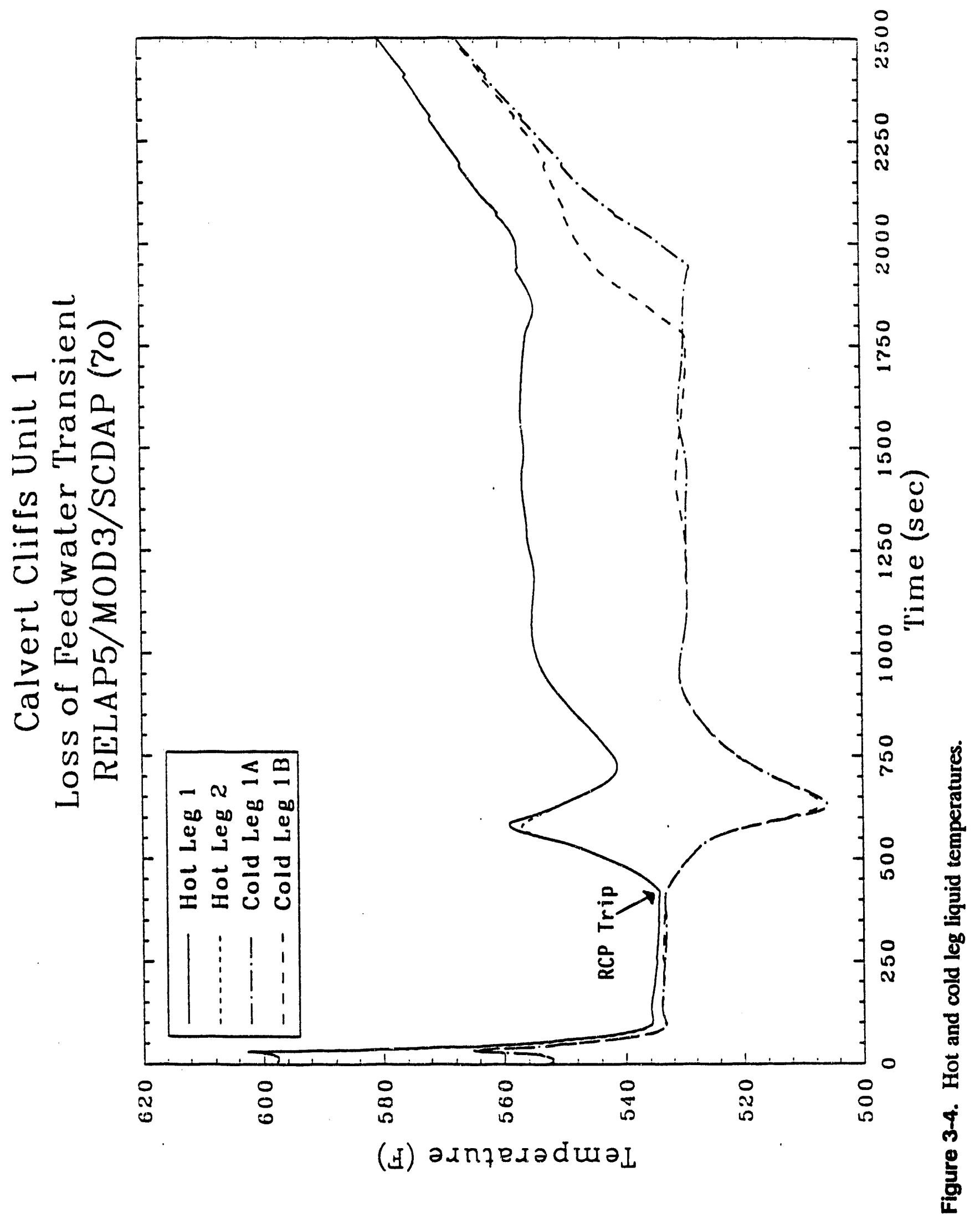


The Loop 1 coolant flows are given in Figure 3-5. There are some flow changes early in the transient because of pressurizer surges, but the flow is then constant until RCP trip at $420 \mathrm{~s}$. Recirculation slow continues to cool the core after pump trip.

Pressurizer level is given in Figure 3-6. The normal level is 215 inches. The pressurizer would be full at 345 inches. The level follows the same behavior as the reactor pressure, swelling initially until reactor trip, then dropping but beginning to rise again when the pressure begins to increase. When the PORV starts to cycle at 1840 s the pressurizer level continues increasing because the PORV flow is steam but the surge line flow is liquid. The level would be expected to increase until the pressurizer is full.

\subsection{Large Break LOCA Accident}

A large break LOCA event was initiated by a $200 \%$ double-ended guillotine break in the Loop 1B cold leg. This analysis was performed to test the plant decks applicability for the prediction of LOCAs that could begin severe accident scenarios. To model a large break it is necessary to add some additional volumes to the deck as shown in Figure 3-7. These additions are necessary because the basic deck does not include components that simulate breaks. Since there are many locations where a break could occur and also many possible sizes for each break, it would be difficult to include generalized components for break modeling. However, as seen in the figure it is simple to add the necessary components. Junction 191 represents the normal flow path. This flow path is modeled with a valve so that it can be closed when the guillotine break occurs. Junctions 193 and 195, representing the break flow paths, are then opened.

The following assumptions are used as boundary conditions:

1. $200 \%$ double-ended guillotine break

2. Accumulator flow inhibited (this was done to increase clad temperature increase for input deck evaluation purposes).

Figure 3-8 shows the calculated upper head pressure (Component 555010000). There is a very rapid pressure drop from 2250 to 1400 psia (15.5 to $9.6 \mathrm{MPa}$ ) during the subcooled blowdown period. The pressure drop becomes more gradual with the vessel pressure dropping to containment pressure by $25 \mathrm{~s}$. This is the anticipated trend in a large break LOCA.

Figure 3-9 shows the break flow. Vessel side break flow (Component 195) is higher than the cold leg side (Component 193) as is normally the case. The maximum break flow rate is approximately $120000 \mathrm{lbm} / \mathrm{s}$ (54 MT/s). The blowdown ends at approximately $25 \mathrm{~s}$. ECCS bypass is indicated by flow surges through the break junctions after the end of blowdown. It should be noted here that RELAP5/MOD3 uses the Ransom-Trapp critical flow model for the prediction of break flow. This calculation is implicit in the code numerical solution so a table look-up method using a published break llow model such as the Moody model, is not used. The Ransom-Trapp model was derived using a thermal-equilibrium assumption in the two-phase flow regime, and therefore tends to approach the homogeneous equilibrium break flow rate. 


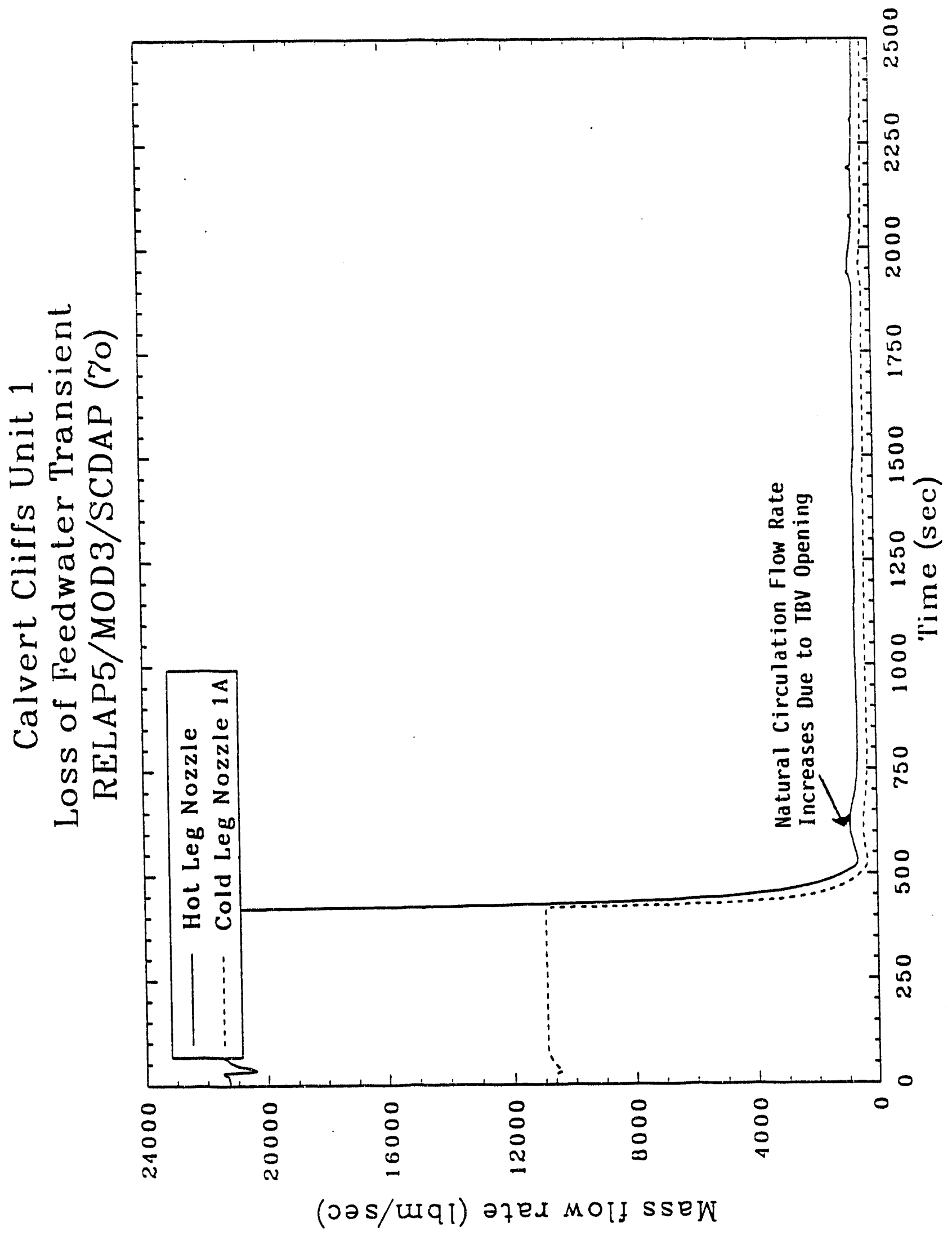

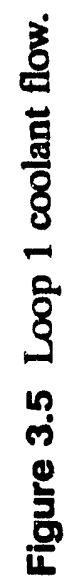




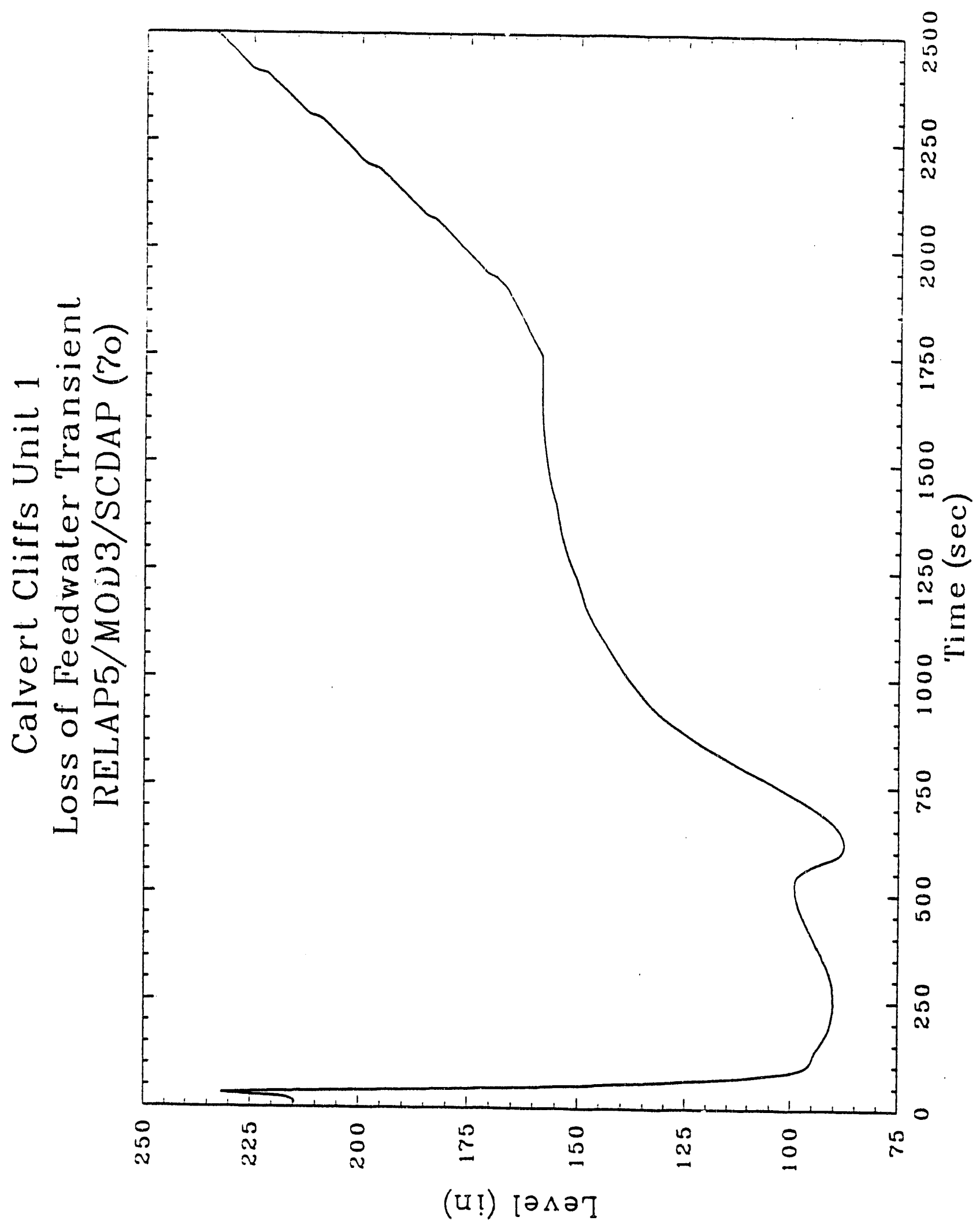

过 


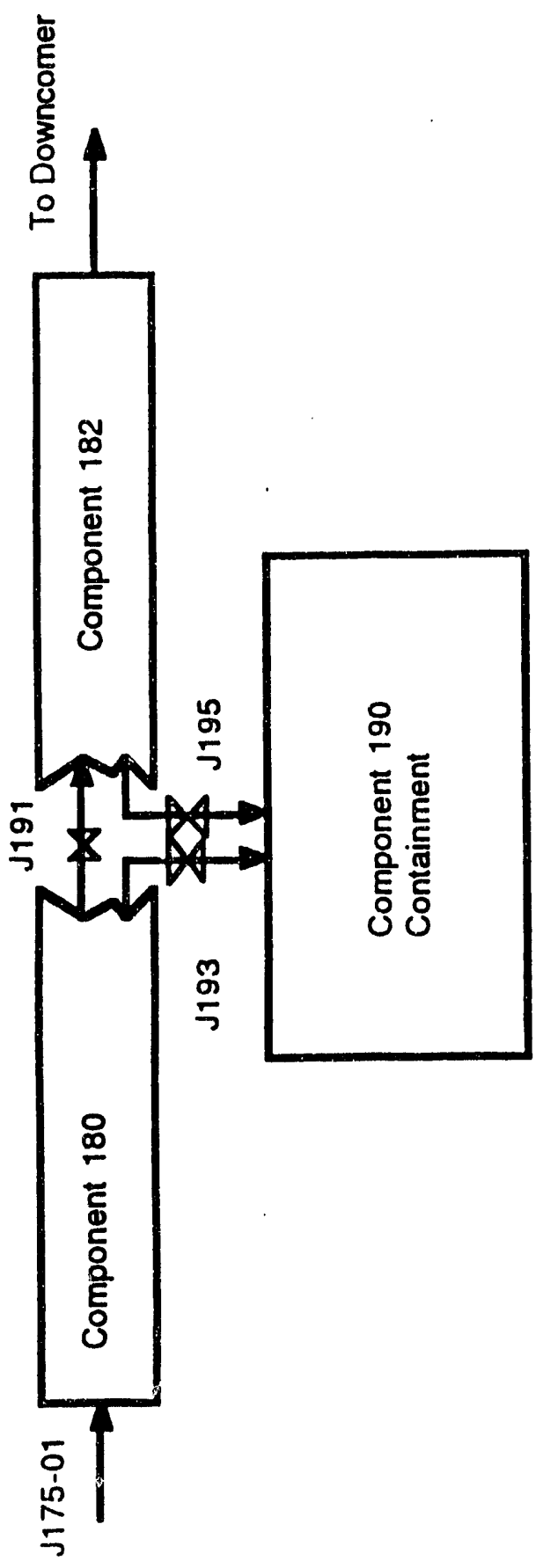

ठิ 

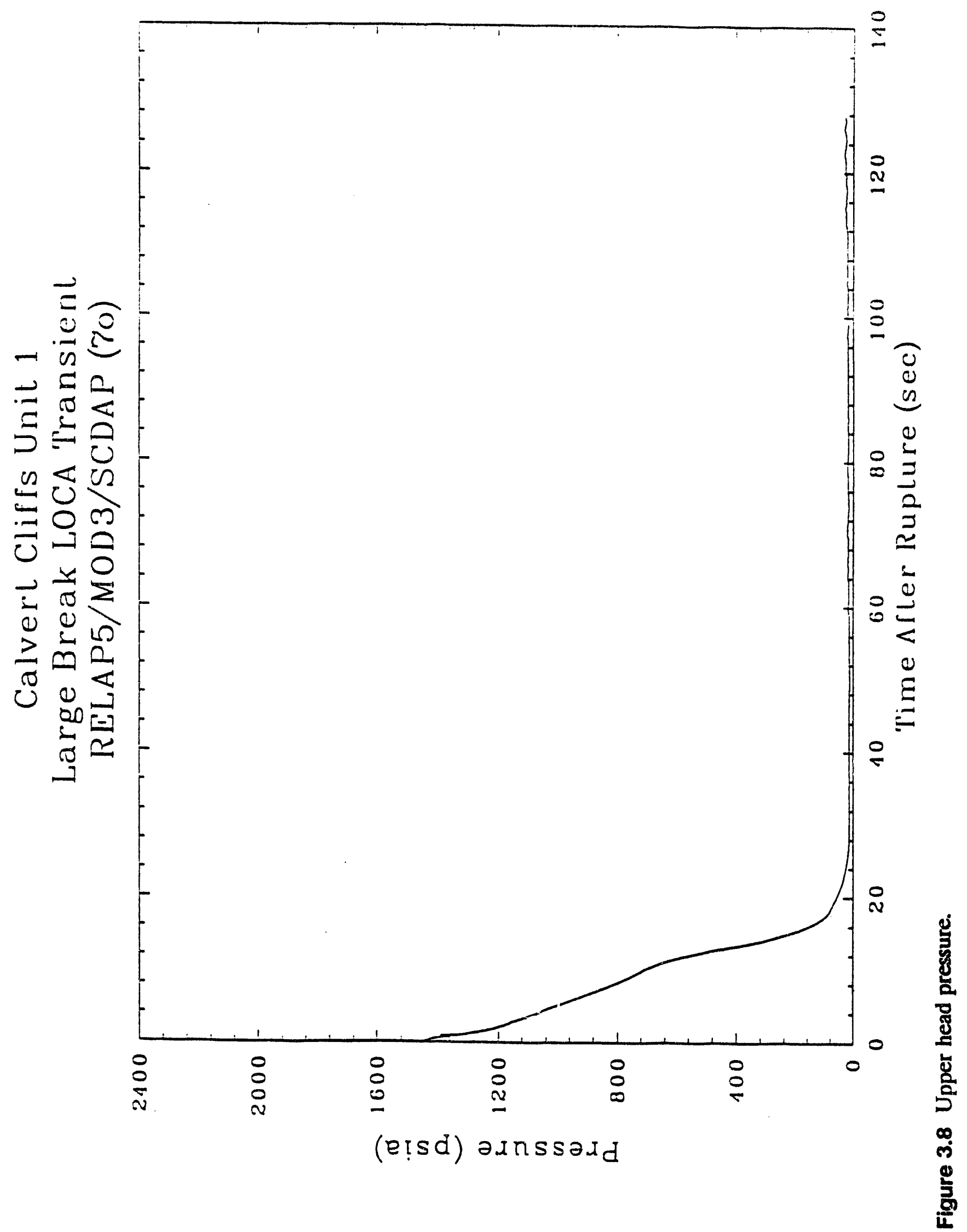


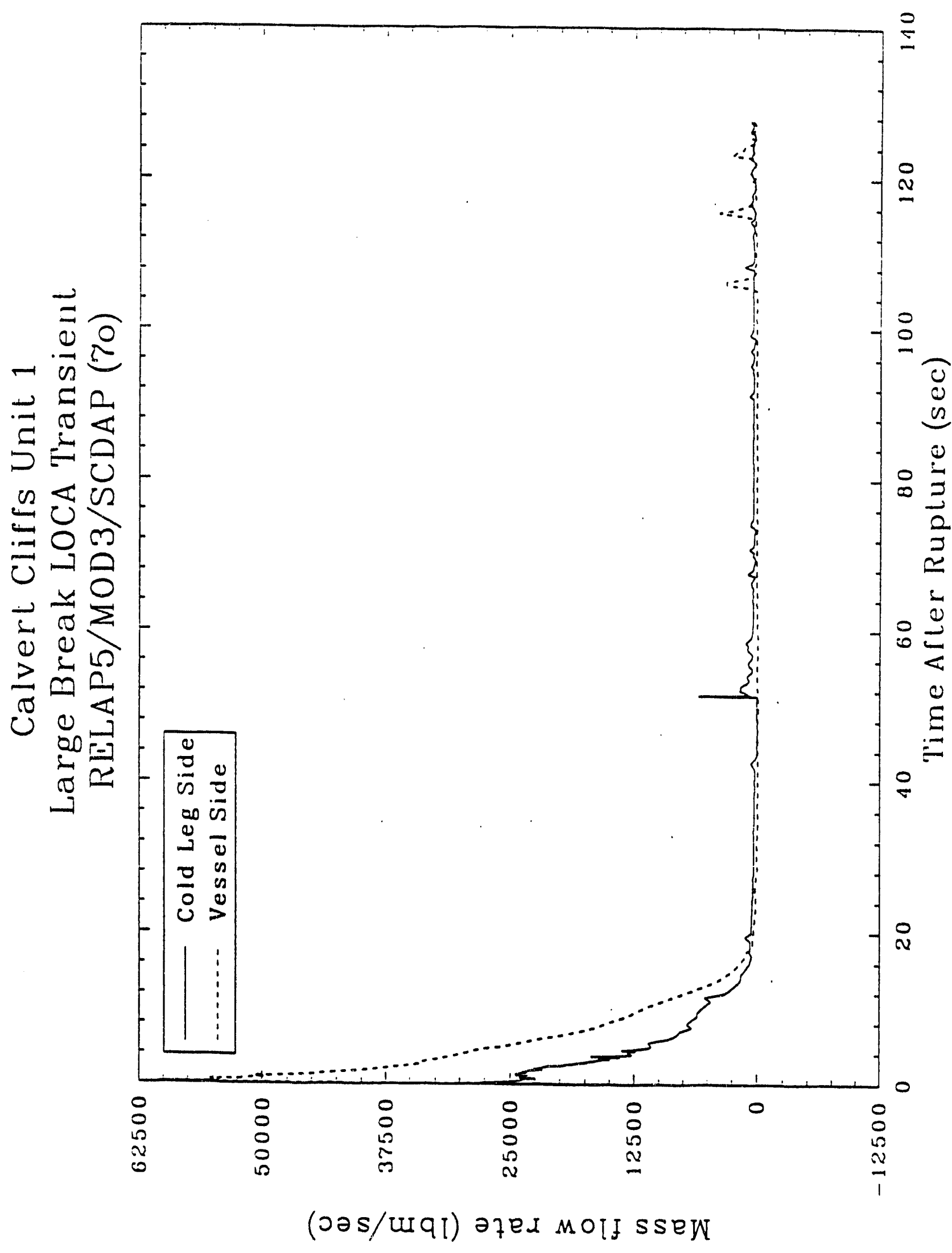

它 
Figure 3-10 shows the inlet flow to the center core region. The flow reverses immediately after the time of break, then reverses again as condensation begins in the primary-side of the U-tubes. Upward flow in the core is short-lived because the primary pressure drops below the secondary pressures at $6 \mathrm{~s}$, changing the condensation to vaporization. Steam is no longer drawn toward the U-tubes and again flows down through the core toward the vessel-side break. The core inlet flow becomes oscillatory after the ECC flow begins to reach the core inlet. Some of the calculated oscillations may be a result of numerical instabilities in the condensation rate calculation.

The highest clad temperature is shown in Figure 3-11. The location of the highest temperatures is at the fourth axial node from the bottom of the center core. This is also the highest power location. CHF occurs immediately after time of break causing a rapid temperature increase to $1772^{\circ} \mathrm{F}$ $(1240 \mathrm{~K})$. The upward llow described above slowed the temperature rise at $3 \mathrm{~s}$, but temperatures remained high until downward flow of steam resumed at $7 \mathrm{~s}$, carrying with it liquid ejected from the Loop 2 hot leg when vaporization occurred. At $12 \mathrm{~s}$ the heatup began because of core dry out. The second heatup was slower than the initial temperature rise because some of the stored energy in the core was removed. The PCT rose to $1952^{\circ} \mathrm{F}(1340 \mathrm{~K})$, higher than expected in an actual LBLOCA because the accumulators were inhibited, before ECCS flow increased the core heat transfer and the temperature began to decrease.

\subsection{Small Break LOCA Calculation}

A small break with an area of $0.01 \mathrm{ft}^{2}$ (1.35 inch diameter) was simulated in the Loop $2 \mathrm{~B}$ cold leg. The break, shown in Figure 3-12, is modeled with a single junction so that the crossflow option may be used. Primary pressure will drop low enough for high pressure injection (HPI) to initiate for breaks of this size, and the break flow rate will exceed the maximum HPI flow rate.

The boundary conditions for this calculation are taken from Reference 4 and are as follows:

1. One hundred percent core power.

2. One available HPI pump.

3. Reactor coolant pumps trip according to the emergency operating procedures (EOPs). The first two RCPs trip $30 \mathrm{~s}$ after the Pressurizer pressure equals 1725 psia (11.9 MPa), and the remaining RCPs trip $30 \mathrm{~s}$ after the RCS pressure equals $1300 \mathrm{psia}(9 \mathrm{MPa})$ and the RCS subcooling drops below $30^{\circ} \mathrm{F}(17 \mathrm{~K})$.

Figure 3-13 shows the predicted pressurizer (primary) and secondary pressures for the analysis that was run for $3300 \mathrm{~s}$ of transient time. After the break at $t=0.0 \mathrm{~s}$, the primary pressure drops rapidly to $1350 \mathrm{psia}(9.3 \mathrm{MPa})$ during the initial $84 \mathrm{~s}$. The depressurization rate then becomes more gradual. The secondary pressure initially rises. The low pressure scram signal occurs at $24 \mathrm{~s}$ and the steam generator pressures approach the initial value of 875 psia $(6 \mathrm{MPa})$ shortly thereafter. The first two RCPs trip at $78.5 \mathrm{~s}$ followed by the trip of the second two RCPs at $255 \mathrm{~s}$. The second trip induces the turbine bypass valve (TBV) to open at $340 \mathrm{~s}$ and close at $420 \mathrm{~s}$. This causes a rapid drop in secondary pressure followed by a pressure increase at $420 \mathrm{~s}$. The primary depressurization rate 


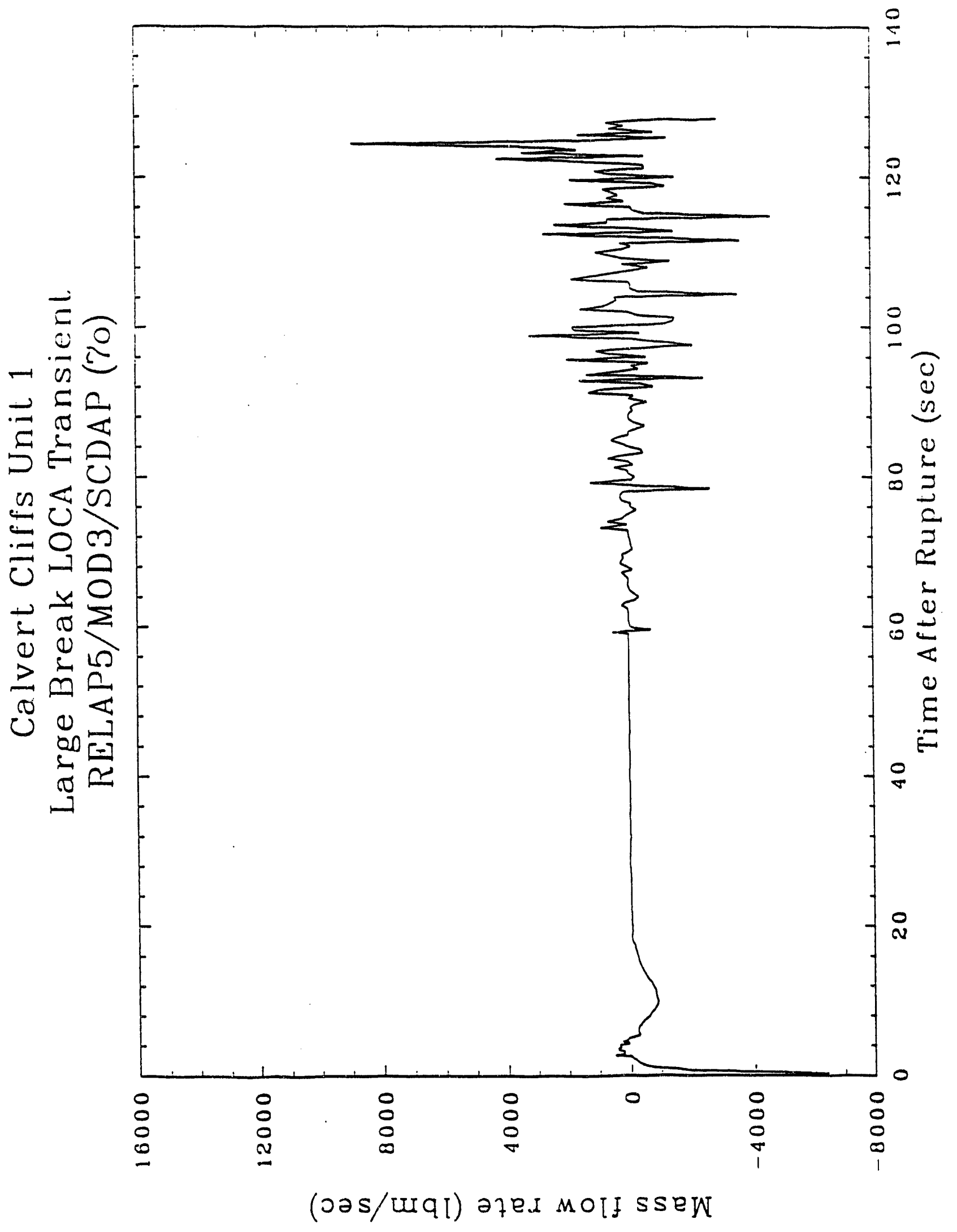




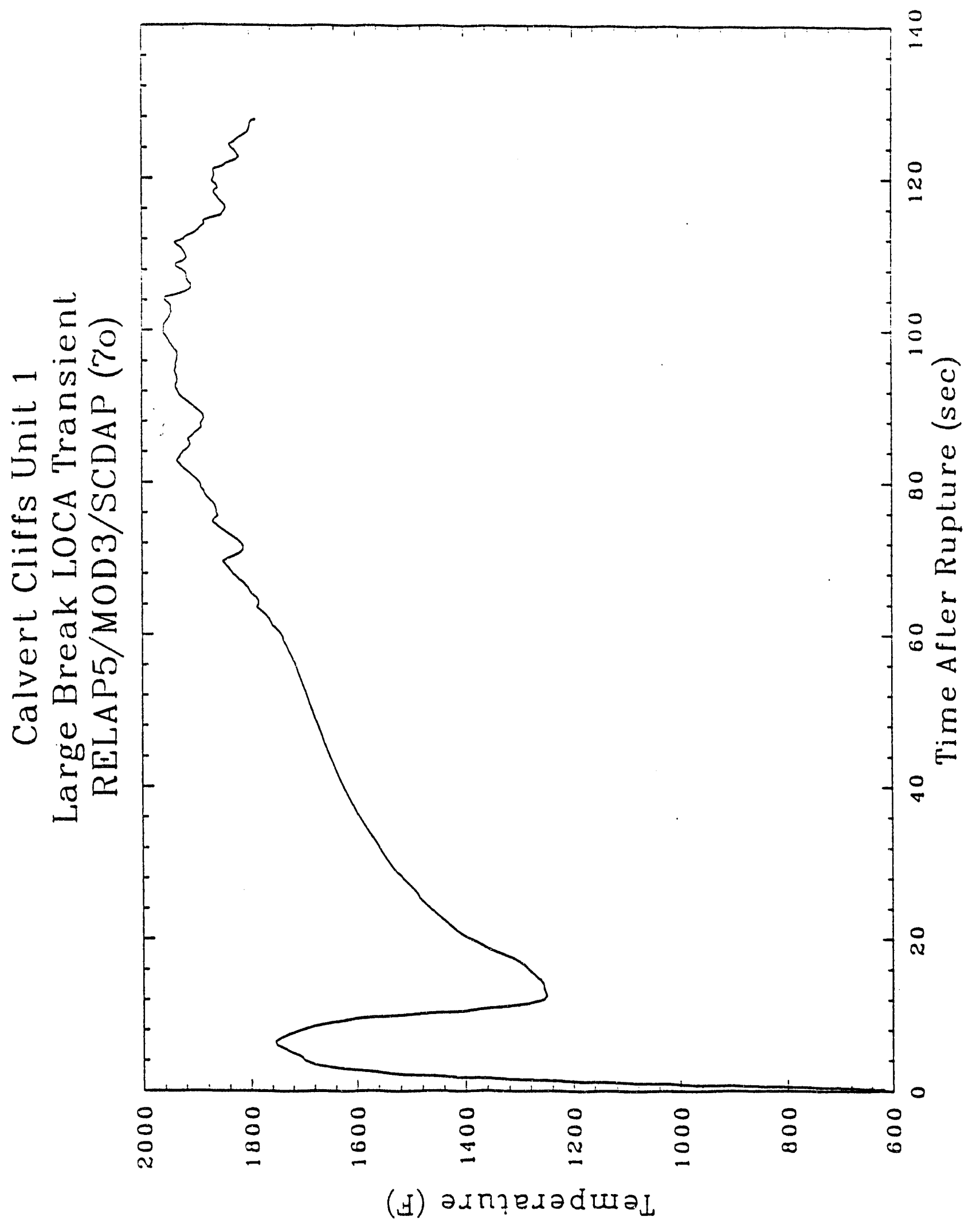

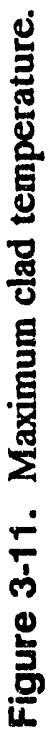




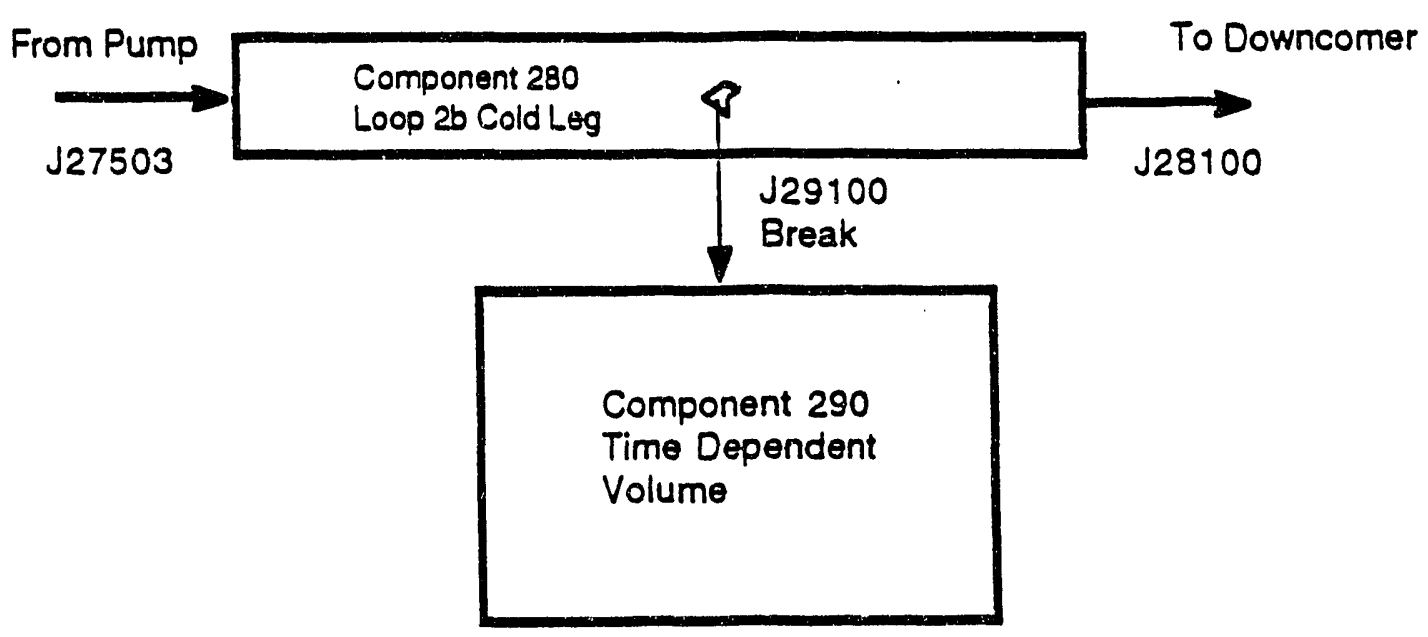

Figure 3-12. Break nodalization for a small break LOCA. 


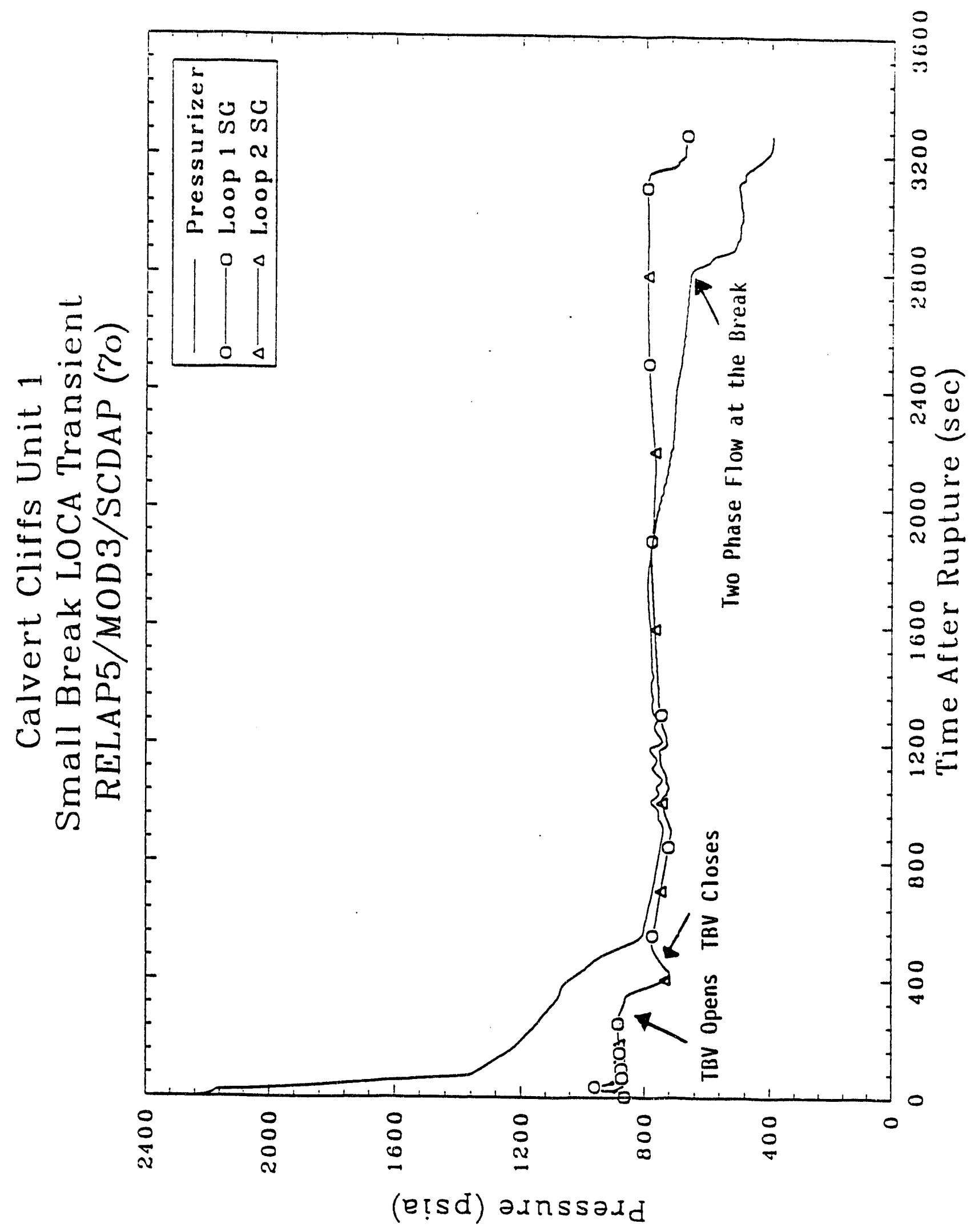

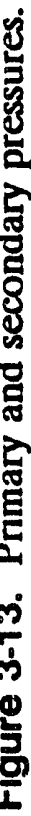


also increases when the valve opens due to increased heat transfer from the primary to the secondary. The primary and secondary pressure curves converge after $500 \mathrm{~s}$. Between 500 and $1800 \mathrm{~s}$ there is little change in the pressure indicating that the heat transfer to the secondary plus the energy loss through the $0.01 \mathrm{ft}^{2}$ break approximately equals the heat generated in the core. During this period the heat transfer to the secondary decreases due to voiding in the primary side of the U-tubes but the energy loss through the break remains constant. The core energy generation is of course decreasing continuously. After $1800 \mathrm{~s}$ the primary and secondary pressures decouple with the primary pressure decreasing while the secondary pressure remains constant. There is little heat transfer between the two systenis at this time because of $U$-tube voiding and recirculation flow stagnation but the break flow is removing more energy than is generated by the core causing the primary to depressurize. The break flow becomes two-phase after $2800 \mathrm{~s}$ increasing the energy flow out the break and increasing the depressurization rate.

Figure 3-14 shows the hot leg temperature for both loops. The temperatures are identical and therefore the two curves overlay. The temperature initially drops after reactor scram and then becomes constant at $533^{\circ} \mathrm{F}(552 \mathrm{~K})$ after the first two RCPs trip at $78.5 \mathrm{~s}$. When the remaining RCPs trip at $255 \mathrm{~s}$ the temperature begins to increase but drops when the TBVs open at $340 \mathrm{~s}$. When the primary and secondary pressures converge after $500 \mathrm{~s}$ the hot leg temperature remains constant following the pressure trends. When the break flow becomes two-phase and the energy loss through the break increases at $2800 \mathrm{~s}$, the temperature begins to drop.

The pressurizer level is given in Figure 3-15. The initial level is 215 inches, the nominal steady state value. The level drops rapidly and the pressurizer empties by $73 \mathrm{~s}$. Because a small aruount of dispersed liquid remains in the pressurizer the level does not indicate zero.

The break flow is shown in Figure 3-16. The break flow is single phase liquid until about $2800 \mathrm{~s}$ as was explained above. The peak break flow of $240 \mathrm{lbm} / \mathrm{s}(109 \mathrm{Kg} / \mathrm{s})$ occurs immediately after the time of break. Between 0 and $900 \mathrm{~s}$ the break flow follows the trends in the primary pressure explained above. After $900 \mathrm{~s}$ some oscillations are seen in the break flow curve. Voiding and condensation on the primary side of the U-tubes induces pressure and enthalpy fluctuations that affect the break flow calculation. Abupt changes in the break flow occur after the flow becomes two-phase at $2800 \mathrm{~s}$. The void fraction upstream of the break fluctuates resulting in rapid changes in the flow. The energy loss through the break increases during two-phase flow because of the high internal energy of the vapor phase.

Figure 3-17 shows the predicted hot leg void fraction. Voiding begins in the hot leg shortly after the second RCP trip at $255 \mathrm{~s}$. The void fraction generally increases until $900 \mathrm{~s}$ when voiding and condensation in the primary side of the U-tubes induces flow and pressure oscillations, which in turn result in void fraction fluctuations. After the U-tubes have voided and flashing occurs in the pump inlet piping downstream of the steam generator, the hot leg void increases rapidly from a value of approximately 0.24 to 0.50 . After this rapid rise, the void fraction further increases until the hot legs are nearly $90 \%$ voided. When two-phase break flow begins at $2800 \mathrm{~s}$, the void fraction drops due to a temperature drop in the primary system.

The void fraction immediately upstream of the break in the Loop $2 \mathrm{~B}$ cold leg is given in Figure 3-18. The onset of two-phase break flow at $2800 \mathrm{~s}$ can be seen clearly in this figure. 


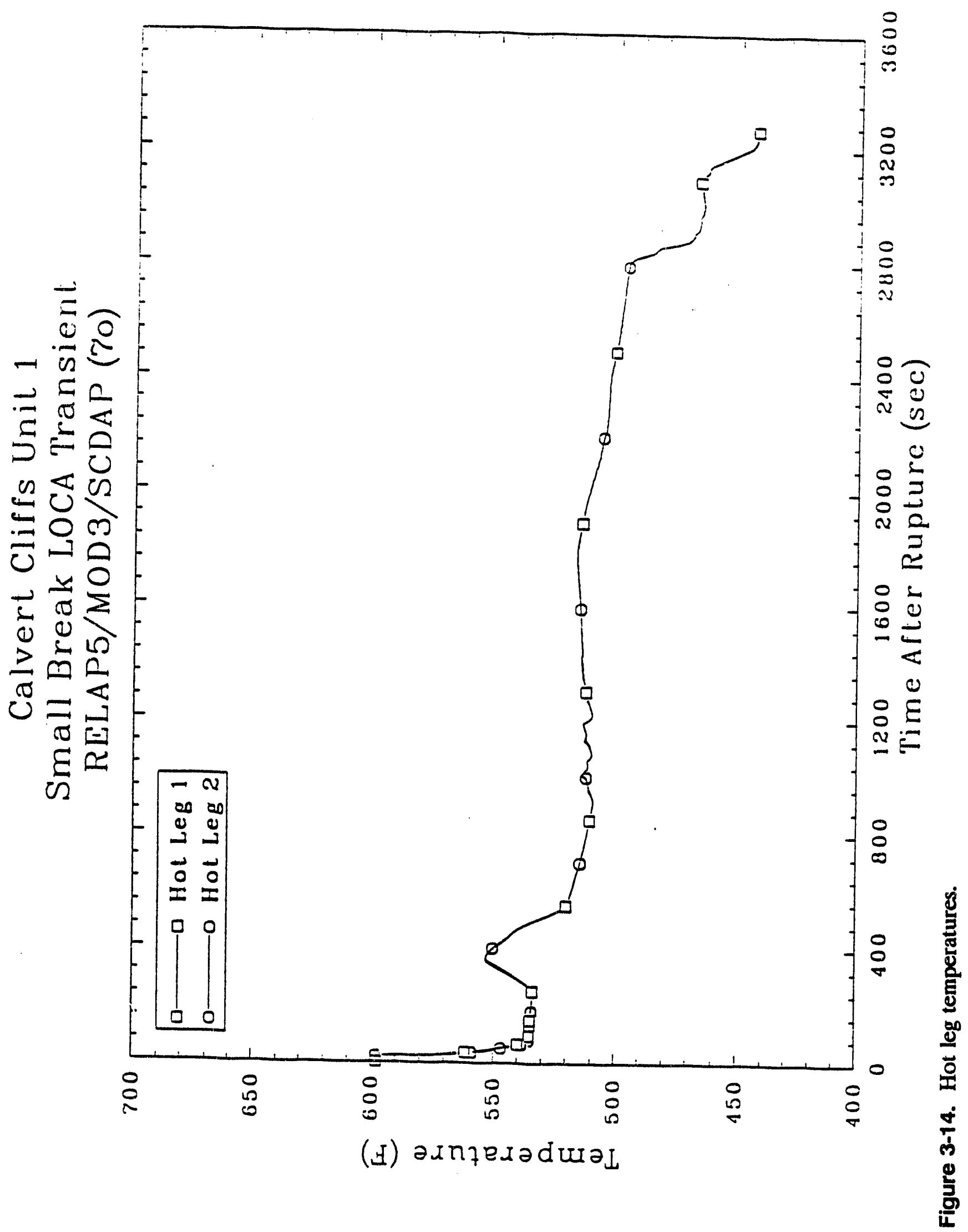




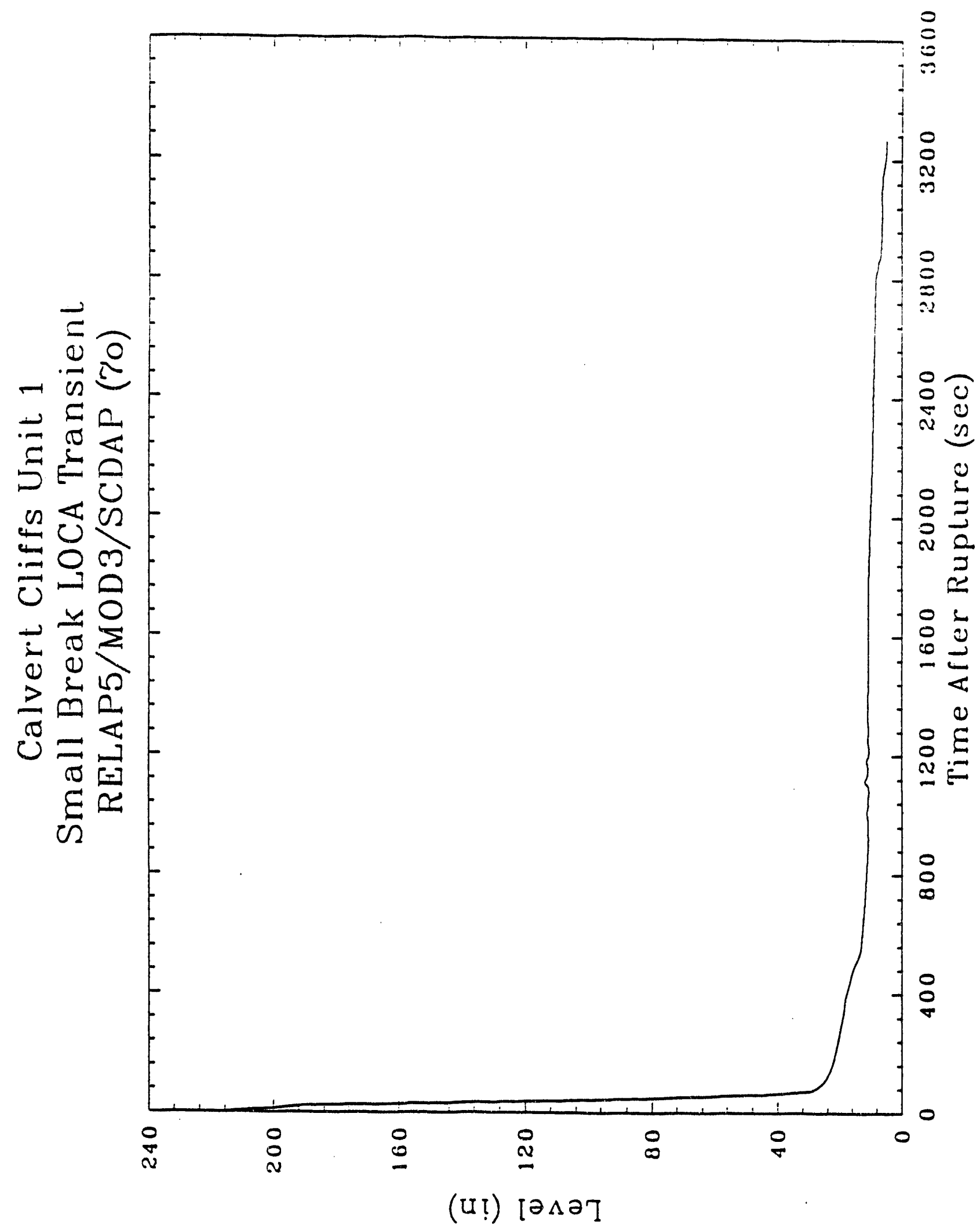

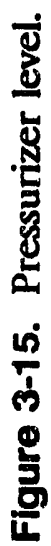




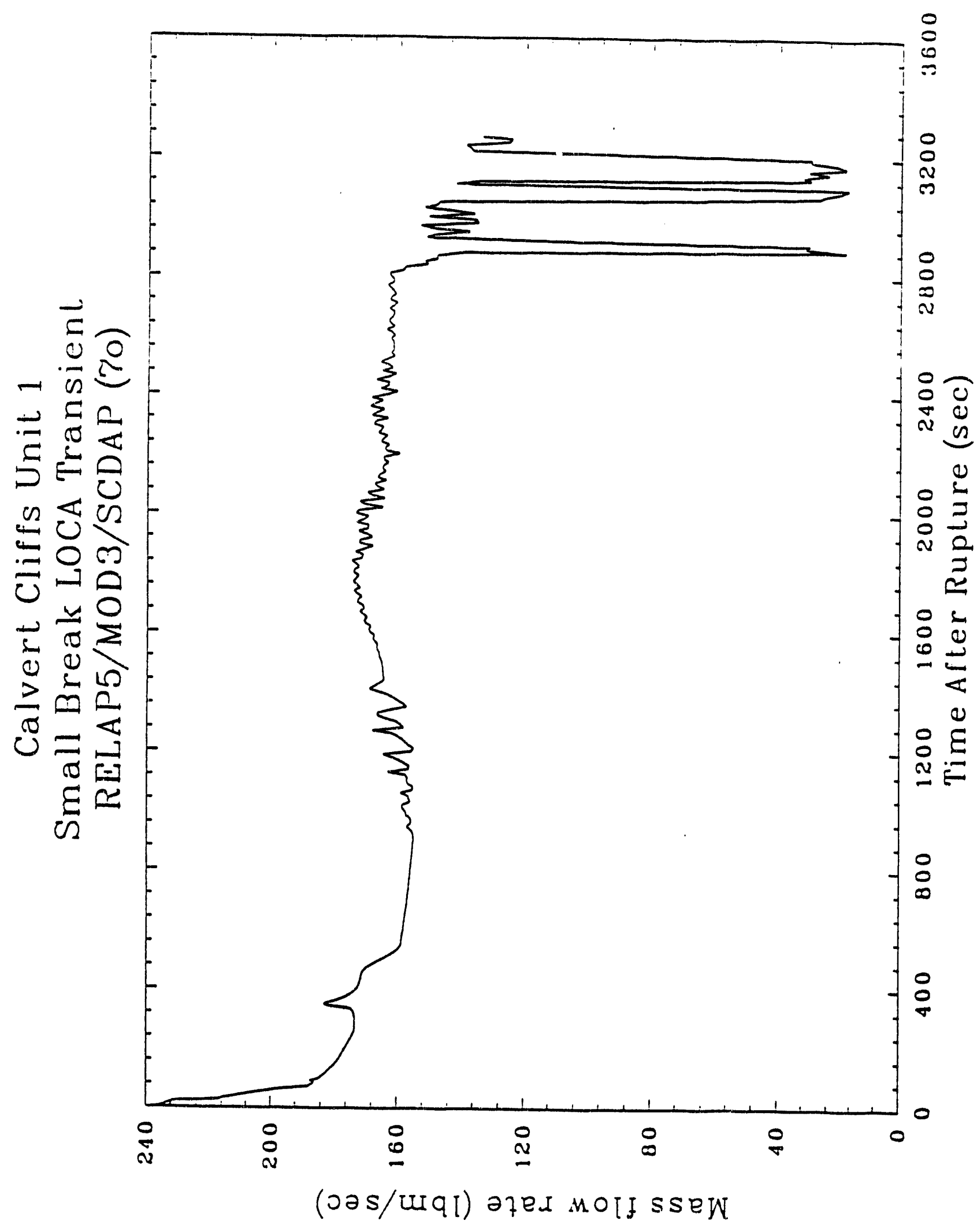

宫 


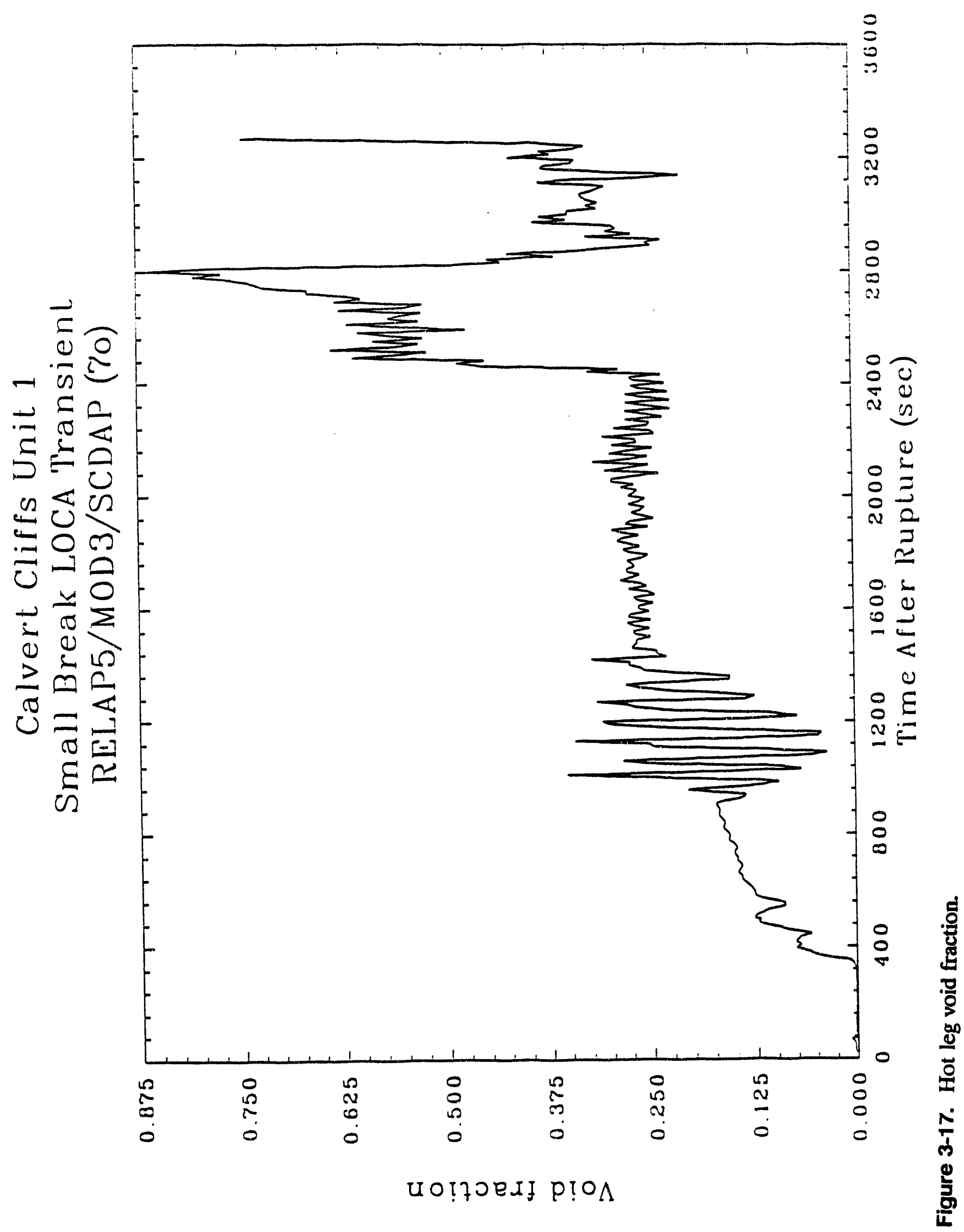




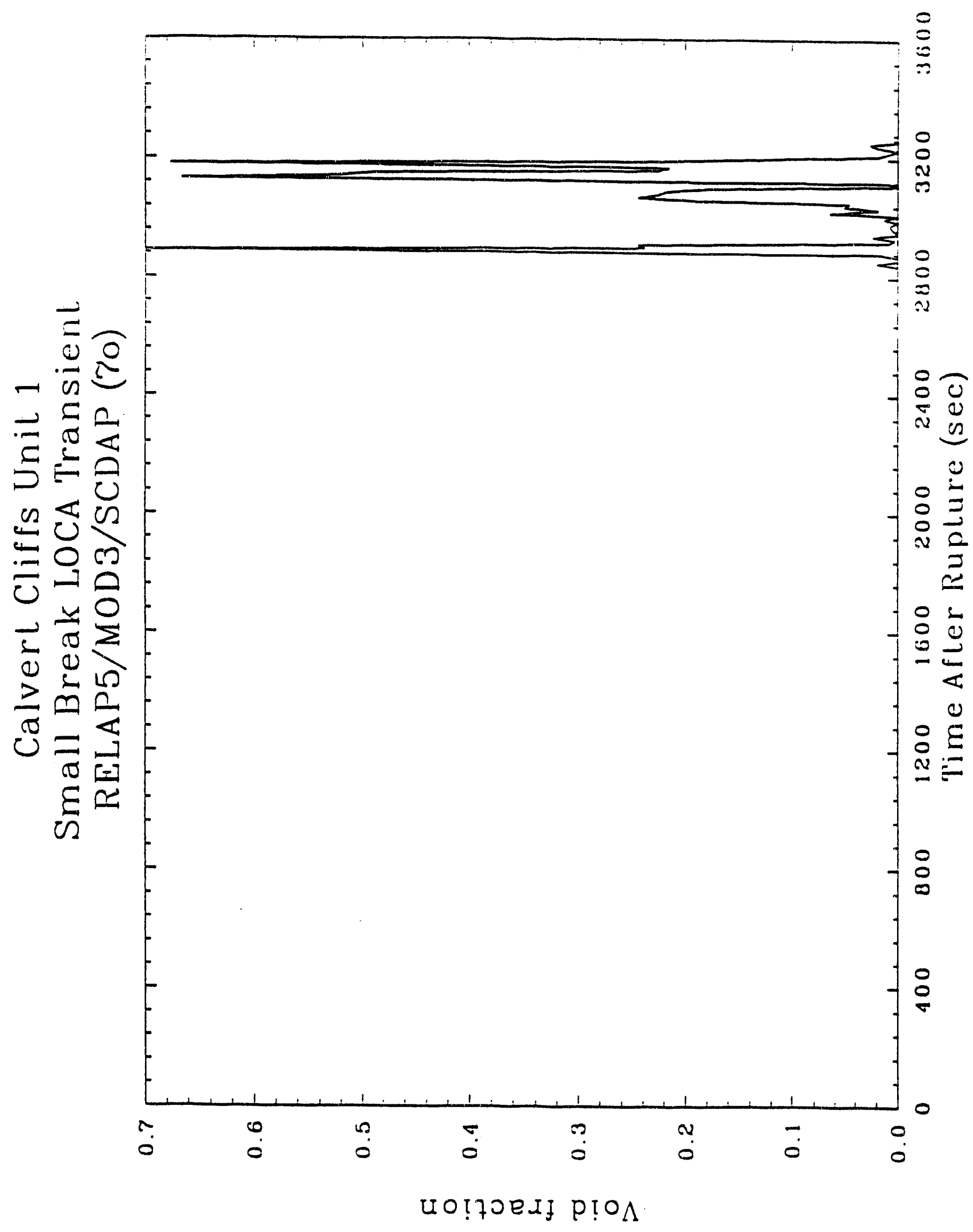

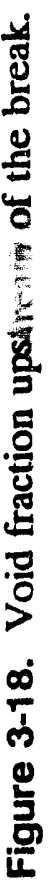


The inlet flows to the three core channels modeled in the Calvert Cliffs plant deck are shown in Figure 3-19. The flows drop initially when the first two RCPs trip at $78.5 \mathrm{~s}$ and drop again after the second trip at $255 \mathrm{~s}$. Ample natural circulation flow is available to the core from the time of the last RCP trip until approximately $900 \mathrm{~s}$. U-tube voiding then begins to inhibit natural circulation and flow surges followed by flow stagnation are seen between 900 and $1450 \mathrm{~s}$. After $1450 \mathrm{~s}$ reflux boiling begins.

Figure 3-20 shows the total HPI flow. A comparison of integrated break and ECC (HPI) flow is given in Figure 3-21. High pressure injection is initiated on low system pressure at $150 \mathrm{~s}$. Between 500 and $2800 \mathrm{~s}$ the HPI flow rate is approximately 65 to $100 \mathrm{lbm} / \mathrm{s}(29$ to $45 \mathrm{Kg} / \mathrm{s})$ less than the predicted break flow during this period. Figure 3-21 indicates that the total mass loss through the break is $490000 \mathrm{lbm}(222 \mathrm{MT})$ at $3000 \mathrm{~s}$ with only $180000 \mathrm{lbm}(82 \mathrm{MT})$ of ECC liquid resupplied to the system during this time.

Figure 3-22 shows that the vessel collapsed liquid level dropped rapidly until the hot leg centerline was reached, at which time flow out of the vessel was reduced and the U-tubes began to void. The collapsed liquid level remained constant in the upper plenum while coolant drained from the legs, but fluctuated when two phase flow out the break began, and dropped momentarily below the top of the fuel. However, the frothy mixture in the voided core volumes was sufficient to cool the cladding, as seen in Figure 3-23, for the PCT did not rise at the time of core uncovery, but instead dropped because of increased core flow. The PCT never rose above its initial value.

\subsection{User Instructions and Recommendations}

This discussion is primarily directed to the user who wishes to perform studies of thermalhydraulic transients and severe accidents using the Calvert Cliffs plant deck, but does not have time to become highly familiar with the RELAP5/MOD3/SCDAP code and the code applications procedures. The NPA capability is very helpful for allowing a user to conduct analyses with a minimum amount of input data manipulation. Users who desire to obtain a greater knowledge of the RELAP5/MOD3/SCDAP code should attend one of the Code Users seminars conducted by EG\&G Idaho.

The preferred method for executing an analysis with the deck is illustrated in Figure 3-24. Five steps are diagramed in the figure and the first three steps have already been completed as part of the deck development process. The user must do steps four and five to complete a calculation. An explanation of the steps is as follows:

\section{Step 1}

Perform a calculation without trips to achieve the desired steady state conditions based on plant data at $100 \%$ power conditions. The restart-plot file created by the steady state calculation is large in terms of computer space and has an end time of $1000 \mathrm{~s}$. 


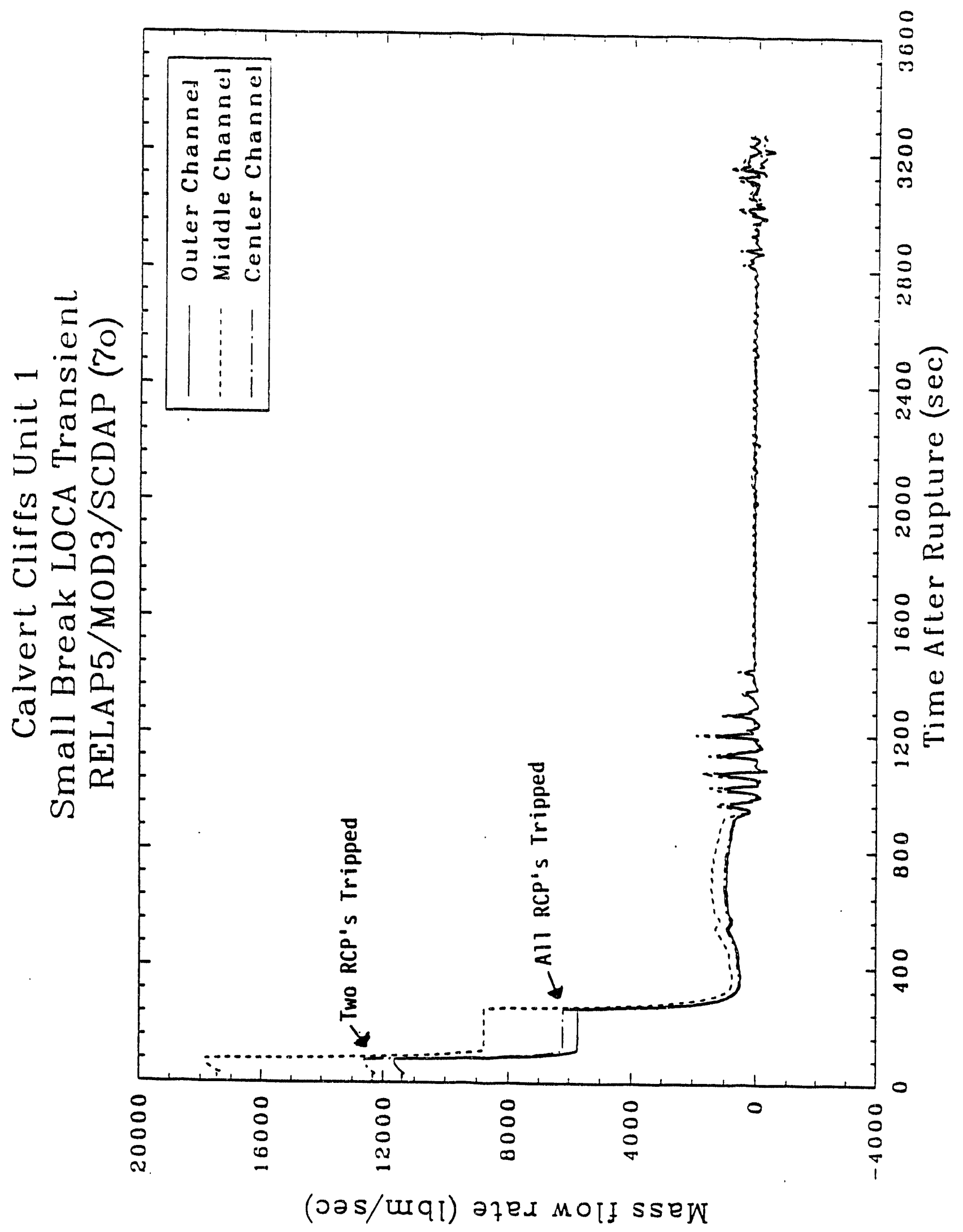

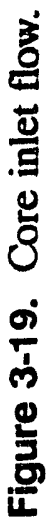




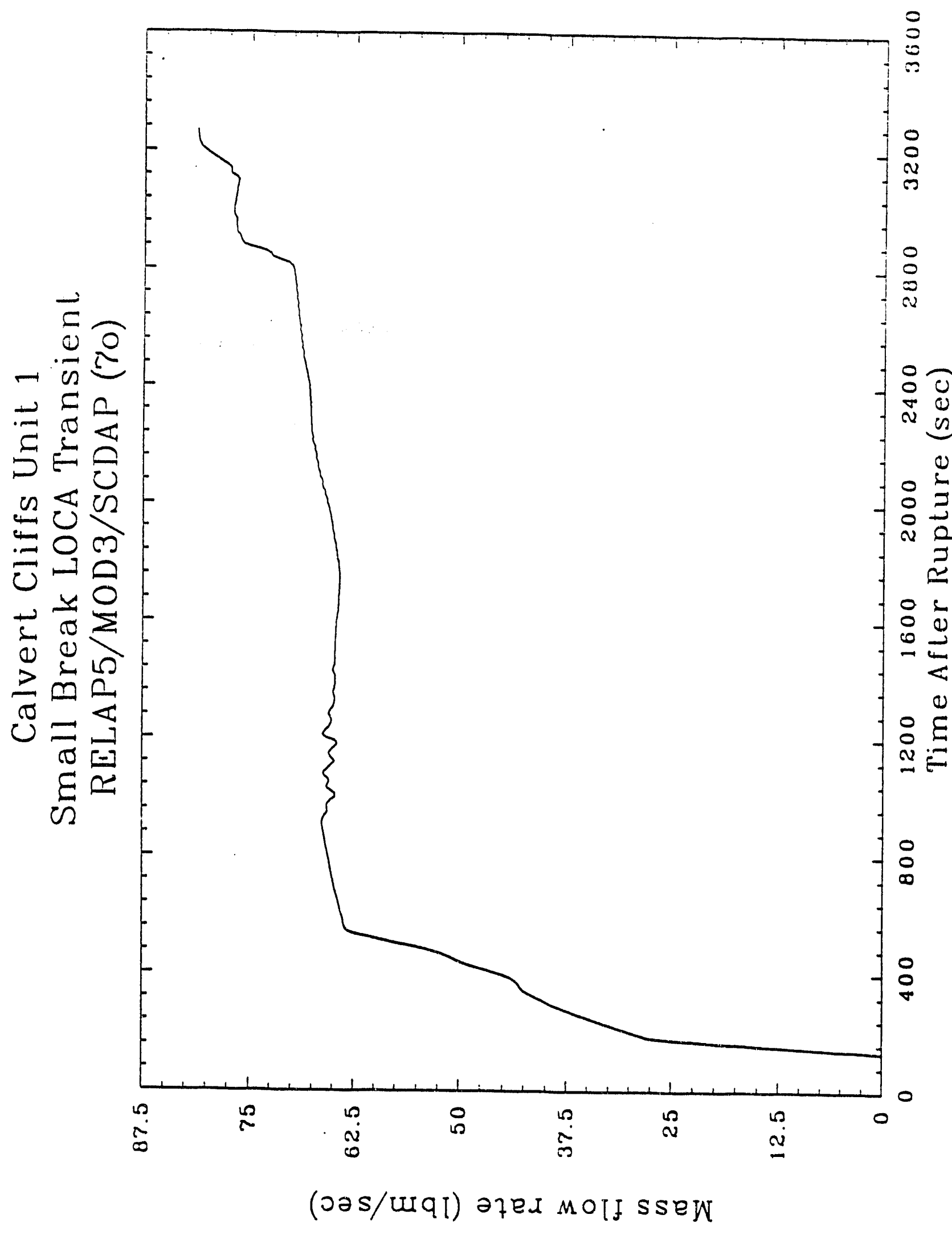

产 


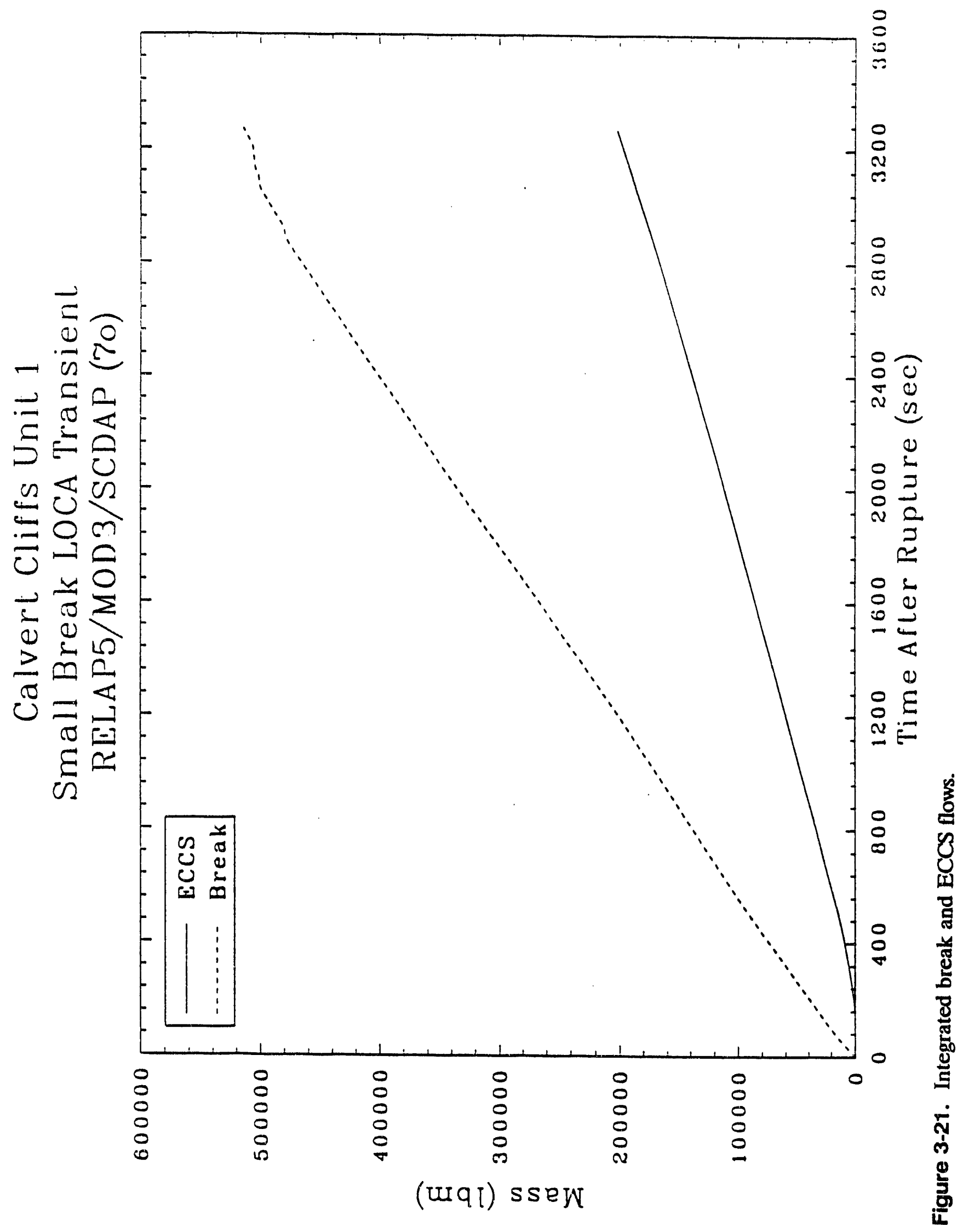




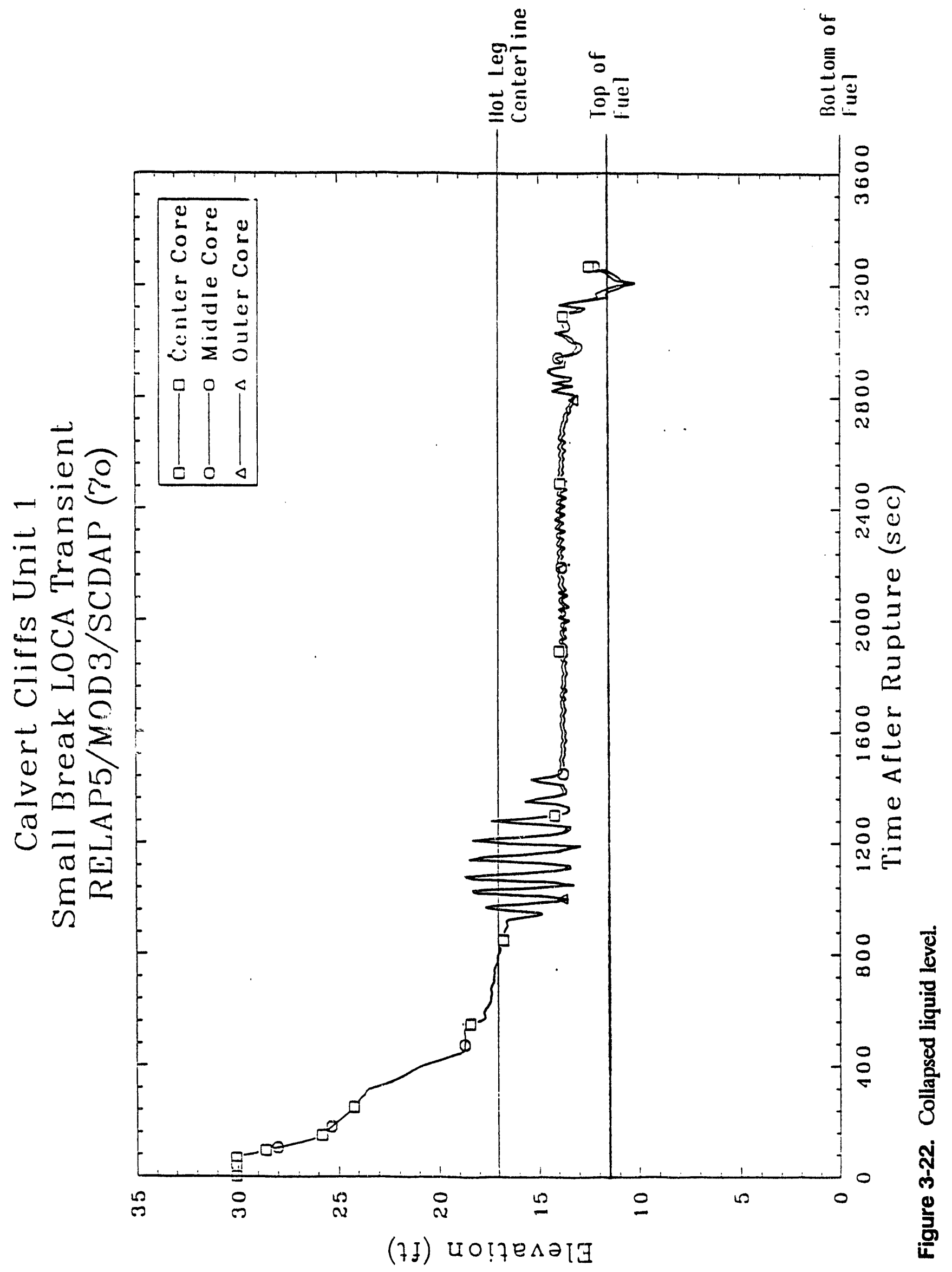




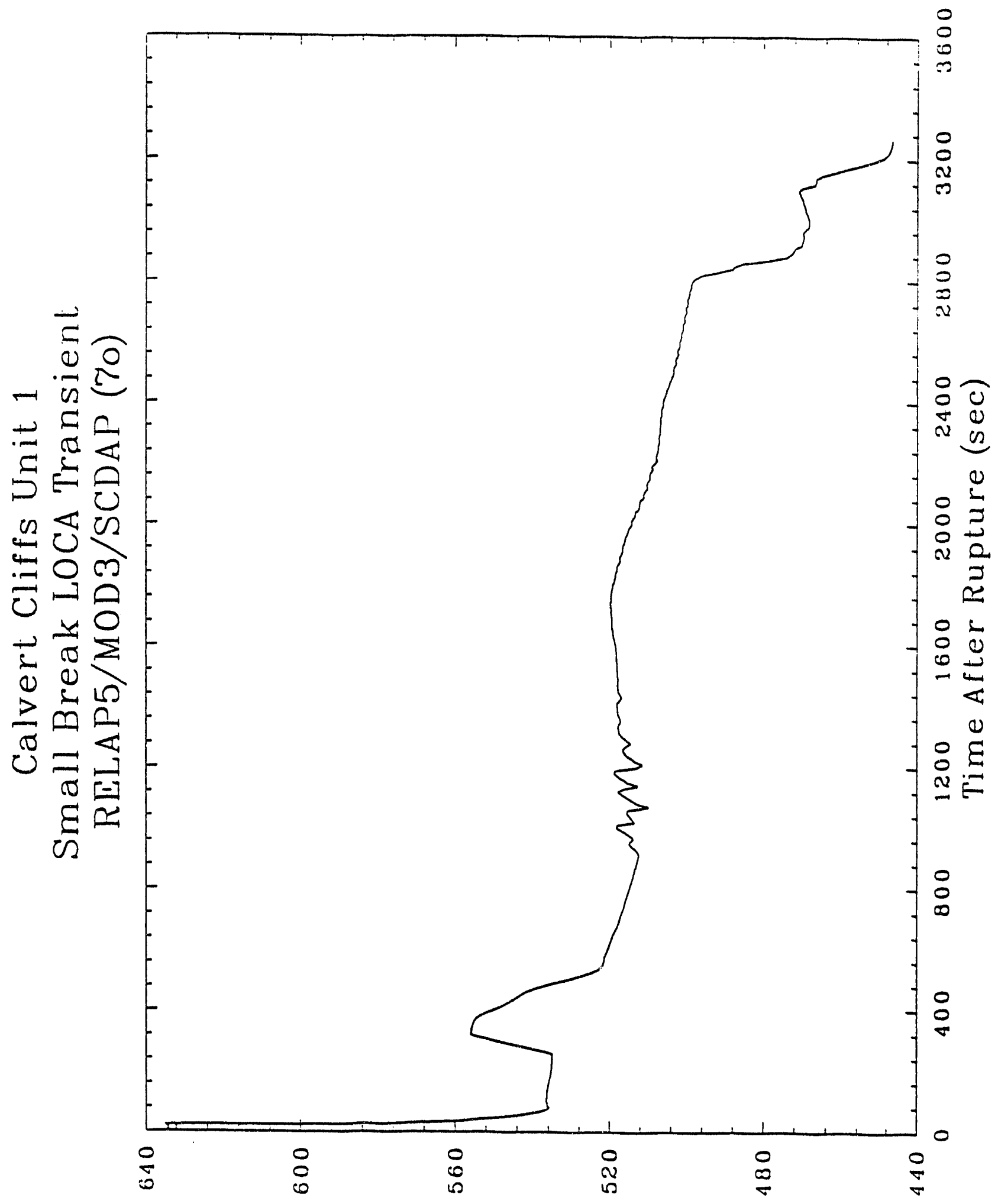

(घ) әлпาедәduәL 


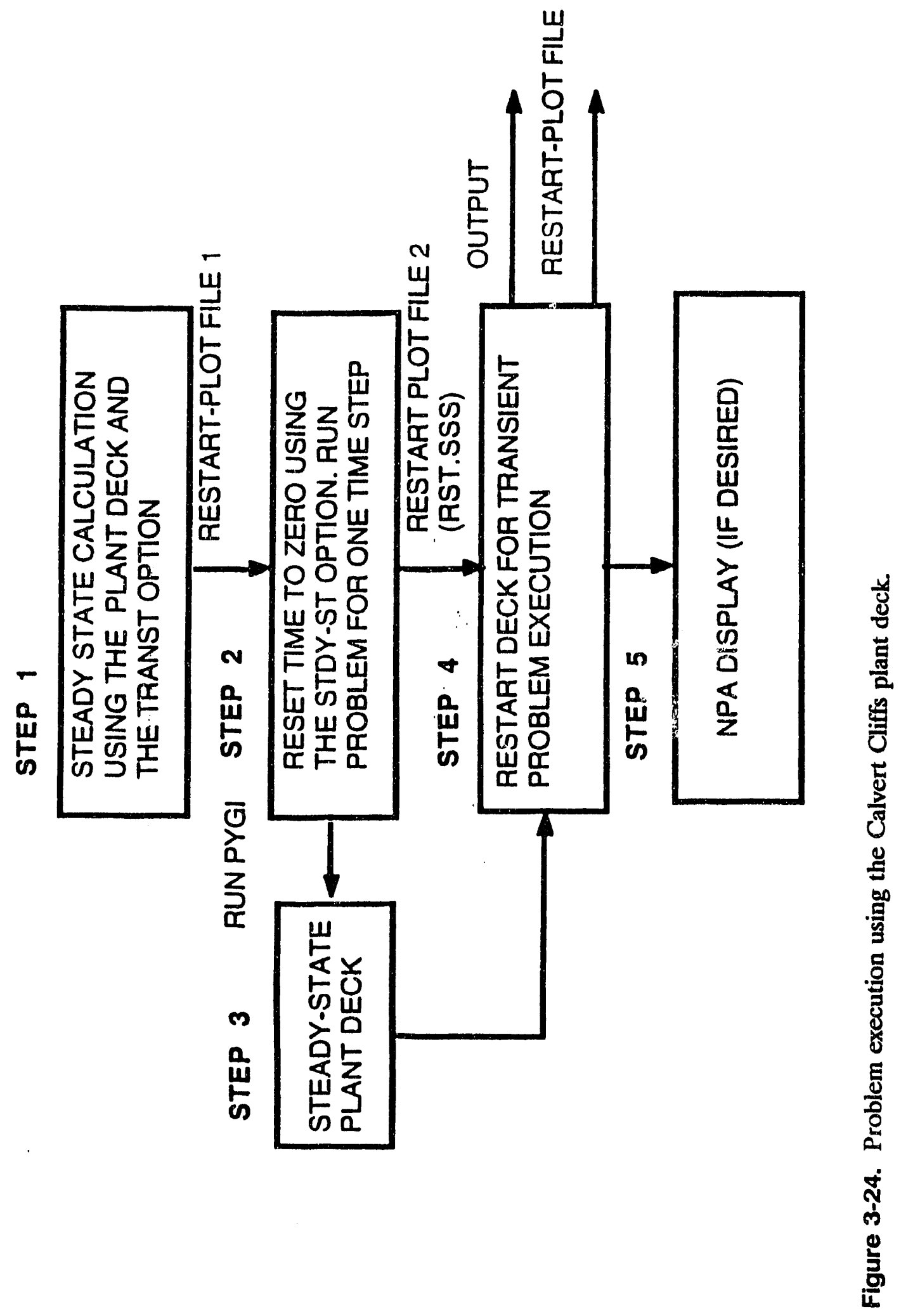


It is convenient for the user to reduce the size of the restart-plot file created in Step 1 and to reset the time from 1000 to zero. When a user begins a transient analysis the transient will begin at zero s. This is accomplished by restarting with stdy-st selected on word two of RELAP5 Card 100. On Card 105 use 100. for word one, 10\%. for word two, and 10. for word three. Word three is the CPU time limit and words one and two are CPU time remaining limits. The code will not execute but will reset the time to zero and write a restart-plot file containing only data from the last edit of the steady-state. This provides a file from which any transient analyses can begin.

Step 3

Run the PYGI program to create a deck with steady-state conditions. The PYGI program is an applications code that will rewrite a RELAP5/SCDAP deck with updated pressure, internal energy, and flow data. The remainder of the input is unaltered from the base deck, so the new deck contains steady-state thermal-hydraulic conditions.

Step 4

The analyst will create a restart deck with appropriate input to simulate the desired transient or accident and then execute the problem by restarting from the file created in Step 2. The deck created in Step 3 can provide useful input for the restart deck because the thermal-hydraulic data will match the data on the restart-plot file. Assume that the user desires to trip two of the RCPs at $10 \mathrm{~s}$. This change can be accomplished by adding the inputs for these two pumps with new trip numbers. The inputs in the steady-state deck will have the correct pump pressure, internal energy, pump speed and pump fluid velocity. The analyst will only change the trip number to trip the pumps.

Step 5

Printed output and restart-plot files will be automatically generated. The analyst may also desire to review the results using the NPA. This is done by using the replay option on the NPA.

The alternative for performing a calculation is to use the NPA and execute interactively. This is often a very useful method of executing a problem because the required manipulation of input data can be reduced. For example, an analysis of a stuck open PORV transient can be initiated by using the NPA to select the full open position of the PORV and begin execution. However, the recommendation is to use the method explained above for problem execution. The NPA is best applied to display results and enhance the users ability to analyze and understand the code calculation after reviewing the printed output. This recommendation is made because some of the important diagnostic information is only given in the printed output.

\subsubsection{Plant Transient Applications}

The analysis of a thermal-hydraulic transient that is not caused by a break in the primary or secondary can normally be performed with few or no component additions to the base model. The interactive input data cards (801 through 999) and the trip input data (cards 20600000 through 206020000) are used to initiate transient events. 
Table 3-2 lists the interactive variable inputs and the method of utilizing these inputs. Assume that the user wants to analyze a pump coastdown test where the RCP's trip when the test starts. If the variable rcps on card 805 is set to a value less than zero, then all of the pumps will trip. Table 3-3 shows a restart deck that will execute this problem with the following inputs:

- Title card

- Card 100-problem type and option card

- Card 102-input units card

- Card 103 -restart number $=0$ for the first restart from the steady state restart-plot file

- Card 105-CPU time remaining card

- Card 201-time step card

- Card 805-set rcps to -1.0

- End of problem card.

This deck will then initiate a transient where the rcp's trip and coastdown. Other inputs might be added such as additional time step control cards to vary the time step size and edit frequency as a function of problem time. The analyst might also desire to edit a different set of variables than were used in the base deck (cards 301 through 399). If new edit cards are added, the edit variables in the steady state deck will be deleted. More complex transient scenarios will require trip cards to initiate events that occur after the beginning of the problem. The analyst should refer to Reference 7 for information on restart decks requirements.

\subsubsection{Loss of Coolant Accident Applications}

The Calvert Cliffs plant deck does not explicitly include components that model break locations since it is difficult to develop generalized break inputs because of the many possible locations and sizes of breaks that can occur. Therefore, the user will normally be required to add certain components to model LOCA's. The nodalization used to describe a $200 \%$ double ended guillotine cold leg break was given in Figure 3-7. Figure 3-12 shows the components used to describe a $0.01 \mathrm{ft}^{2}$ small break located in the cold leg. These components can be added in the restart deck. The minor edit cards should be also input with edits of break flow parameters added.

The horizontal stratification entrainment/pullthrough option at the break junction (the $v$ digit on the junction flag) will affect results for small break analyses. If 0 is selected then the break flow calculation will use the calculated fluid conditions in the volume immediately upstream of the break. If 1,2 , or 3 is selected then the fluid conditions will be modified by the horizontal stratification model. A selection of 1 indicates that the break is at the top of the pipe, 2 means a break at the bottom of the pipe, and 3 means a centrally located break. 
Table 3. 2. Calvert Cliffs plant deck interactive variable input summary.

* List of interactive variable initial values

* npa interactive variables

$*$

0000801 rep1a $\quad 0.0$

0000802 rcp1b $\quad 0.0$

0000803 rсp $2 \mathrm{a} \quad 0.0$

0000804 rcp2b $\quad 0.0$

0000805 rcps $\quad 0.0$

$0000806 \mathrm{si} \quad 0.0$

0000807 hpi1 $\quad 0.0$

0000808 hpi2 $\quad 1.0$

0000810 lpi $\quad 1.0$

0000812 spray $\quad 0.0$

0000813 scram $\quad 0.0$

$00 n 0814$ acc1a $\quad 0.0$

$0000815 \mathrm{acc} 1 \mathrm{~b} \quad 0.0$

0000816 acc $2 \mathrm{a} \quad 0.0$

0000817 acc2b $\quad 0.0$

0000818 ttrip $\quad 0.0$

0000819 sgis $\quad 0.0$

0000820 heaters $\quad 0.0$

0000821 porv $\quad 0.0$
0000822 mupumps 1.0

0000823 letdown 0.0

$0000824 \mathrm{sg} 1 \mathrm{mfiv} \quad 0.0$

$0000825 \mathrm{sg} 2 \mathrm{mfiv} \quad 0.0$

$0000826 \mathrm{sg} 1 \mathrm{mfrv} \quad 0.0$

$0000827 \mathrm{sg} 2 \mathrm{mfrv} \quad 0.0$

0000828 tstopv $\quad 0.0$

$0000829 \mathrm{sg} 1 \mathrm{mfbv} \quad 0.0$

$0000830 \mathrm{sg} 2 \mathrm{mfbv} \quad 0.0$

$0000831 \mathrm{sg} 1 \mathrm{msiv} \quad 0.0$

$0000832 \mathrm{sg} 2 \mathrm{msiv} \quad 0.0$

$0000833 \mathrm{mfp} 1 \quad 0.0$

$0000834 \mathrm{mfp} 2 \quad 0.0$

$0000835 \mathrm{sg} 1 \mathrm{adv} \quad 0.0$

$0000836 \mathrm{sg} 2 \mathrm{adv} \quad 0.0$

0000837 tbv $\quad 0.0$

0000838 sglafw $\quad 1.0$

0000839 sg2afw $\quad 1.0$

* List of interactive options

*No. Name

Parameter

Description

*801 rep1a Reactor coolant pumpd

manually on at rated speed if rcpxx $>0.0$

manually tripped if rcpxx $<0.0$

automatic control (includes normal manual trips if $\operatorname{rcpxx}=0.0$

*804 rсp2b

*805 reps

All reps

same as 801-804 except applies to all rcps

*806 si Safety injection signal

si $>0.0$, manual si signal

si $<0.0$, si signal manually inhibited

si $=0.0$, normal automatic operation 
Table 3-2. (continued).

\begin{tabular}{|c|c|c|c|c|}
\hline *No. & Name & Parameter & & Description \\
\hline *807 & hpi1 & $\begin{array}{l}\text { Multiplier for } 1 \mathrm{hpi} \\
\text { pump delivery curve }\end{array}$ & hpi1 & $\begin{array}{l}=1.0,100 \% \text { delivery } \\
=0.0,0 \% \text { delivery }\end{array}$ \\
\hline *808 & hpi2 & $\begin{array}{l}\text { Multiplier for } 2 \text { hpi } \\
\text { pump delivery curve }\end{array}$ & hpi2 & $\begin{array}{l}=1.0,100 \% \text { delivery } \\
=0.0,0 \% \text { delivery }\end{array}$ \\
\hline * 810 & lpi & $\begin{array}{l}\text { Multiplier for } 2 \text { lpi } \\
\text { pump delivery curve }\end{array}$ & lpi & $\begin{array}{l}=1.0,100 \% \text { delivery } \\
=0.0,0 \% \text { delivery }\end{array}$ \\
\hline *812 & spray & $\begin{array}{l}\text { Pressurizer spray valve } \\
\text { normalized area }\end{array}$ & spray & $\begin{array}{l}=0.0, \text { automatic operation } \\
=-1.0, \text { manually closed } \\
=1.0, \text { manually wide open } \\
>-1 . \text { and }<1 ., \text { automatic operation } \\
\quad \text { plus constant manual offset }\end{array}$ \\
\hline${ }^{*} 813$ & scram & Manual reactor trip & scram & $\begin{array}{l}=0.0, \text { automatic operation } \\
>0.0, \text { manual reactor trip } \\
<0.0, \text { reactor trip inhibited }\end{array}$ \\
\hline *814 & acc1a & Accumulator isolation & $\operatorname{accxxg}$ & ge 0.0 , normal automatic operation \\
\hline *815 & acc1b & valves & & It 0.0 , accumulator $x x$ is isolated \\
\hline *816 & $\begin{array}{l}a c c 2 a \\
a \operatorname{acc} 2 b\end{array}$ & & & \\
\hline *818 & ttrip & Manual turbine trip & ttrip & $\begin{array}{l}=0.0, \text { automatic operation } \\
>0.0, \text { manual turbine trip }\end{array}$ \\
\hline * & sgis & $\begin{array}{l}\text { Steam generator } \\
\text { isolation signal }\end{array}$ & sgis & $\begin{array}{l}=0.0, \text { automatic operation } \\
>0.0, \text { manual isolation signal } \\
<0.0 \text {, isolation signal inhibited }\end{array}$ \\
\hline * & heaters & $\begin{array}{l}\text { Pressurizer } \\
\text { heaters }\end{array}$ & heaters & $\begin{aligned} & s=0.0, \text { automatic operation } \\
&=-1.0, \text { manually off } \\
&=1.0, \text { manually full on } \\
&>-1 . \text { and }<1 ., \text { automatic operation } \\
& \text { plus constant manual offset }\end{aligned}$ \\
\hline * ${ }^{*}$ & porv & $\begin{array}{l}\text { Pressurizer porv } \\
\text { normalized area }\end{array}$ & porv & $\begin{array}{l}=0.0, \text { automatic operation } \\
>0.0, \text { porv manually full open } \\
<0.0 \text {, porv manually closed }\end{array}$ \\
\hline$*$ & mupumps & $\begin{array}{l}\text { Number of makeup } \\
\text { pumps running }\end{array}$ & & $\begin{aligned} \text { mps } & =0.0, \text { no pumps running } \\
& =1.0, \text { normal automatic operation } \\
& =2.0, \text { two pumps running } \\
& =3.0, \text { three pumps running }\end{aligned}$ \\
\hline${ }^{*} 823$ & letdown & $\begin{array}{l}\text { Letdown flow } \\
\text { normalized area }\end{array}$ & letdow & $\begin{aligned} \mathrm{m}= & 0.0, \text { automatic operation } \\
= & 1.0, \text { maximum letdown } \\
= & -1.0, \text { letdown isolated } \\
& \text { ge }-0.03 \text { and le } 0.03, \text { automatic } \\
& \text { operation plus constant offset }\end{aligned}$ \\
\hline *824 & $\begin{array}{l}\text { sg1mfiv } \\
\text { sg2mfiv }\end{array}$ & $\begin{array}{l}\text { Main feed isolation } \\
\text { valves }\end{array}$ & mfiv & $\begin{array}{l}=0.0, \text { zutomatic operation } \\
>0.0, \text { manually full open }\end{array}$ \\
\hline
\end{tabular}


Table 3-2. (continued).

\begin{tabular}{|c|c|c|c|c|}
\hline *No. & Name & Parameter & & Description \\
\hline * & & & & $<0.0$, manually closed \\
\hline $\begin{array}{l}* 826 \\
* 827 \\
* \\
*\end{array}$ & $\begin{array}{l}\text { sg1mfrv } \\
\text { sg2mfrv }\end{array}$ & $\begin{array}{l}\text { Main feed regulating } \\
\text { valves }\end{array}$ & mfiv & $\begin{array}{l}=0.0, \text { automatic operation } \\
=1.0, \text { manually full open } \\
=-1.0, \text { manually closed } \\
>-1 . \text { and }<1 . \text {, automatic operation } \\
\quad \text { plus constant offset }\end{array}$ \\
\hline *829 & sg1mfbv & Main feed bypass & mfbv & $=0.0$, automatic operation \\
\hline $\begin{array}{l}* 830 \\
* \\
*\end{array}$ & $\mathrm{sg} 2 \mathrm{mlbv}$ & valves & & $\begin{array}{l}=1.0, \text { manually full open } \\
=-1.0, \text { manually closed } \\
>-1 . \text { and }<1 ., \text { automatic operation } \\
\quad \text { plus constant offset }\end{array}$ \\
\hline $\begin{array}{l}* 831 \\
* 832 \\
*\end{array}$ & $\begin{array}{l}\text { sg1msiv } \\
\text { sg2msiv }\end{array}$ & $\begin{array}{l}\text { Main steam isolation } \\
\text { valves }\end{array}$ & msiv & $\begin{array}{l}=0.0, \text { automatic operation } \\
>0.0, \text { manually full open } \\
<0.0, \text { manually closed }\end{array}$ \\
\hline *833 & $\mathrm{mfpl}$ & Main feed pump status & $\mathrm{mfp}$ & $=0.0$, automatic operation \\
\hline $\begin{array}{l}* 834 \\
*\end{array}$ & $\mathrm{mfp} 2$ & & & $\begin{array}{l}>0.0, \text { manually on } \\
<0.0 \text {, manually tripped }\end{array}$ \\
\hline $\begin{array}{l}* 835 \\
* 836 \\
* \\
* \\
*\end{array}$ & $\begin{array}{l}\text { sg1adv } \\
\text { sg2adv }\end{array}$ & $\begin{array}{l}\text { Atmospheric dump } \\
\text { valves }\end{array}$ & adv & $\begin{array}{l}=0.0, \text { automatic operation } \\
=-1.0, \text { manually closed } \\
=1.0, \text { manually full open } \\
>-1 . \text { and }<1 ., \text { automatic operation } \\
\quad \text { plus constant offset }\end{array}$ \\
\hline $\begin{array}{l}\text { *837 } \\
* \\
* \\
* \\
*\end{array}$ & tbv & Turbine bypass valves & tbv & $\begin{array}{l}=0.0, \text { automatic operation } \\
=-1.0, \text { manually closed } \\
=1.0, \text { manually full open } \\
>-1 . \text { and }<1 ., \text { automatic operation } \\
\text { plus constant offset }\end{array}$ \\
\hline
\end{tabular}


Table 3-3. Restart deck input listing.

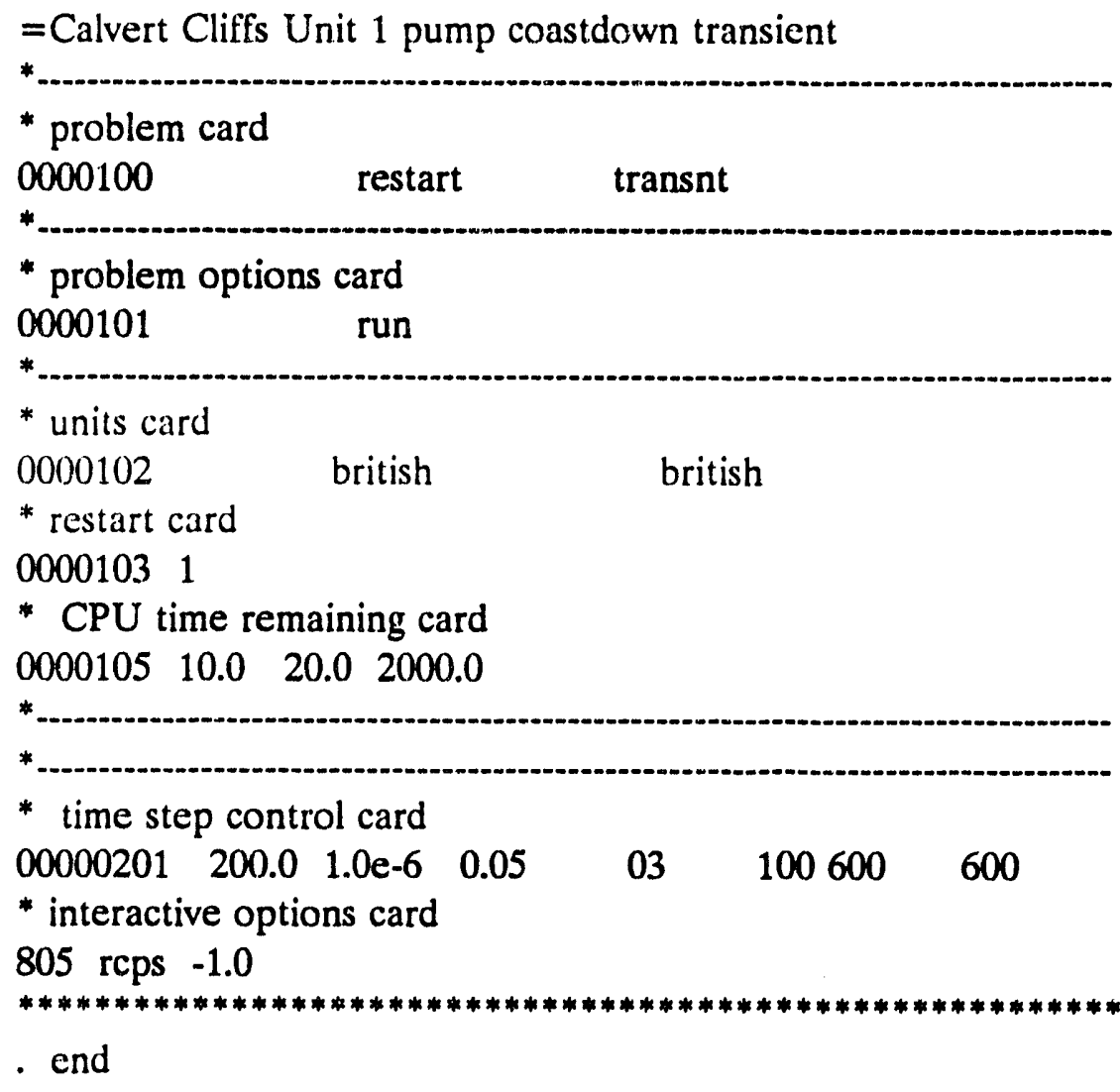

\subsubsection{Severe Accident Applications}

The plant deck should be directly applicable for severe accident studies as was explained in Section 2.2. Analyses which extend into the region of severe accident behavior will require detailed interpretation of the SCDAP output. It is recommended that minor edits related to the SCDAP calculation be added. Table 3-4 gives a suggested list. Also the NPA core mask is very helpful for interpreting severe accident phenomena.

\subsection{Problem Resolution}

This section discusses the options available to solve problems encountered while applying the Calvert Cliffs plant deck. The most common problem encountered when executing RELAP5/MOD3/SCDAP is water property failure. When this occurs the message "Water property error with minimum time step, transient being terminated" will be written after the last major edit before the error occurred. The message is followed by an extensive diagnostic printout that contains data on each component in the model. The data is always in SI units in the diagnostic printout. This is then followed by a major edit at the time the error occurred. The final major edit contains all the normal major edit data. 
Table 3-4. Suggested SCDAP minor edits.

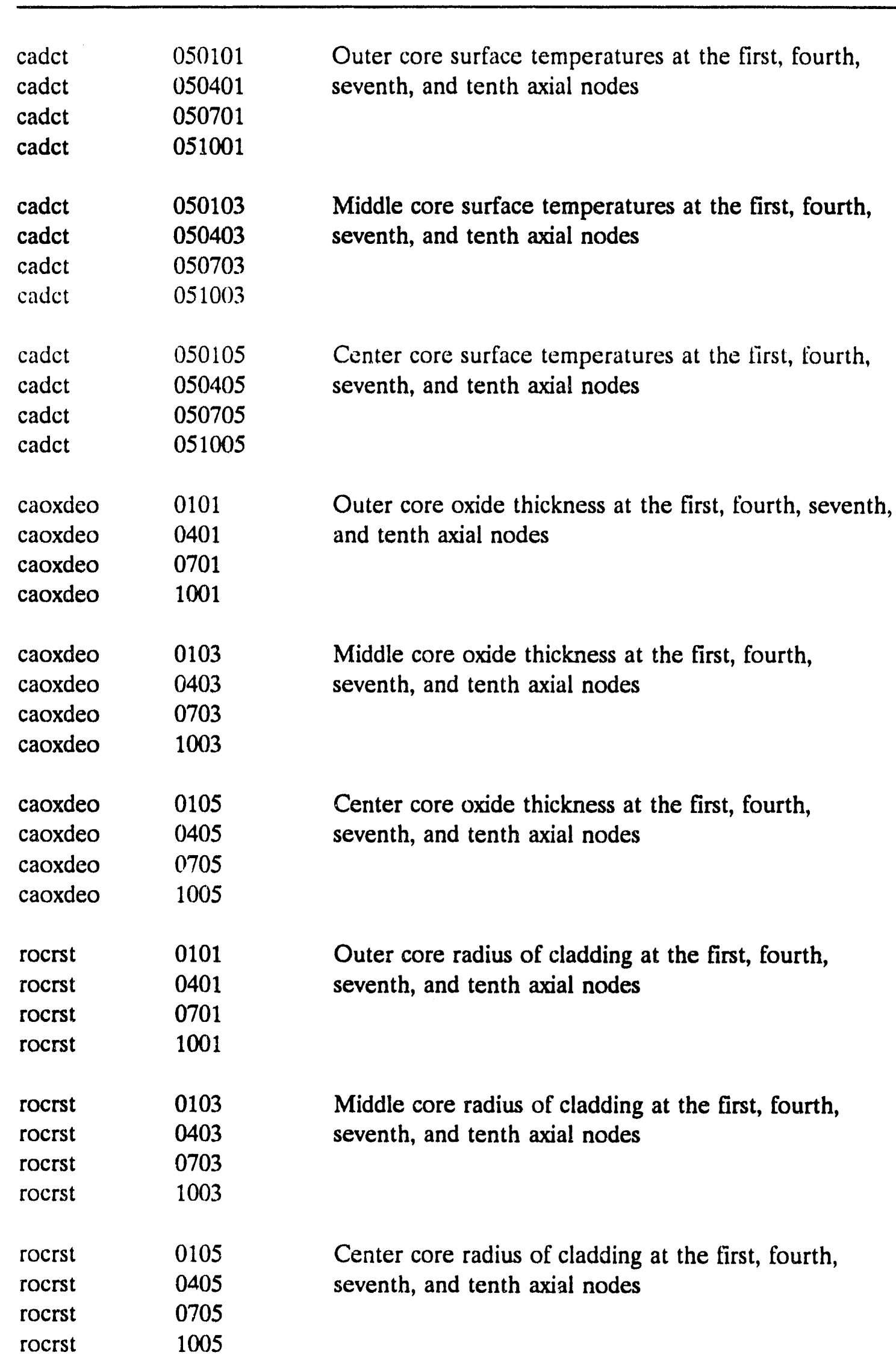


Table 3-4. (continued).

\begin{tabular}{|c|c|c|}
\hline $\begin{array}{l}\text { damlev } \\
\text { damlev } \\
\text { damlev } \\
\text { damlev }\end{array}$ & $\begin{array}{l}0101 \\
0401 \\
0701 \\
1001\end{array}$ & $\begin{array}{l}\text { Outer core level of damage at the first, fourth, seventh, } \\
\text { and tenth axial nodes }\end{array}$ \\
\hline $\begin{array}{l}\text { damlev } \\
\text { damlev } \\
\text { damlev } \\
\text { damlev }\end{array}$ & $\begin{array}{l}0103 \\
0403 \\
0703 \\
1003\end{array}$ & $\begin{array}{l}\text { Middle core level of damage at the first, fourth, seventh, } \\
\text { and tenth axial nodes }\end{array}$ \\
\hline $\begin{array}{l}\text { damlev } \\
\text { damlev } \\
\text { damlev } \\
\text { damlev }\end{array}$ & $\begin{array}{l}0105 \\
0405 \\
0705 \\
1005\end{array}$ & $\begin{array}{l}\text { Center core level of damage at the first, fourth, seventh, } \\
\text { and tenth axial nodes }\end{array}$ \\
\hline bgth & 0 & Core total hydrogen generation rate $(\mathrm{kg} / \mathrm{s})$. \\
\hline bgnhg & 0 & Core nuclear heat generation (W). \\
\hline bgmet & 0 & Core maximum surface temperature (K). \\
\hline bgthq & 0 & Core total oxidation heat generation (W). \\
\hline
\end{tabular}

The water property error indicates that the transient has been stopped because an unrealistic state condition has been calculated in one or more components. The diagnostic printout will contain the message "Water property error in component" followed by the component number. The data on the component in the final major edit can then be checked. Generally a negative pressure or an extremely high or low liquid or vapor internal energy will be seen in the major edit. After identifying the component where the water property error occurred severai actions can be taken that may solve the problem. The calculational results prior to the error should be studied, particularly near the component where the water property error occurred. Phenomena that should be checked for when reviewing the resuits are:

- Unrealistic flow surges or spikes in junction components

- Rapid pressure changes in a component that do not follow the pressure transient in adjacent components

- Flow or pressure oscillations that cannot be explained.

The internal time step control logic that selects the time step for the next advancement does not always function perfectly. If the results appear reasonable prior to the error, then the cause may 
be in the time step selection. In this case, the problem can be solved by restarting the problem at the last restart edit before the error occurred and using a smaller maximum time step. The minimum time step is automatically set to $1.0 \mathrm{e}-06 \mathrm{~s}$ unless the user selects a smaller minimum time step. Attempting to avoid the water property error by using a lower minimum time step is not recommended because this technique usually does not solve the problem and can cause excessive calculation time.

An example of avoiding a water property error follows. Assume that a transient analysis with the Calvert Cliffs deck fails at $96.27 \mathrm{~s}$ into the calculation. At the time of failure the time step control specifies a 0.1 second maximum time step, a 1.0e-06 minimum time step, and a major and restart edit every $10.0 \mathrm{~s}$. So the time step control card would be:

$\begin{array}{llllllll}* * & \text { end } & \min & \max & \text { control } & \text { minor edit } & \text { major edit } & \text { restart } \\ * * & \text { time } & \mathrm{dt} & \mathrm{dt} & \text { tlag } & \text { frequency } & \text { frequency } & \text { frequency } \\ 0000201 & 500.0 & 1.0 \mathrm{e}-6 & 0.10 & 03 & 10 & 100 & 100\end{array}$

If the last restart edit is at $90.0 \mathrm{~s}$ the following cards would be used on restart to void the water property error:

$\begin{array}{llllllll}* * & \text { end } & \min & \max & \text { control } & \text { minor edit } & \text { major edit } & \text { restart } \\ \text { ** } & \text { time } & \text { dt } & \text { dt } & \text { flag } & \text { frequency } & \text { frequency } & \text { frequency } \\ 0000201 & 94.0 & 1.0 \mathrm{e}-6 & 0.10 & 03 & 10 & 40 & 40 \\ 0000202 & 97.0 & 1.0 \mathrm{e}-6 & 0.005 & 03 & 100 & 600 & 600 \\ 0000203 & 100.0 & 1.0 \mathrm{e}-6 & 0.05 & 03 & 10 & 40 & 40 \\ 0000204 & 500.0 & 1.0 \mathrm{e}-6 & 0.10 & 03 & 10 & 100 & 100\end{array}$

The problem has been restarted at $90 \mathrm{~s}$ and the maximum time stey: wize reduced from $0.10 \mathrm{~s}$ to $0.005 \mathrm{~s}$ at $94 \mathrm{~s}$. After $97 \mathrm{~s}$ the water property problem will have been bytossed and the time step size is gradually increased back to $0.10 \mathrm{~s}$.

Some water property failure problems cannot be solved this easily. The naximum time step size may have been too large during the time period before the error occurred. Flow spikes or pressure oscillations are indicators of this problem. The problem would have to be restarted with a smaller maximum time step at a restart edit where the results wete still actoptaible.

The trip signal edits should also be reviewed to see $\mathrm{i}^{\prime}$ a of the water property error. Sometimes the actions caused by trip will result in calculational problems. Applications using the Calvert Cliffs plant deck have sailed when the condensate pumps or the condensate booster pumps trip. If this occurs the user should check if the feedwater system is still active in terms of influencing the results of the calculation. If it is not active, then the steam generator feedwater system is isolated. Then the feedwater line components can be deleted and the analysis continued. Table 3-5 lists the cards that will eliminate the feedwater line. 
Table 3-5. Inputs to remove the main feedwater line.

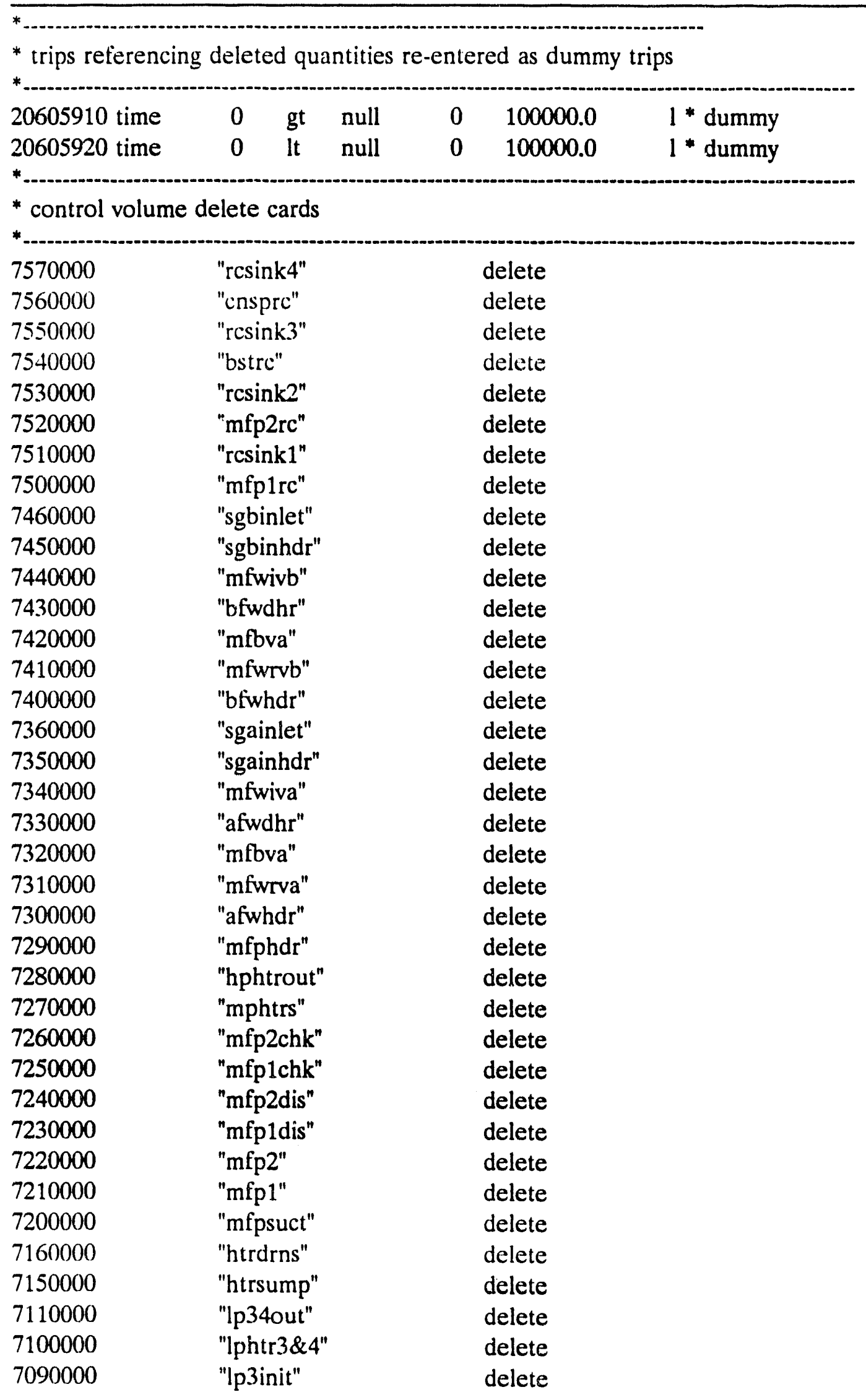


Table 3-5. (continued).

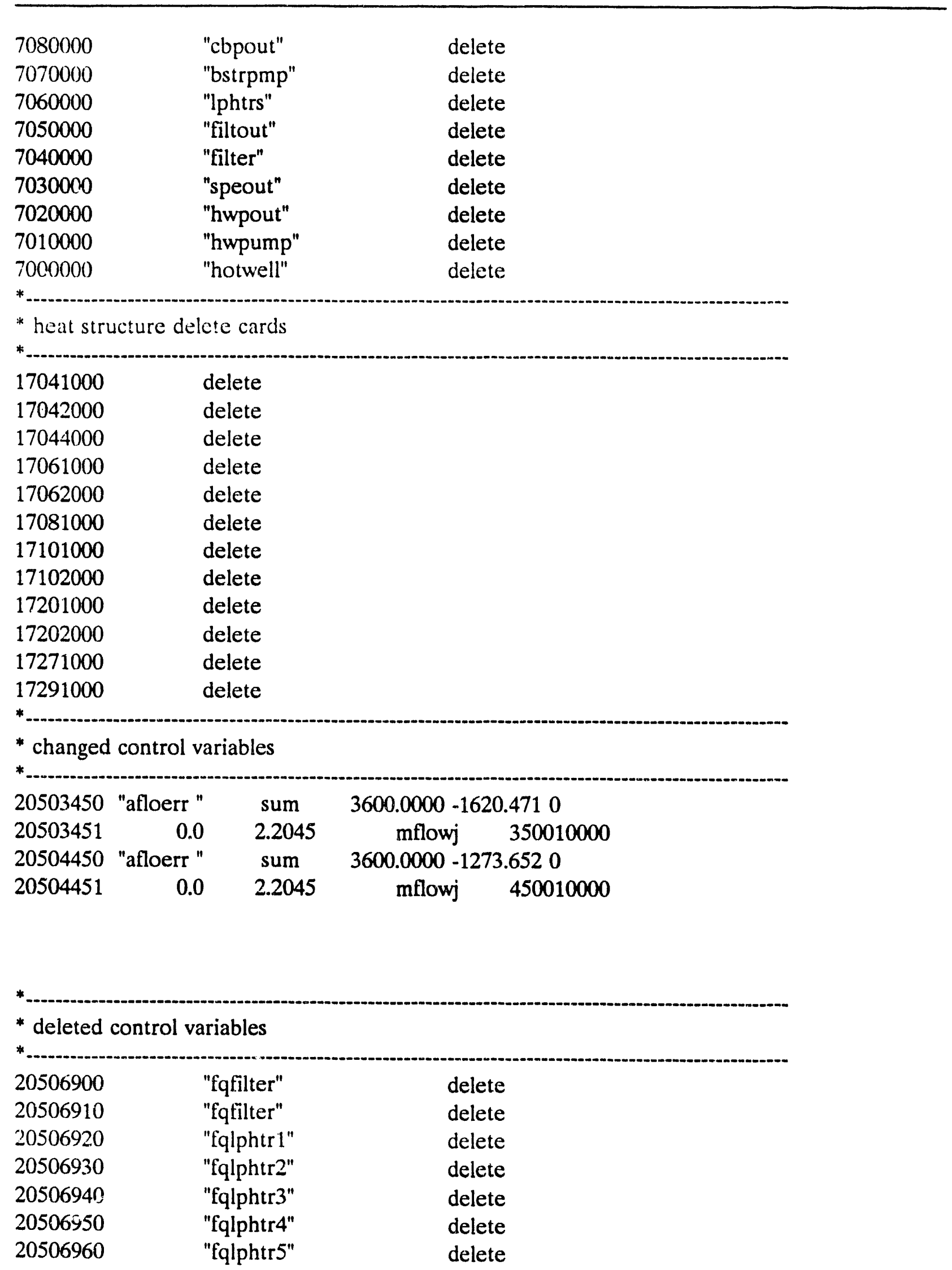


Table 3-5. (continued).

\begin{tabular}{lll}
\hline 20506970 & "fiphphtr7" & delete \\
20507020 & "p720" & delete \\
20507030 & "maxhd" & delete \\
20507050 & "mhtrdrm" & delete \\
20507060 & "tafttt" & delete \\
20507070 & "htrdrain" & delete \\
20507200 & "delpa" & delete \\
20507210 & "delpb" & delete \\
20507220 & "dpmax" & delete \\
20507230 & "dperr" & delete \\
20507240 & "delrpm" & delete \\
20507250 & "mfpspd" & delete \\
20507300 & "mfbvarea" & delete \\
20507320 & "sg1mfbva" & delete \\
20507420 & "sg2mfbva" & delete \\
20507500 & "velf725s" & delete \\
20507520 & "velf726s" & delete \\
20507540 & "velf710s" & delete \\
20507560 & "velf703s" & delete \\
\hline
\end{tabular}

The calculation will also fail due to a thermo-properties error if the temperature in a heat conductor becomes either greater than or less than the temperature range input on the thermal conductivity cards $(201 \mathrm{mmm} 01$ through $201 \mathrm{mmm} 49$ ) or the volumetric heat capacity cards (201 mmm51 through 201 mmm99). This is an unusual error. To correct this type of problem the user should identify the reason that the table range was exceeded and extend the table range if appropriate. If the range of other tables is exceeded then the end value will be used. The code will not extrapolate beyond the end of the table so the user should be aware of this.

Another potential problem is excessive mass error. High mass error is an indicator of unrealistic analytical results. The mass error and mass error ratio is given in the time advancement summary at the beginning of each major edit. If this error becomes excessive, the user should then refer to the time step control matrix that is printed after the volume data at each major edit for information on the location of the volume component or components where the largest mass error occurs. Reduction of the maximum time step size should reduce the mass error.

RELAP5/MOD3/SCDAP has been applied for many different types of studies, and therefore most code applications problems can be solved in some manner. Efforts are currently in progress to fix various problems in the code that can cause failures of the types described and it is anticipated that the code will be much more robust in the future. 


\section{CONCLUSIONS}

A. RELAP5/MOD3/SCDAP plant deck of the Calvert Cliffs $2700 \mathrm{MWt} \mathrm{CE}$ reactor system has been developed and is described in the body of this report. The deck can be used for plant transient, LOCA, and severe accident applications and has NPA display capability. The following features are contained in the deck:

1. The thermal-hydraulic input is in RELAP5/MOD3 format

2. The core is modeled with three radial channels and ten axial nodes per channol

3. SCDAP heat structures model the fuel rods and the control rods

4. The downcomer is divided into four radial divisions

5. Files allowing interactive execution with the NPA are included with the deck

6. A detailed NPA display of the core region only is also provided

7. Steady state at $100 \%$ power, $100 \%$ flow conditions.

The deck has been tested by applying it for the analysis of a loss of feedwater transient, a large break LOCA, and a small break LOCA. The results of these studies were satisfactory and it is concluded that the input deck is suitable for general applications and for accident management applications. The NPA display capability was also thoroughly tested. Applying the input deck with the NPA display allows a significant enhancement for result interpretation and analysis.

A set of user instructions and recommendations are also provided to aid users who wish to perform studies with the Calvert Cliffs plant deck but who do not have time to become RELAP5/MOD3/SCDAP experts. Methods for avoiding or resolving calculational problems are included in these instructions. 


\section{REFERENCES}

1. C. M. Allison et al., SCDAP/RELAP5/MOD3 Code Manual Volume II: SCDAP Code Structure, System Models, And Solution Methods (Draft), EG\&G Idaho, NUREG/CR-5535, EGG-2596, Draft, September 1990.

2. D. M. Snider and K. L. Wagner, Nuclear Plant Analyzer Computer Visual System. (CVS) Reference Manual, EG\&G Idaho, EGG-EAST-9095, April 1990.

3. D. M. Snider, K. L. Wagner, W. H. Grush, Nuclear Plant Analyzer (NPA) Reference Manual, EG\&G Idaho, EGG-EAST-9096, April 1990.

4. P. D. Wheatley et al., Evaluation of Operational Safety at Babcock \& Wilcox Plants Volume 2Thermal-Hydraulic Results (Draft), EG\&G Idaho, NUREG/CR-4966, EGG-2515, DRAFT, July 1987.

5. I. E. Idel'Chik, Handbook of Hydraulic Resistance, Coefficients of Local Resistance and of Friction, U.S. Department of Commerce, AEC-TR-6630, 1960.

6. Calvert Cliffs Final Safety Analysis Report (FSAR).

7. C. M. Allison et al., SCDAP/RELAP5/MOD3 Code Manual Volume III: Users Guide and Input Requirements (Draft), EG\&G Idaho, NUREG/CR-5535, EGG-2596, Draft, June 1990.

8. D. L. Selby et al., Pressurized Thermal Shock Evaluation of the Calvert Cliffs Unit 1 Nuclear Power Plant, Martin Marietta Energy Systems, Inc., NUREG/CR-4022, ORNL/TM-9408, September 1985. 

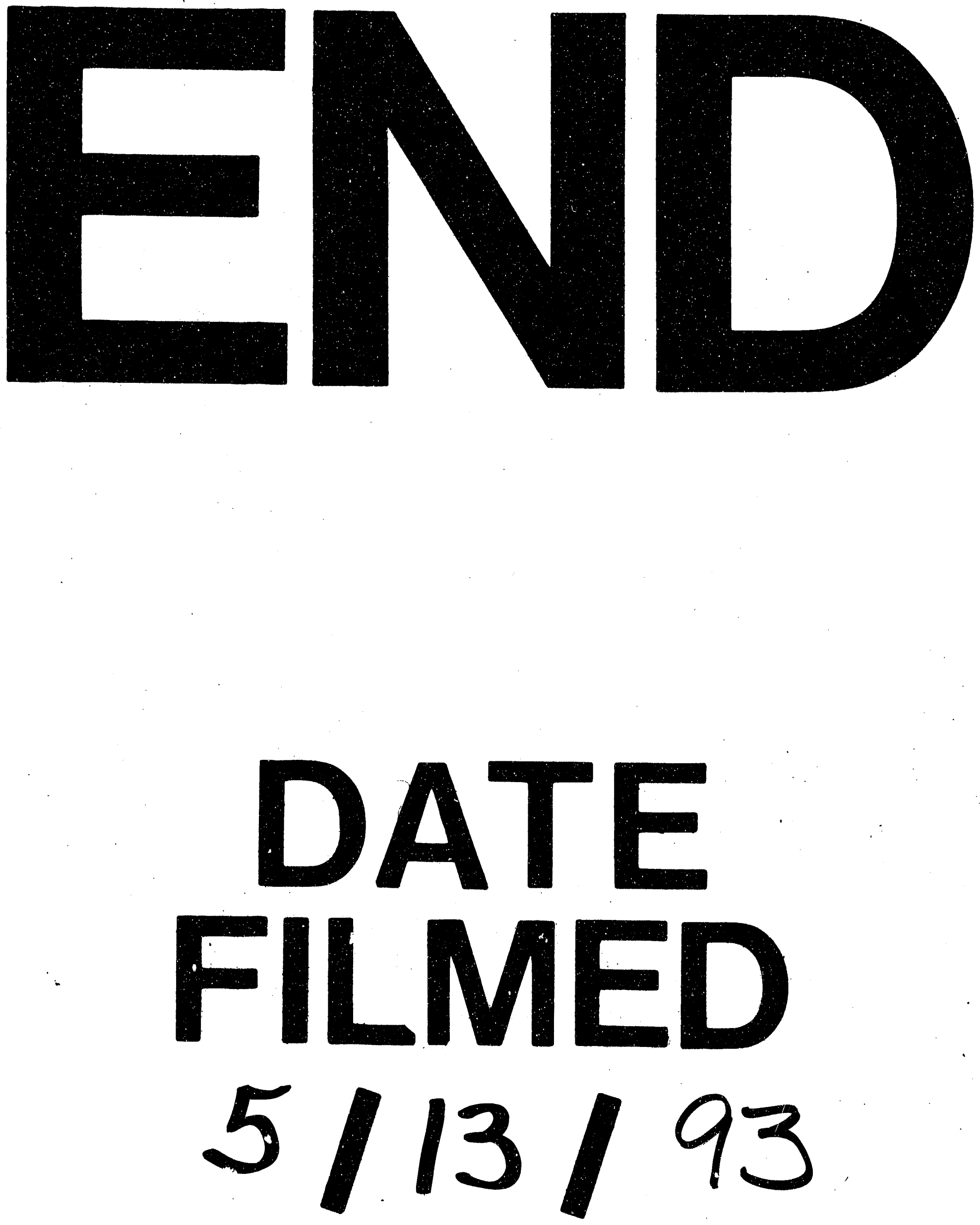

1 
